UNIVERSIDADE DE SÃO PAULO - ESCOLA POLITÉCNICA DEPARTAMENTO DE ENGENHARIA MECÂNICA

FELIPE DE SOUSA MAZUCO

Adhesion improvement of thick DLC coatings produced by cathodic arc evaporation over stainless steel using carbon bombardment step 
FELIPE DE SOUSA MAZUCO

\title{
Adhesion improvement of thick DLC coatings produced by cathodic arc evaporation over stainless steel using carbon bombardment step
}

\author{
Revised Version
}

Dissertation presented to the Pos-Graduate Program in Mechanical Engineering (PPGEM) of the Escola Politécnica da Universidade de São Paulo (EPUSP) to obtain the degree of Master of Science.

Concentration Area: Projects and Manufacturing

Advisor: Prof. Dr. Roberto Martins de Souza 
Autorizo a reprodução e divulgação total ou parcial deste trabalho, por qualquer meio convencional ou eletrônico, para fins de estudo e pesquisa, desde que citada a fonte.

Este exemplar foi revisado e corrigido em relação à versăo original, sob responsabilidade única do autor e com a anuência de seu orientador.

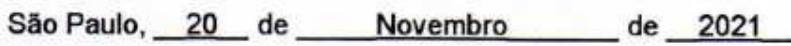

Assinatura do autor:

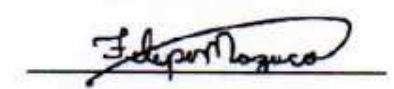

Assinatura do orientador:

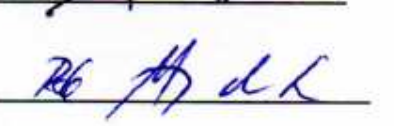

Catalogação-na-publicação

Mazuco, Felipe

Adhesion improvement of thick DLC coatings produced by cathodic arc evaporation over stainless steel using carbon bombardment step / F. Mazuco - versão corr. -- São Paulo, 2021.

$96 \mathrm{p.}$

Dissertação (Mestrado) - Escola Politécnica da Universidade de São Paulo. Departamento de Engenharia Mecânica.

1.Materiais 2.Materiais nanoestruturados 3.Recobrimentos espessos 4.Adesão I.Universidade de São Paulo. Escola Politécnica. Departamento de Engenharia Mecânica II.t. 
À minha noiva Vivian e meus pais, João e Rosana, com amor, carinho e admiração pelos esforços que me permitiram estar escrevendo este documento. 


\section{AGRADECIMENTOS}

Agradeço à minha noiva Vivian pelo carinho, apoio e inspiração que me fizeram trilhar e finalizar essa jornada. Você é meu modelo de empenho e dedicação e a pessoa com quero compartilhar todas a jornadas que estão por vir.

Agradeço aos meus pais, João e Rosana, por todo esforço e dedicação investidos na minha educação e minha vida. Este trabalho é só uma parte do que pretendo retribuir.

Agradeço aos meus avós João, Maximiliano e Edna por terem feito parte tão importante da minha vida. Espero que vocês estejam orgulhosos de mim de onde estiverem. E à minha vó Marina por continuar se preocupando e participando da minha vida.

Agradeço à minha irmã Giovana por ter me aguentado durante muitos anos e ao cunhado Alexandre que agora cuida dela.

Agradeço aos meus primos e tios das famílias Mazuco e Sousa por todos os momentos de descontração e felicidade que compartilhamos juntos.

Sou grato ao Prof. Roberto por ter me orientado desde 2012 durante toda minha jornada acadêmica e que me permitiu exercer a profissão e atividades de que tenho orgulho.

Também sou grato a todos do Laboratório de Fenômenos de Superfície (LFS) por disponibilizar os recursos humanos e operacionais para que pudéssemos alcançar nosso melhor. Em especial aos professores Amilton, Izabel, Francisco, Newton e aos doutores e mestres Alexander, Sebastian, Gustavo, Rafael, Vanessa, Iramar, Ana Julia, Franco, Marcos, Marcionila e Thiago pelas discussões e ajuda durante minha vida acadêmica.

Agradeço aos médicos, fisioterapeutas, enfermeiras e voluntários do CHESP e da Unidade de Hemofilia da Unicamp que permitiram com que eu acompanhasse todas as atividades profissionais e acadêmicas de forma normal.

Ainda agradeço à empresa Kobelco e ao LNano, em especial ao Dr. Jefferson Bettini, por terem conduzido as análises de Microscopia de Transmissão Eletrônica e EELS que deram vida às principais discussões do trabalho.

Por fim, agradeço à empresa MAHLE Metal Leve por ter disponibilizado diversos recursos para que este trabalho fosse realizado. Em especial, aos engenheiros e gerentes Robert Banfield, Samantha Uehara, Eduardo Nocera, Andre Ferrarese e José Valentim Sarabanda por 
terem orientado o trabalho e dedicado os recursos da empresa para a inovação durante tantos anos. Ao time da planta de Itajubá, em especial ao Marcos Piccilli, Luiz Felipe Rezende, Rubens Silverio e Mauricio Ciminelli, que fizeram a deposição das camadas e participaram de diversas discussões sobre conceitos e resultados. Ao time do laboratório metalúrgico de Jundiai, em particular ao Rodrigo Sant'Anna, Nilson Luvizutto, Emerson Reginaldo, Washington Carvalho, Roberta Rodrigues, Donizete de Souza e Elaine Augusto, por terem sido responsáveis pelas análises de nanodureza, Scratch test e MEV. Aos amigos Dr. Juliano Araujo e Paulo Mordente por terem me introduzido nesse complexo e divertido mundo de deposição de camadas por PVD. E aos amigos da equipe de Pesquisa e Desenvolvimento que me apoiaram em diversas atividades durante toda a jornada na inovação, em particular ao Rafael Bruno, Bruno Fineto, Marcelo Miyamoto, Paulo Morais, Matheus Ferreira, Ednaldo Laube, Gisela Marques, Victor Cechini, Rafael Rabello, Davi Silva, Renata Tanigava e Marcia Fernandez. 


\begin{abstract}
The main restriction in the application of thick hydrogen-free amorphous carbon (a-C) coatings is the adhesion to the substrate, since high compressive stresses tend to delaminate the coating when a certain thickness is reached. In the present work, amorphous carbon films were deposited by unfiltered cathodic arc over a gas nitrided stainless steel substrate with metallic chromium as bond layer. An additional step was included, where carbon ions were accelerated by high bias potential before the deposition of functional a-C, to produce a carbon transition layer to act as a buffer layer. During a preliminary analysis, different thicknesses of this transition layer were produced, including a sample without this step, for reference purposes. The coating adhesion was evaluated by scratch test. In addition, the microstructure of the interface was analyzed by scanning transmission electron microscopy (STEM) and the sp-type bonds were quantified by electron energy loss spectroscopy (EELS). The analysis of the microstructure close to the interface with the chromium bond layer revealed a mixing layer of $\mathrm{Cr}$ and $\mathrm{C}$. Furthermore, it was observed the formation of the transition layer characterized by a homogeneous carbon layer with high $\mathrm{sp}^{2}$ content, when compared to the functional amorphous carbon layer. Results indicate a significant enhancement of adhesion for the samples prepared with the carbon bombardment step, which can be correlated to the presence of the mixing layer and the carbon transition layer. Moreover, a decrease in adhesion was observed for an increase in the thickness of the transition layer, which can be attributed to the lower shear strength of this $\mathrm{sp}^{2}$ rich layer. In a second phase, three sets of experiments were designed to optimize the carbon bombardment step. The parameters studied were the duration combined with the bias voltage, the cathode current and the temperature. It was found that not only the thickness of the carbon transition layer is important for the adhesion but also the $\mathrm{sp}^{3}$ content. For instance, a lower bias voltage was able to increase the $\mathrm{sp}^{3}$ content of the carbon transition layer mitigating the negative impact of a thicker carbon transition layer. Also, an increase in the carbon cathode current could increase the adhesion possibly by extending the mixing layer. Finally, the best adhesion result was achieved when the substrate temperature of the bombardment was reduced. The most probable cause for that is a compositional modification in the mixing layer, like a change in the carbides formed in that region.
\end{abstract}

Keywords: Amorphous carbon, Cathodic arc, Thick DLC coatings, Adhesion, Scratch test, Interface analysis. 


\section{RESUMO}

A principal restrição na aplicação de revestimentos espessos de carbono amorfo como diamante livre de hidrogênio (em inglês $a$-C -amorphous carbon) é a adesão ao substrato, uma vez que as altas tensões internas tendem a delaminar o revestimento quando uma certa espessura é alcançada. Neste trabalho, um filme de carbono amorfo (a-C) foi depositado por arco catódico não filtrado sobre um substrato de aço inoxidável nitretado a gás com Cr metálico como camada de ligação. Foi incluído um passo adicional em que os íons de carbono foram acelerados por alto potencial de polarização antes da deposição do recobrimento funcional de a-C, para produzir uma camada de transição de carbono. Durante a primeira fase do trabalho, diferentes espessuras desta camada de transição foram produzidas, incluindo uma amostra sem esta etapa, para fins de referência. A adesão do revestimento foi avaliada por teste de riscamento (esclerometria). Além disso, a microestrutura da interface foi analisada por microscopia eletrônica de transmissão no modo varredura (STEM) e as ligações do tipo sp3/sp2 foram quantificadas por espectroscopia de perda de energia de elétrons (EELS). A análise da microestrutura próxima à interface com a camada intermediária de $\mathrm{Cr}$ revelou uma camada mista composta por $\mathrm{Cr}$ e C. Além disso, observou-se a formação da camada de transição caracterizada por uma camada de carbono homogênea com alto teor de sp2, quando comparado ao a-C funcional. Os resultados indicam um aumento significativo da adesão nas amostras de a-C preparadas com o passo de bombardeamento de carbono, o que pode ser correlacionado com a presença da camada mista e da camada de transição de carbono. Além disso, observouse diminuição da adesão para aumento da espessura da camada de transição, o que pode ser atribuído à menor resistência ao cisalhamento desta camada rica $\mathrm{em} \mathrm{sp}^{2}$. Em uma segunda fase do trabalho, três conjuntos de experimentos foram projetados para otimizar a etapa de bombardeamento por carbono. Os parâmetros estudados foram a duração em combinação com voltagem de polarização, a corrente de cátodo e a temperatura. Foi encontrado que, além da espessura da camada de transição, a quantidade de ligações $\mathrm{sp}^{3}$ também é importante para a adesão. Por exemplo, uma menor tensão de polarização foi responsável pelo aumento da quantidade de ligações $\mathrm{sp}^{3}$ presentes na camada de transição de carbono, mitigando o impacto negativo de uma camada de transição mais espessa. Também, um aumento na corrente de cátodo de carbono pode aumentar a adesão, possivelmente pelo aumento da camada mista. Finalmente, o melhor resultado de adesão foi alcançado quando a temperatura do substrato durante o bombardeamento foi reduzida. A causa mais provável para esse efeito é a modificação química da camada mista, como uma mudança nos carbonetos formados nessa região.

Palavras-chave: Carbono amorfo tipo diamante, Arco catódico, Recobrimentos espessos, Adesão, Teste de risco, Análise da interface. 


\section{LIST OF FIGURES}

Figure 1 - Topography of the arc spot after explosive electron emission..............................22

Figure 2 - Schematic representation of the three carbon hybridizations. ...............................24

Figure 3 - Ternary phase diagram for various DLC films with respect to their $\mathrm{sp}^{2}, \mathrm{sp}^{3}$, and

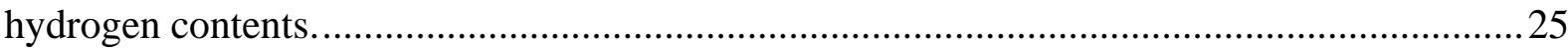

Figure 4 - Schematic set-up of DCAE and FCAE evaporation sources. ..............................26

Figure 5 - Schematic of ion subplantation, the formation of a high-density region and the relaxation.

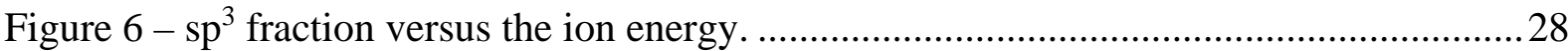

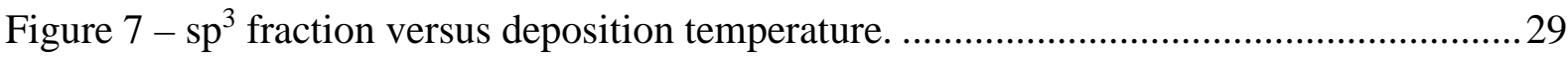

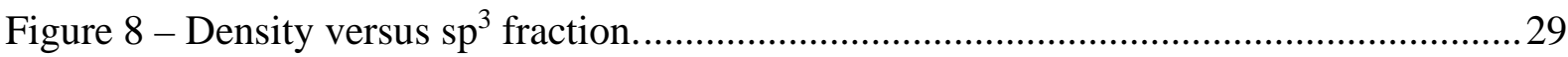

Figure 9 - Hardness and Young's modulus dependence on the $\mathrm{sp}^{3}$ fraction for FCAE. ..........30

Figure 10 - Hardness and Young's modulus dependence on the $\mathrm{sp}^{3}$ fraction for DCAE........30

Figure 11 - Correlation of compressive stresses and sp3 fraction. ......................................31

Figure 12 - Collection of stress and sp3 data from as-deposited H-free DLC samples found in literature.

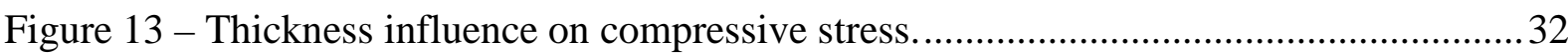

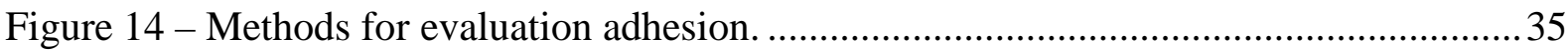

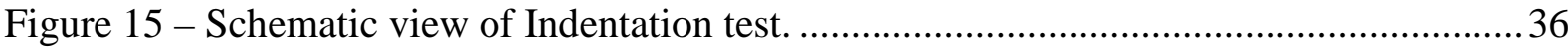

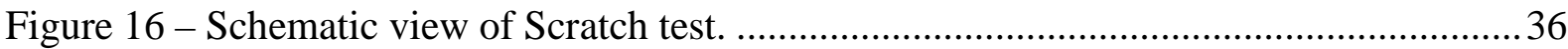

Figure 17 - Cross-sectional TEM image showing the mixed layer between $\mathrm{Cr}$ and Steel substrate.

Figure 18 - Influence of chromium intermediate thickness on adhesion of DLC coating. (a) 0.1 $\mu \mathrm{m}$, (b) $0.3 \mu \mathrm{m}$ and (c) $0.5 \mu \mathrm{m}$.

Figure 19 - Scratch test track in (a) coated sample, (b) duplex sample.

Figure 20 - Schematic of the functionally gradient Ti/TiC/DLC coating design.

Figure 21 - Scratch test tracks for the gradient coatings based in $\mathrm{Cr}, \mathrm{CrC}$ and DLC.

Figure 22 - Bright field TEM image showing the formation of mixed layer and a lower density carbon layer.

Figure 23 - Critical load as a function of substrate bias voltage during bombardment stage..43

Figure 24 - Cross section scheme of the deposition machine

Figure 25 - Instrumented indentation of load/unload curve. 48 
Figure 26 - Summary of the calculation procedure for the hardness and Young's modulus using the instrumented indentation

Figure 27 - Commercial nano-indenter, Anton Paar $\mathrm{NHT}^{3}{ }^{\circledR}$.

Figure 28 - (a) Path of the electron beam to form the image, (b) Path of the electron beam for

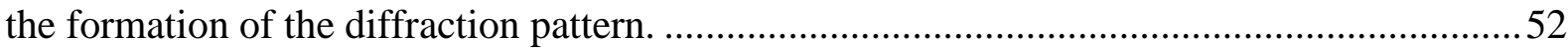

Figure 29 - Scheme for the formation of images in the STEM mode...................................53

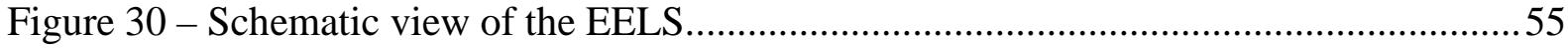

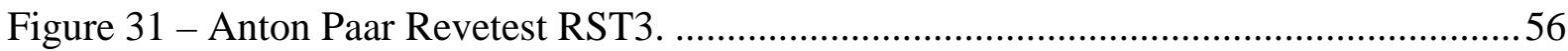

Figure 32 - Representative cross section of DLC coating obtained by SEM. Section taken from coating produced by Experiment A.

Figure 33 - STEM - Bright-Field images of the chromium/DLC interface for experiments A (a) and B (b).

Figure 34 - Detailed picture of functional a-C layer, where the multilayer aspect can be seen.

Figure 35 - sp2 profile of functional a-C layer measured by EELS.

Figure 36 - Dark-field image of a representative region analyzed in sample A. Two EELS spectra extracted from different points of the spectral line marked with 1 (functional a-C layer) and 2 (carbon transition layer) and Gaussian fits of the $\sigma$ and $\pi$ peaks marked with red color.

Figure 37 - Representative pictures of sample surface after Scratch test for experiments A (top)

B (middle) and C (bottom). 65

Figure 38 - Critical load $\left(\mathrm{L}_{\mathrm{c} 2}\right)$ for experiments $\mathrm{A}, \mathrm{B}$, and C. 65

Figure 39 - Representative pictures of sample surface after Scratch test for experiments D to G. 68

Figure 40 - Critical load $\left(\mathrm{L}_{\mathrm{c} 2}\right)$ for experiments D, E, F and G. 68

Figure 41 - Representative pictures of sample surface after Scratch test for experiments H, I and $\mathrm{J}$.

Figure 42 - Critical load $\left(\mathrm{L}_{\mathrm{c} 2}\right)$ for experiments $\mathrm{H}$, I and J. .72

Figure 43 - Representative pictures of sample surface after Scratch test for experiments K and L. 
Figure 45 - STEM - Bright-Field images of the chromium/DLC interface for experiments J and L. The images at the top have lower amplification and the images at the bottom have higher amplification.......

Figure 46 - Critical load $\left(\mathrm{Lc}_{2}\right)$ in function of carbon transition layer thickness. The solid line indicates the trend based on the available data, whilst the dashed line indicates uncertainty due to lack of data for thicknesses below $25 \mathrm{~nm}$. 


\section{LIST OF TABLES}

Table 1 - Parameters used in the carbon bombardment for preliminary analysis and for the

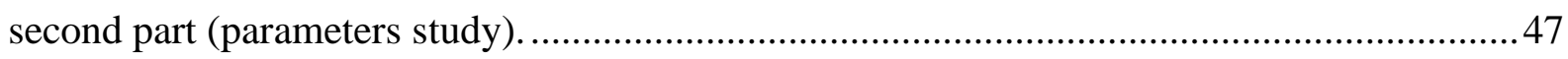

Table 2 - Thickness, hardness, Young's modulus and coating stress for the experiments A, B and $\mathrm{C}$

Table 3 - Thicknesses and sp3 content of functional a-C, carbon transition layer and mixed layer for the experiments $\mathrm{A}$ and $\mathrm{B}$. 62

Table 4 - Thickness and hardness for the experiments D to G. 67

Table 5 - Thickness and hardness for the experiments H, I and J. .70

Table 6 - Thickness and hardness for the experiments K and L........................................ 72

Table 7 - Parameters used in the carbon bombardment phase for the experiments $\mathrm{J}$ and L. Both experiments were selected to be analyzed by TEM. 


\section{ABBREVIATIONS}

a-C amorphous carbon

a-C:H hydrogenated amorphous carbon

AISI American Iron and Steel Institute

BF Bright-Field

DC Direct Current

DCAE Direct Cathodic Arc Evaporation

DF Dark-Field

DLC Diamond-like Carbon

EDX Energy-dispersive X-ray spectroscopy

EDS Energy-dispersive X-ray spectroscopy

EELS Electron Energy Loss Spectroscopy

FCAE Filtered Cathodic Arc Evaporation

FIB Focused Ion Bean

H-DLC Hydrogenated Diamond-like Carbon

H-Free Hydrogen-Free

HiPIMS High-Power Impulse Magnetron Sputtering

PACVD Plasma-assisted Chemical Vapor Deposition

PVD Physical Vapor Deposition

SEM Scanning Electron Microscope

STEM Scanning Transmission Electron Microscope

ta-C Tetrahedral amorphous carbono

ta-C:H Hydrogenated tetrahedral amorphous carbon

TEM Transmission Electron Microscope

XRD X-Ray Diffraction 


\section{LIST OF SYMBOLS}

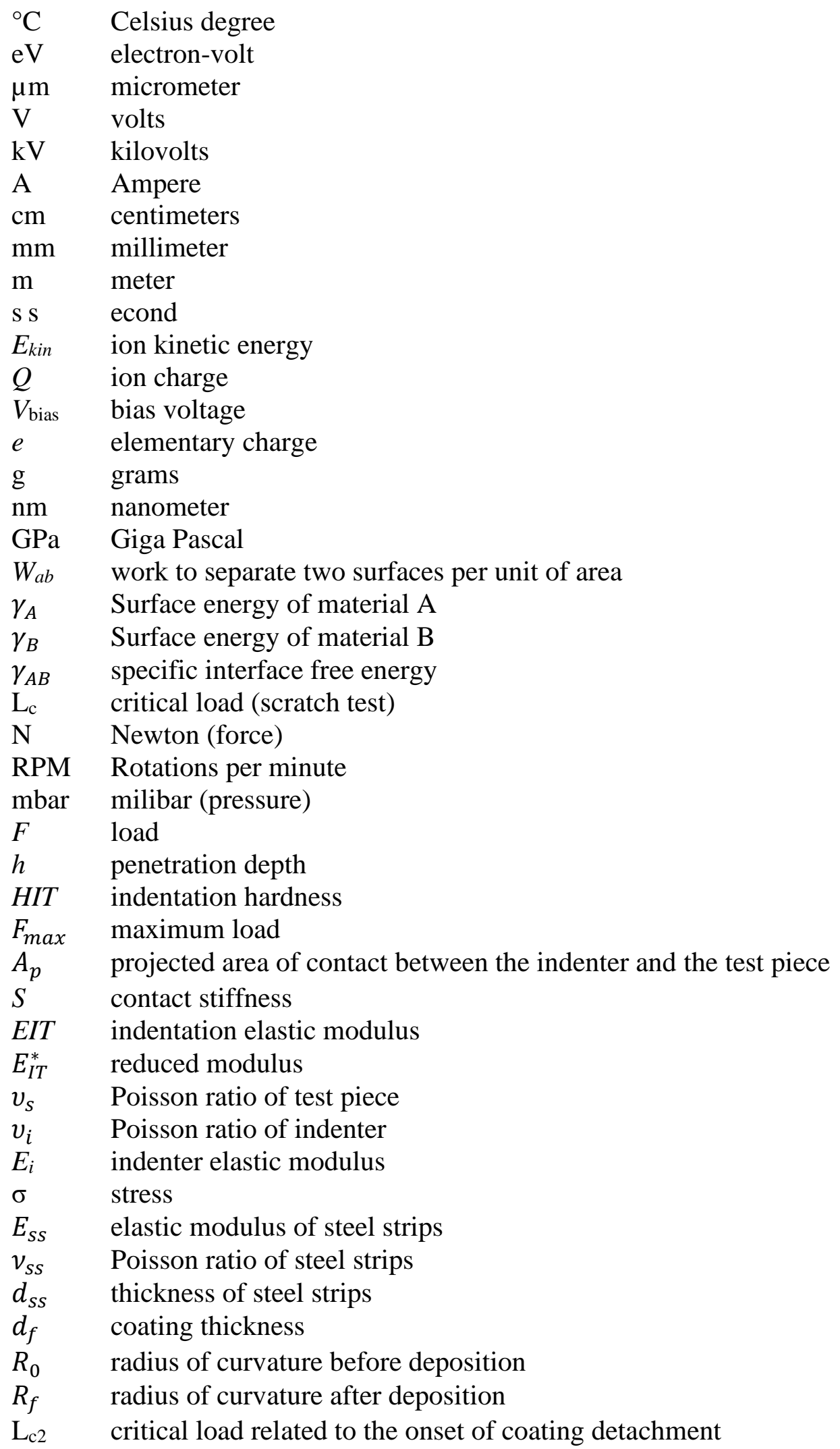




\section{TABLE OF CONTENTS}

1. INTRODUCTION............................................................................................................. 17

2. OBJECTIVES ....................................................................................................20

3. LITERATURE REVIEW .......................................................................................21

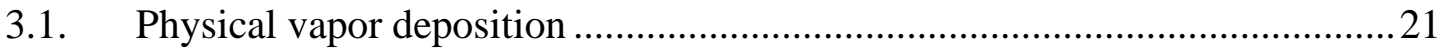

3.1.1. Cathodic arc evaporation .............................................................................

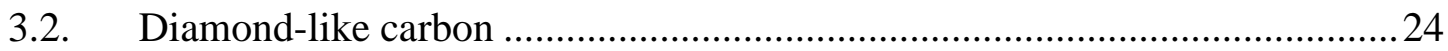

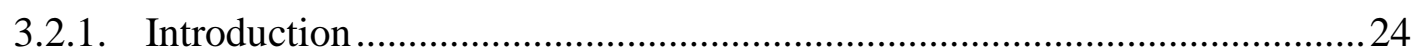

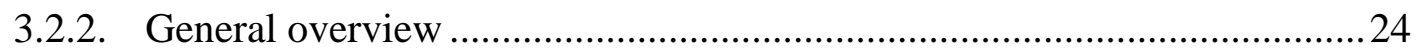

3.2.3. DLC growth process for a-C ....................................................................2

3.2.4. DLC coatings deposited by Cathodic Arc Evaporation .................................29

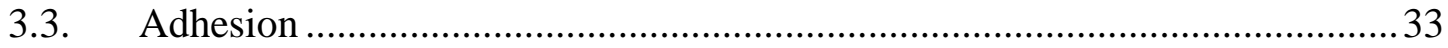

3.3.1. Adhesion of coatings deposited by PVD ..................................................... 34

3.3.2. Methods to assess coating adhesion.............................................................. 35

3.4. Methods for improving DLC adhesion on steel substrates...............................37

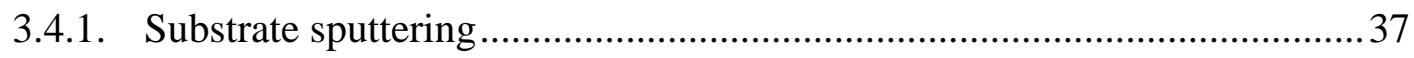

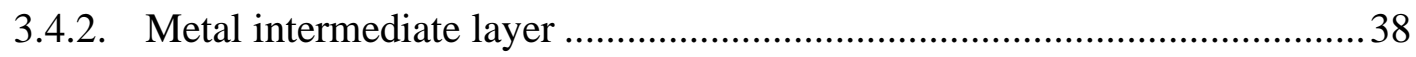

3.4.3. Duplex treatment ................................................................................... 40

3.4.4. Gradient coatings ....................................................................................... 41

3.4.5. Carbon bombardment............................................................................... 42

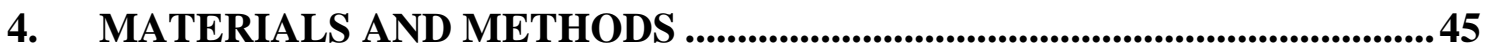

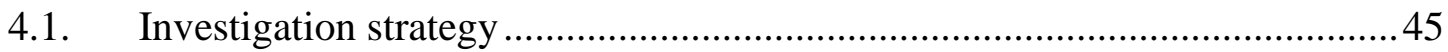

4.2. Coating deposition ..................................................................................4

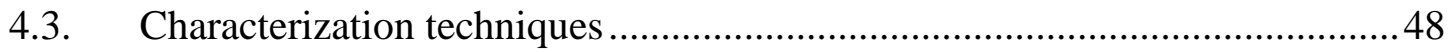

4.3.1. Instrumented indentation......................................................................... 48

4.3.2. Internal stress measurement ...................................................................51

4.3.3. Transmission Electron Microscopy - TEM …………………………….......51 
4.3.4. Electron Energy Loss Spectroscopy - EELS ..........................................54

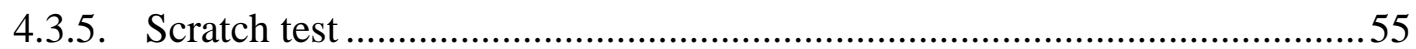

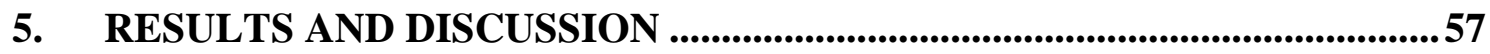

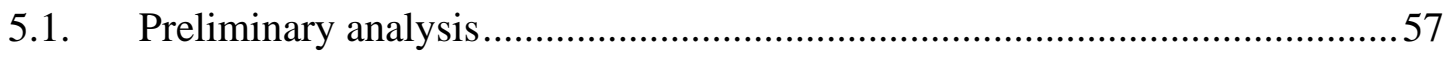

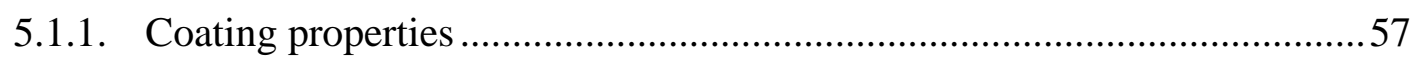

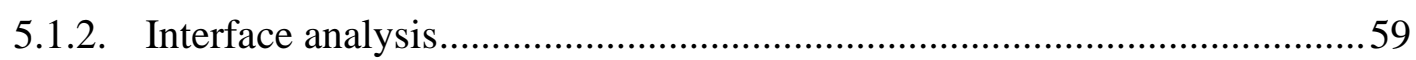

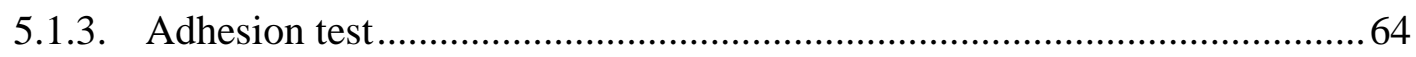

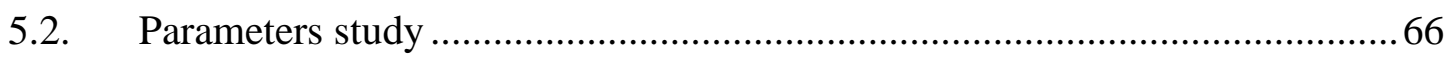

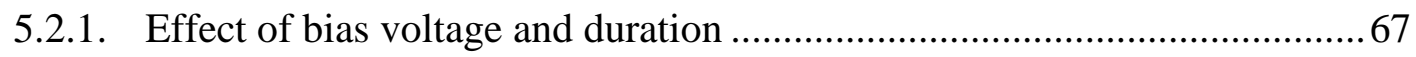

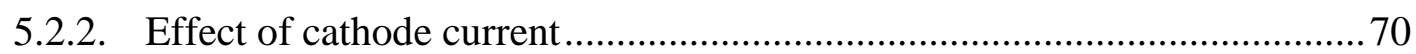

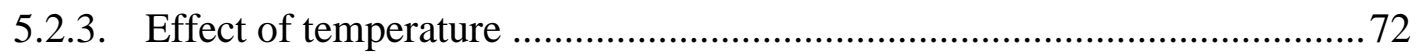

5.2.4. Interface analysis of selected experiments ............................................. 74

5.2.5. Model of impact of carbon transition layer thickness on adhesion..............77

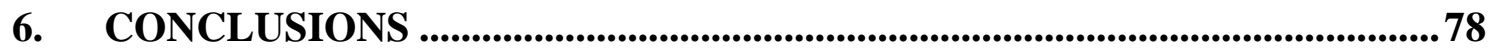

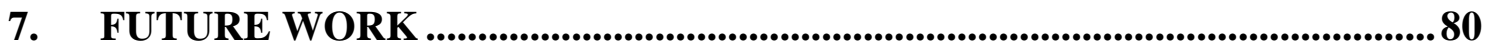

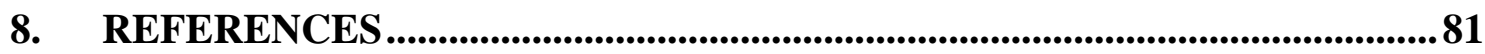




\section{INTRODUCTION}

Nowadays, materials for engineering are being applied in increasingly severe conditions (high loads, high temperatures), driven by environmental regulations and financial benefits. Traditionally, materials that support a high level of stress are heavy, costly and difficult to be produced. In this context, an important topic of study called "surface engineering" is inserted. The main objective of this research topic is the functionalization of materials through treatments or processes performed only on the surface. Consequently, with the developed solutions it is still possible to use cheaper materials, with easier production, even in the most severe applications, only with the inclusion of one or more surface processes. The use of hard coatings produced by physical vapor deposition (PVD) techniques is one of the examples of surface engineering solutions.

Diamond-like carbon (DLC) coatings can be listed as one of the hard coatings in use today. Its use is spread over many applications, due to features such as biocompability (HAUERT; THORWARTH; THORWARTH, 2013), low friction (ERDEMIR; MARTIN, 2018), wear resistance (FONTAINE; DONNET; ERDEMIR, 2008) and scuffing resistance (PODGORNIK, 2008). Such behaviors can be correlated to the carbon amorphous structure with significant fraction of $\mathrm{sp}^{3}$ bonds (ROBERTSON, 2002). Early studies reported that the DLC coating structure, in turn, can be changed by the combination of two important factors during deposition: ion energy and substrate temperature (LIFSHITZ, 1996; LIFSHITZ et al., 1993; MCKENZIE; MULLER; PAILTHORPE, 1991). The maximum $\mathrm{sp}^{3}$ content is achieved for ion energies in the range of 40 to $300 \mathrm{eV}$, when the temperature does not exceed $150{ }^{\circ} \mathrm{C}$. Recent studies have also pointed low friction as a result of a self-lubricating behavior observed mainly in Hydrogen-Free amorphous carbon, abbreviated by a-C (KANO et al., 2014). The HFree a-C coatings are mainly produced by cathodic arc evaporation, due to its high ionization rate and ease in the control of the ion energy.

The excellent tribological behavior of H-Free a-C coatings, together with the high deposition rates provided by cathodic arc evaporation, resulted in important industrial applications for automotive components (FERREIRA et al., 2019; KANO, 2015; MEHRAN et al., 2018), machinery parts and cutting tools (GRIMM; WEIHNACHT, 2010). In these applications, demands for thicker coatings (up to $30 \mu \mathrm{m}$ ) have recently grown, due to their high demands for wear and scuffing resistance, when applied in combination with low viscosity oils and magnified contact loads (TOMANIK et al., 2017). 
Along with good mechanical properties, the increase in $\mathrm{sp}^{3}$ content also leads to increasing stresses in the films. Different studies reported that the stresses may reach $10 \mathrm{GPa}$ when the film thickness exceeds $50 \mathrm{~nm}$ (CHHOWALLA, 2001; HIRVONEN et al., 1993). This behavior limits the total film thickness that can be achieved without delamination. Improvements on substrate cleaning, the use of ion sputter cleaning (BROITMAN; HULTMAN, 2012) and the use of metallic interlayer (CHEN; HONG, 2005) are wellestablished concepts to enhance adhesion. However, for thicker and highly stressed layers, other strategies must be used to ensure adhesion during coating lifespan.

Some authors reported improvements on adhesion for thin $(20-150 \mathrm{~nm})$ a-C layers by adding a high energy carbon bombardment step before the deposition of the functional layer (ANDERS et al., 1994; GERSTNER et al., 1995; HIRVONEN et al., 1993; KOSKINEN et al., 1994; PIVIN et al., 1993). Further investigations stated improvement in adhesion for thicker coatings, from 2 to $8 \mu \mathrm{m}$, using the same concept, when combined with metal interlayers (ANTTILA et al., 1997; CHHOWALLA, 2001; ZAVALEYEV et al., 2013; ZAVALEYEV; WALKOWICZ, 2015). Both pulsed bias (HIRVONEN et al., 1993; KOSKINEN et al., 1994; PIVIN et al., 1993) and dc bias (ANTTILA et al., 1997; CHHOWALLA, 2001) were used in those studies, with values ranging from $0,5 \mathrm{kV}$ to $20 \mathrm{kV}$. The observed benefits were accounted for the formation of carbides at the interface between the chromium bond layer and carbon transition layer (ANTTILA et al., 1997; KOSKINEN et al., 1994; PIVIN et al., 1993; ZAVALEYEV et al., 2013), the formation of an amorphous interfacial structure (GERSTNER et al., 1995) and/or the formation of a mixed layer between the metal interlayer and carbon (ANDERS et al., 1994; CHHOWALLA, 2001; HIRVONEN et al., 1993), where the mixed layer thickness ranged from 5 to $30 \mathrm{~nm}$. Another strategy used for adhesion enhancement is the deposition of a transition a-C layer with low $\mathrm{sp}^{3}$ content and low stress (ANDERS et al., 1997).

In summary, thick and hard a-C coatings are being used for parts with high wear resistance requirements, but the adhesion of the coatings is one important issue to be solved. Failures during operation or during the part production itself are usually seen. In the present work, a-C films with thicknesses about $20 \mu \mathrm{m}$ were studied. The coatings were deposited by unfiltered cathodic arc over a gas nitrided stainless steel substrate with metallic chromium as bond layer. An additional step was included during film processing, where carbon ions were accelerated by high bias potential before the deposition of functional a-C, to produce a carbon transition layer. Different parameters for the deposition of this layer were employed. The 
coating properties, interfacial structure and adhesion were analyzed to investigate the impact of the carbon bombardment step in the adhesion of a-C thick coatings and to have a concept proposition for adhesion improvement of these coatings. 


\section{OBJECTIVES}

The main objective of the current study is to analyze a concept to improve the adhesion of thick amorphous carbon coatings over steel substrate. The secondary goal is the understanding of the impact of a carbon bombardment step and its deposition parameters on adhesion by the application of advanced interface analysis and adhesion measurement procedures. 


\section{LITERATURE REVIEW}

\subsection{Physical vapor deposition}

Physical vapor deposition (PVD) processes consist of the deposition of atoms or molecules obtained by vaporization from a solid or liquid surface followed by transport through a low-pressure environment in direction of a substrate, where the material is condensed to form the desired coating or thin film. The vaporization can occur by thermal heating of the surface of the material or by sputtering. The latter relates to the ejection of particles from the material by momentum transfer from a massive bombarding particle, usually an ion (plasma). It also does not need a heating source (MATTOX, 2010). The PVD process usually requires vacuum to minimize the contaminations in the coating, to facilitate the formation and control of the plasma and to reduce interactions during the transport from the source to the substrate.

\subsubsection{Cathodic arc evaporation}

Cathodic arc evaporation is one type of PVD method. It is the main path followed for the deposition of hard, wear resistant coatings, due to its high ionization and ease in ion control. Both features lead to the growth of thicker coatings with a wide range of properties, depending on the deposition parameters (ANDERS, 2002).

The main difference from other deposition methods is the phenomenon used to produce the ions. In cathodic arc evaporation, the main process to generate ions is an electric discharge between the cathode, usually a solid target made of the material to be deposited, and the anode. The discharge process is affected with high current $(80-300 \mathrm{~A})$ and low voltage $(15-40 \mathrm{~V})$. The area in the target where the arc is applied is called arc spot. The size of an arc spot is about $10^{-6} \mathrm{~mm}^{2}$. Consequently, in this region, the current density is very high, in the range of $10^{6}$ to $10^{8} \mathrm{~A} / \mathrm{cm}^{2}$. The current density is one of the most important parameters in cathodic arc evaporation, because it governs the electron emission process, phase transitions and plasma production (ANDERS, 2002). A high current density implies in high power density, which is responsible to transform the cathode material from solid to plasma phase in a short period of time (JÜTTNER, 2001). Some authors refer to this phase transition as an explosion. In line with this concept, the electron emission mechanism has been called "explosive electron emission" (MESIATS; PROSKUROVSKII, 1984; MESYATS, 2014). Electrons are emitted by the synergetic presence of high temperature, high electric field, and via ionization of the cathode material. These conditions are fulfilled in arc spots, which become electron emission zones. 
The arc spot structure is non-stationery, because of the explosive behavior. The microexplosions change the surface topography and heat the zone beneath the spot. Figure 1 is representative of an arc spot, where one can see the topography changes due to the explosive behavior. Both factors increase the arc spot zone and change the local conductivity. The increase of the arc spot lead to a decrease in power density and to a significant decrease in the amount of material transformed from the cathode. In some cases, the electron emission activity and plasma density can be reduced to a point where the discharge can be extinguished. The other possibility is that the plasma condition near the cathode enables the formation of another location to form a new arc spot region. In this way, the arc process continues, and, in a macroscopic view, the arc moves over the cathode. The movement of the arc spot over the cathode is extremely important, since the ionization is higher for plasmas produced in the explosive phase. Due to this effect, some commercial deposition chambers use steered arcs, which consist of applying a magnetic field in front of the targets to induce a rapid and constant movement of the arc (FALABELLA; KARPOV, 1996).

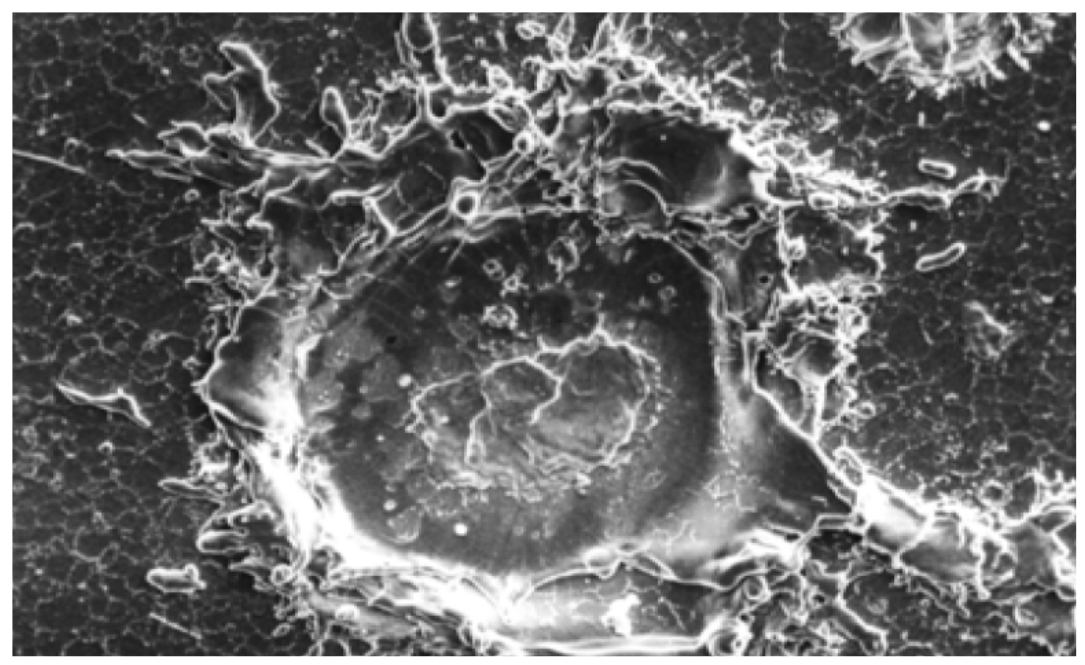

Figure 1 - Topography of the arc spot after explosive electron emission.

Source: (JÜTTNER, 1979).

The plasma generated at arc spots is characterized by very high density and temperature, resulting in pressure. Driven by the high pressure, the ions are accelerated to very high velocities, 0.5 to $3 \times 10^{4} \mathrm{~m} / \mathrm{s}$ (ANDERS; YUSHKOV, 2004). The velocity that the ion is expelled depends on the arc voltage and the cathode material (ANDERS; YUSHKOV, 2002). The velocity is important because it defines the energy of the ion that will reach the substrate, impacting directly on the coating properties. The ion energy is not defined only by the initial velocity, but also by the potential applied between the substrate and the plasma. This potential 
is well-known as substrate biasing. The ion kinetic energy, $E_{k i n}$ is calculated based on Equation (1), where $E_{k i n, 0}$ is related to the velocity gained in the arc spot, $Q$ is the ion charge, $e$ elementary charge and $V_{\text {bias }}$ is the bias voltage.

$$
E_{k i n}=E_{k i n, 0}+Q \cdot e \cdot V_{b i a s}
$$

Finally, the ions get to the surface, where the energy is released. The energy release processes include collisions with substrate atoms, subplantation and condensation in the form of film. The subplantation process consists in the penetration of ions into the substrate (LIFSHITZ; KASI; RABALAIS, 1989). This process leads to very high bonding between the target species and the substrate atoms, conferring good adhesion to the film (MONTEIRO, 2001).

The main drawback of cathodic arc deposition is the presence of macroparticles. Macroparticles are liquid or solid debris particles that are produced at arc spots along with the plasma. Juttner (1979) explained particle formation through the action of plasma pressure on the melted cathode material that is present between the dense plasma and the relatively cold cathode. Therefore, the production of macroparticles is inherent of the process and linked to the existence of non-stationary cathode spots. The macroparticles are named due to its size difference in relation to the electrons and ions in the plasma. Usually, the size of macroparticles is between a few nanometers up to a few micrometers (ANDERS et al., 1993). The main impact of the macroparticles is the production of defects and discontinuities in the coating (DRESCHER et al., 1998; PETROV et al., 1997), besides the increase in roughness of the coated parts. The defects produced can impact on the corrosion resistance of the coating and can also lead to more extreme failures like chipping and detachment. Along with the steered arc, other process modifications can be introduced to minimize the presence of macroparticles in the coating. The main modification used for this reason is the use of filters. The filters typically consist of curved magnetic coils that are placed between the targets (production of plasma) and the substrate. The magnetic field, produced by the filters, guide only the plasma (charged particles) to the substrate, while the macroparticles do not deflect and do not reach the substrate (ANDERS, 1999). 


\subsection{Diamond-like carbon}

\subsubsection{Introduction}

Carbon is an element of great importance in nature, since it is fundamental for organic compounds. It can be found in different allotropic forms such as the graphite, diamond, fullerenes and nanotubes. Besides its crystalline forms, it also appears in amorphous forms. The diamond-like carbon refers to some of those amorphous forms and it will be better explored in the next sections. The main reason for such wide range of forms is the three possible hybridizations that carbon can present, $\mathrm{sp}^{1}, \mathrm{sp}^{2}$ and $\mathrm{sp}^{3}$ (ROBERTSON, 1991). In the $\mathrm{sp}^{3}$ configuration, observed in diamond, each atom has its four valence electrons assigned to tetrahedral $\mathrm{sp}^{3}$ orbitals, which make strong type $\sigma$ bonds between atoms. For the $\mathrm{sp}^{2}$ configuration, as seen in graphite, three of the four electrons are assigned to trigonally directed $\mathrm{sp}^{2}$ orbitals, which forms strong type $\sigma$ bonds in the plane. The fourth electron is assigned in an p-orbital perpendicular to the plane formed by the trigonal bonds. The p-orbital formed by the fourth electron forms weak type $\pi$ bonds with p-orbitals from other atoms. Figure 2 gives a schematic representation of the three carbon hybridizations.
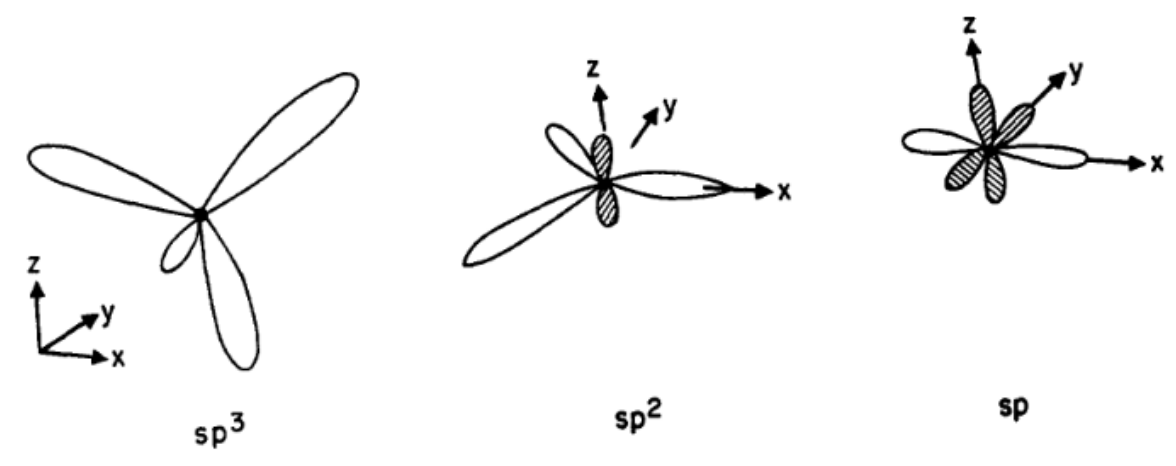

Figure 2 - Schematic representation of the three carbon hybridizations.

Source: (ROBERTSON, 1991).

\subsubsection{General overview}

DLC, diamond-like carbon, consists of an amorphous carbon film that has a high fraction of $\mathrm{sp}^{3}$ bonds, which are the main carbon hybridization seen in the diamond, hence its denomination (ROBERTSON, 2002). DLC coatings are divided into some types, which are defined according to $\mathrm{sp}^{2}$ and $\mathrm{sp}^{3}$ fractions, hydrogen content and presence of dopants. The ternary diagram of the carbon-hydrogen system is shown in Figure 3. The main types are the ta-C $(: \mathrm{H})$ and the a-C $(: \mathrm{H})$. ta-C has predominantly $\mathrm{sp}^{3}$ bonds, while a-C has predominantly $\mathrm{sp}^{2}$ 
bonds (FERRARI; ROBERTSON, 2000). The $\mathrm{sp}^{2} / \mathrm{sp}^{3}$ fraction, in turn, has a strong influence on the properties of the coating. The Young's modulus, hardness and general diamond-like quality arise from the $\mathrm{sp}^{3}$ bonds, and are monotonically dependent to it (FERRARI et al., 1999). It is found that the density also varies linearly with the $\mathrm{sp}^{3}$ fraction (FERRARI et al., 2000).

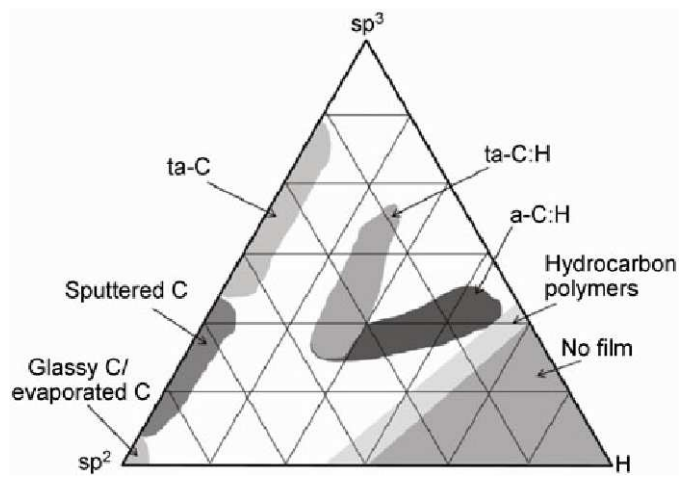

Figure 3 - Ternary phase diagram for various DLC films with respect to their $\mathrm{sp}^{2}, \mathrm{sp}^{3}$, and hydrogen contents.

Source: (ROBERTSON, 1992).

The formation of hydrogenated DLC (H-DLC) or hydrogen-free DLC, or a-C, depends on the deposition process used. H-DLC is produced with the use of precursor gases like acetylene, in which the hydrogen is incorporated into its structure. The deposition process used is PACVD (Plasma-assisted Chemical Vapor Deposition) with DC glow discharge. The a-C can be produced by sputtering (including High-Power Impulse Magnetron Sputtering HiPIMS) and cathodic arc evaporation, with the use of solid graphite targets (VETTER, 2014). The cathodic arc evaporation is the preferred method, due its higher ionization rate, which leads to high deposition rates and better control of the ion energy. For cathodic arc deposition, two main processes are used for industrial applications. The first one is the direct cathodic arc evaporation (DCAE), in which a direct or pulsed current is used in the arc discharge with no means to separate the plasma from the macroparticles. The second is the filtered cathodic arc evaporation (FCAE), in which some strategies are selected to separate the macroparticles from the plasma flux. The typical strategy for separation is the use of magnetic filters. A schematic set-up of DCAE and FCAE evaporation sources is shown in Figure 4. The choice of using filtered or direct arc evaporation is made based on the application. For applications that require high thicknesses $(>5 \mu \mathrm{m})$ produced in large scale, the usual recommendation relies on the use of direct evaporation, while applications with thin layers that require very small defect quantities normally require the use of filtered arc. 


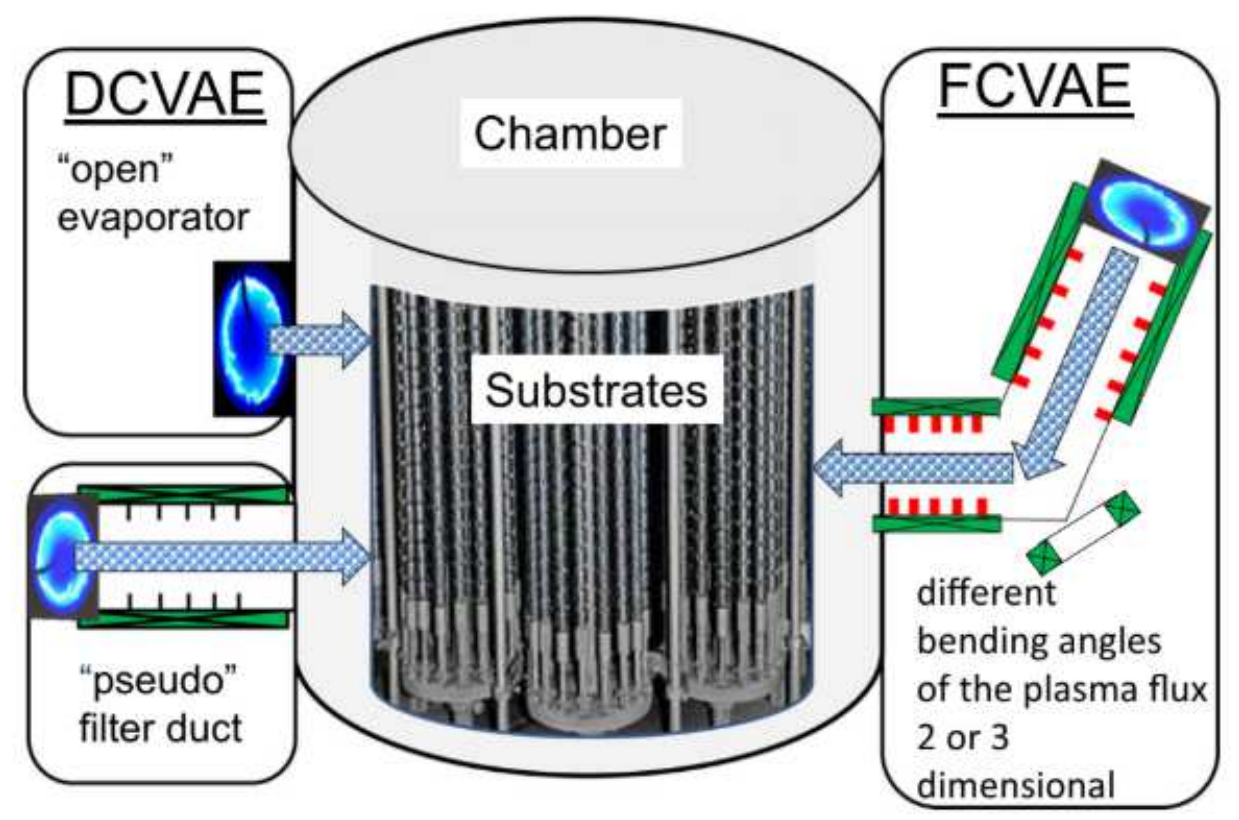

Figure 4 - Schematic set-up of DCAE and FCAE evaporation sources.

Source: (VETTER, 2014).

The study and development of DLC coatings are conducted since the 1950's and can be accounted for the great versatility of the coating and its suitable properties in relation to friction and hardness (ERDEMIR; FONTAINE; DONNET, 2008). DLC coatings can have very high hardness (in the order of $70 \mathrm{GPa}$ ) (PHARR et al., 1996), leading to optimal wear performance and also friction coefficients below 0.2 in case of lubrication-free contacts (RONKAINEN et al., 1994) and coefficients below 0.07 in lubricated contacts (TOMANIK et al., 2017).

The applications of DLC coatings are diverse and include the fields of microelectronics, optics, manufacturing, transport and biomedicine (BUNSHAH, 2001). Some applications should be highlighted because they are related to the present work, linked to the high demand for wear resistance and need of hard and thicker films. These applications are the use of DLC coatings for combustion engine components (BRUNO et al., 2017; MEHRAN et al., 2018) and for machining tools (GRIMM; WEIHNACHT, 2010).

\subsubsection{DLC growth process for a-C}

The most accepted model for the growth of a-C coatings is the subplantation model, which was first proposed by Lifshitz, Kasi and Rabalais (1989). The model is based in the penetration of carbon ions into the uppermost surface layers. The growth process progresses along the following steps. 
i) Penetration of energetic carbon ions into subsurface layers.

ii) Stopping of the energetic ions in the substrate by energy loss mechanisms. The main mechanisms are atomic displacements and electron excitations, sometimes called as thermal spikes (WEISSMANTEL et al., 1980).

iii) Positioning at a site in the host matrix. Hyperthermal species may occupy another site during further impacts from other energetic species.

iv) Increase in the concentration of penetrating species in the matrix up to a point where a new phase is formed.

v) Film growth by expansion of the new phase initiated at the subsurface. In the first stages, the substrate atoms are sputtered or diluted by the impinging species. This dilution occurs up to a point where all the surface and subsurface structure are composed of the deposited material.

In terms of duration, Schultrich (2011) translated the subplantation growth model into four stages: The collisional stage $\left(<10^{-13} \mathrm{~s}\right)$, the thermalization stage $\left(10^{-13}\right.$ to $\left.10^{-11} \mathrm{~s}\right)$, the diffusional stage $\left(10^{-11}\right.$ to $\left.1 \mathrm{~s}\right)$ and the technological stage $(>1 \mathrm{~s})$. Similar to the previous description, in the collisional stage, the carbon ions are stopped by collisions with atoms at the surface, where some energy is lost by ionization, and displacement of atoms. In the thermalization phase, the excess of energy is distributed over the surroundings. The final bonding structure is formed in the diffusional stage, where a competition between the local $\mathrm{sp}^{3}$ stabilization and $\mathrm{sp}^{2}$ relaxation by diffusion towards the surface occurs. The technological stage is dependent of major deposition parameters such as rotation of substrate and duty cycle (On/Off time) and is linked with the overall structure (e.g. layered systems).

It was found that the competition between $\mathrm{sp}^{3}$ formation and $\mathrm{sp}^{2}$ relaxation is closely dependent on ion energy. According to Robertson (1992), the $\mathrm{sp}^{3}$ structure is formed in the collisional stage, where high density regions are formed. For higher ion energies, more penetration is expected, increasing the high-density regions. However, further increase in ion energy induces more energy dissipation in the thermalization stage. The energy dissipation in excess will increase the relaxation of the structure, decreasing the local density. In this case, the transformation of the formed $\mathrm{sp}^{3}$ into $\mathrm{sp}^{2}$ occurs. Hence, the optimum ion energy for maximum density is a balance between a sufficiently high penetrative yield and a small relaxation of the density increment. A schematic of ion subplantation, the formation of a high-density region and the relaxation is shown in Figure 5. 

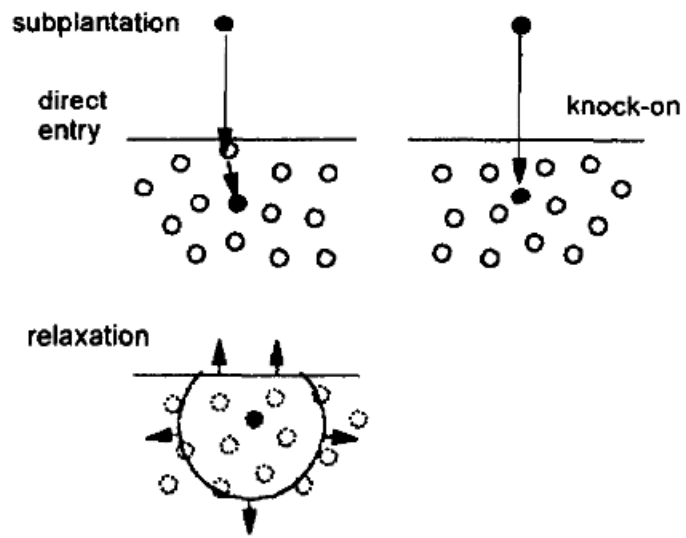

Figure 5 - Schematic of ion subplantation, the formation of a high-density region and the relaxation. Source: (ROBERTSON, 1994)

The effect described by Robertson (1992) was experimentally proven by other studies (CHHOWALLA et al., 1997; FALLON et al., 1993; MCKENZIE et al., 1991; VEERASAMY et al., 1993; XU et al., 1996). In all those studies, an optimal ion energy of about $100 \mathrm{eV}$ was found, where the $\mathrm{sp}^{3}$ fraction is the maximum. Figure 6 presents the behavior of $\mathrm{sp}^{3}$ fraction as a function of ion energy obtained by Chhowalla et al. (1997).

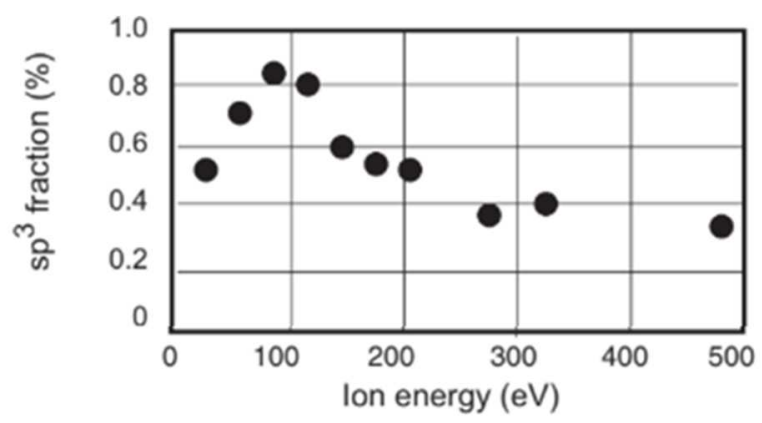

Figure $6-\mathrm{sp}^{3}$ fraction versus the ion energy.

Source: (CHHOWALLA et al., 1997).

Other important factor that influences the $\mathrm{sp}^{3}$ formation is the deposition temperature. This influence can also be accounted for to the structure relaxation during the deposition. As seen by Lifshitz (1993 and 1994) and Chhowalla et al. (1997), a sharp decrease in $\mathrm{sp}^{3}$ fraction occurs for deposition temperatures higher than $150{ }^{\circ} \mathrm{C}$. Figure 7 presents the result obtained by Chhowalla et al. (1997). Other effects that also impact in the $\mathrm{sp}^{3}$ formation are deposition rate and impingement angle (DRESCHER et al., 1998; SCHULTRICH, 2011). 


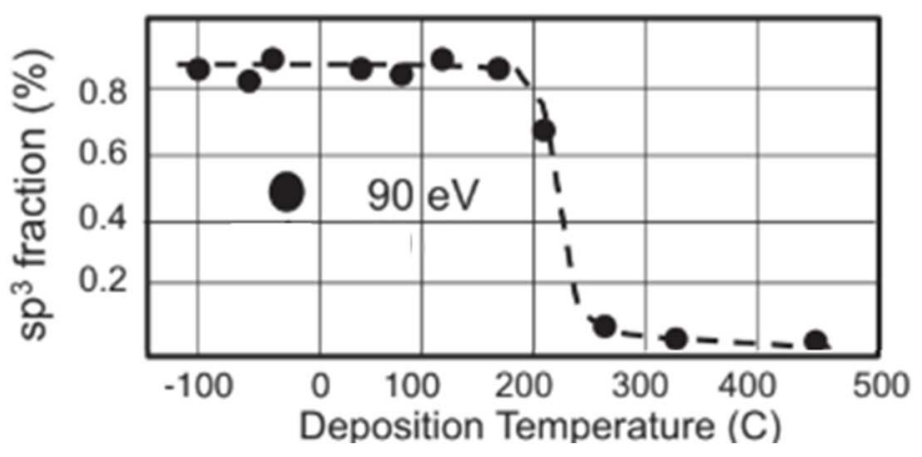

Figure $7-\mathrm{sp}^{3}$ fraction versus deposition temperature.

Source: (CHHOWALLA et al., 1997).

\subsubsection{DLC coatings deposited by Cathodic Arc Evaporation}

The $\mathrm{sp}^{3}$ content, density, stress, Young's modulus and hardness form a field of interrelated properties for a-C coatings (VETTER, 2014). For most cases, the main coating properties can be described by two of these parameters. In the following topics, the general trend and ranges will be described for each property.

\subsubsection{Density}

The density of a-C coatings ranges from $2,0 \mathrm{~g} / \mathrm{cm}^{3}$ to $3,3 \mathrm{~g} / \mathrm{cm}^{3}$ (VEERASAMY et al., 1993). As a reference, the density of diamond and graphite are $3,5 \mathrm{~g} / \mathrm{cm}^{3}$ and $2,0 \mathrm{~g} / \mathrm{cm}^{3}$, respectively. The density varies linearly with the $\mathrm{sp}^{3}$ fraction, as shown in Figure 8 . The same trend was also seen by Fallon et al. (1993).

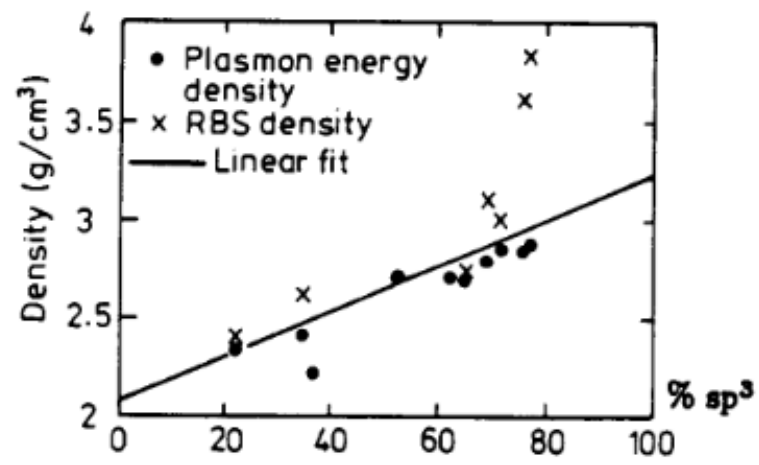

Figure 8 - Density versus $\mathrm{sp}^{3}$ fraction.

Source: (VEERASAMY et al., 1993).

\subsubsection{Hardness and Young's modulus}

The hardness and Young's modulus follow the same trend as the density. Xu et al (1997) reported an increase in hardness and Young's modulus for higher $\mathrm{sp}^{3}$ fractions, as shown in 
Figure 9. In their study (XU et al., 1997), coatings of $60 \mathrm{~nm}$ were deposited by FCAE with different ion energies, with corresponding achieved hardness in the range of 20 to $55 \mathrm{GPa}$ and Young's modulus from 200 to $400 \mathrm{GPa}$.
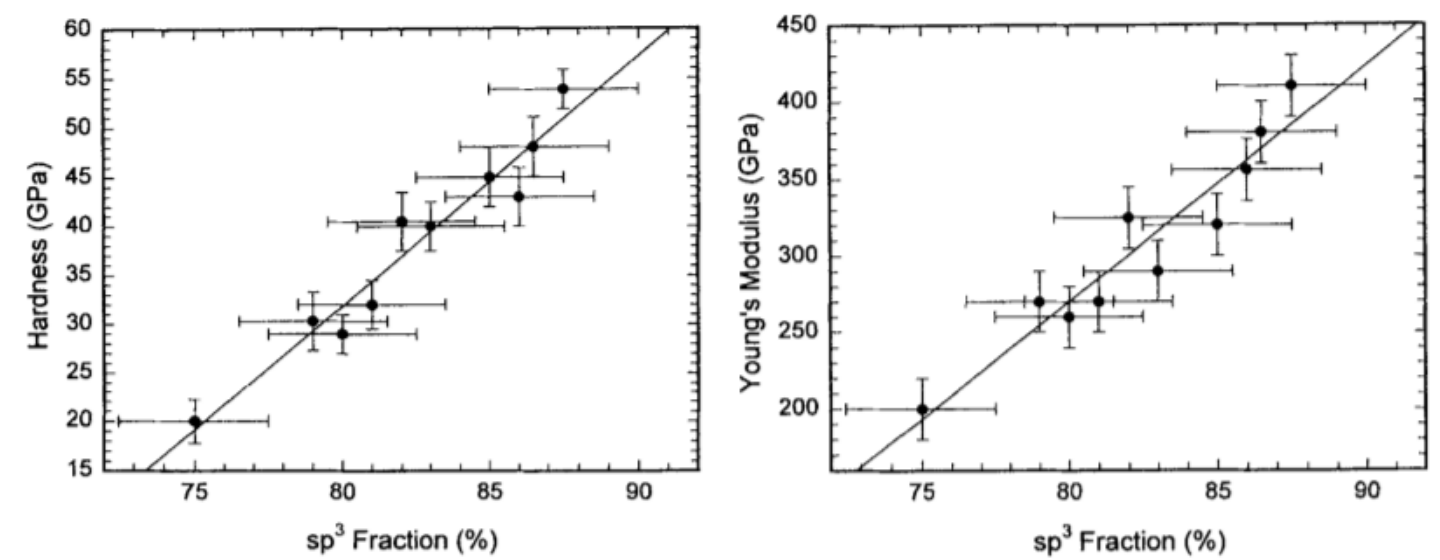

Figure 9 - Hardness and Young's modulus dependence on the $\mathrm{sp}^{3}$ fraction for FCAE.

Source: (XU et al., 1997).

A similar trend was also seen for coatings deposited by DCAE. Zou et al. (2011) reported a linear variation between hardness and Young's modulus with $\mathrm{sp}^{3}$ fraction in films with $2 \mu \mathrm{m}$, as seen in Figure 10. Their study found hardness of 19 to $28 \mathrm{GPa}$, when the $\mathrm{sp}^{3}$ fraction varied from 24 to $34 \%$.

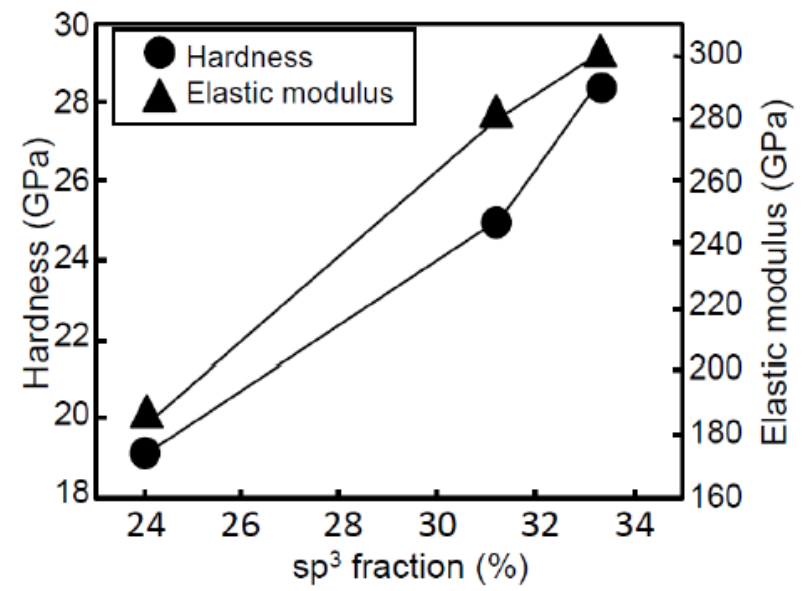

Figure 10 - Hardness and Young's modulus dependence on the $\mathrm{sp}^{3}$ fraction for DCAE.

Source: (ZOU et al., 2011)

Hardness measurements are difficult to compare due to differences in measurement procedures and calculation models. For instance, Pharr et al. (1996) showed that the hardness values depend on the thickness of thin a-C coatings because of the interference of the substrate properties on the measured values. The recommendation is to conduct the hardness 
measurements with penetration depth under $10 \%$ of the film thickness, to minimize the substrate effects (INTERNATIONAL ORGANIZATION FOR STANDARDZATION, 2016).

\subsubsection{Residual internal stress}

The internal stress of a-C coatings is composed of intrinsic compressive stresses and thermal stresses (PAULEAU, 2008). The intrinsic stress is the major component, which is produced due to the ion bombardment during deposition, to form the $\mathrm{sp}^{3}$ bonds (ROBERTSON, 2002). The magnitude of overall compressive stresses is related to adhesion, since highly stressed films are limited in thickness (CHOLERIDIS et al., 2018).

The magnitude of residual (intrinsic) stresses in DLC films is dependent on the deposition process and process parameters such as pressure in the deposition chamber, substrate bias voltage, and power density (PAULEAU, 2008). For a-C coatings deposited by cathodic arc evaporation, a significant correlation between stress and $\mathrm{sp}^{3}$ fraction was found, when data from Fallon et al. (1993, apud ROBERTSON, 2002) and Chhowalla et al. (1997, apud ROBERTSON, 2002) were considered. In these studies, compressive stresses up to $11 \mathrm{GPa}$ were found, when the $\mathrm{sp}^{3}$ fraction was about 70\%. However, another study (POLO et al., 2000, apud ROBERTSON, 2002) suggests that very high $\mathrm{sp}^{3}$ fractions can be achieved with stresses below $5 \mathrm{GPa}$. The results of these studies are shown in Figure 11.

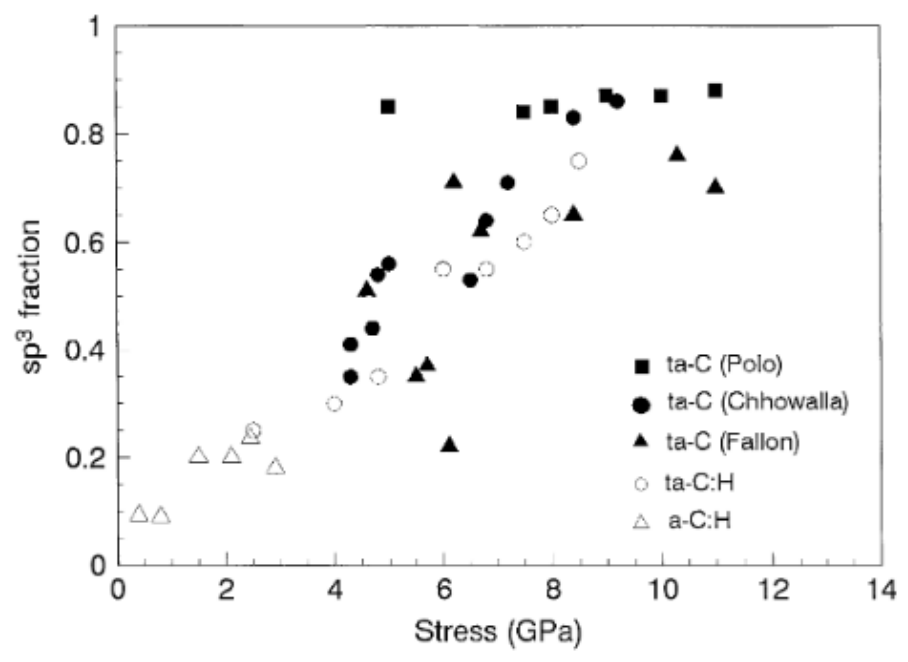

Figure 11 - Correlation of compressive stresses and sp3 fraction.

Source: (ROBERTSON, 2002).

A more complete survey regarding the correlation between $\mathrm{sp}^{3}$ fraction and compressive stresses was conducted by Ferrari et al. (2002). In that study, no correlation was found when all the available data were considered. Figure 12 presents the complete collection of data 
considered in the study. Ferrari et al. (2002) concluded that the main cause for stress build-up is the ion bombardment, and that the macroscopic stress is not necessary to stabilize the $\mathrm{sp}^{3}$ phase.

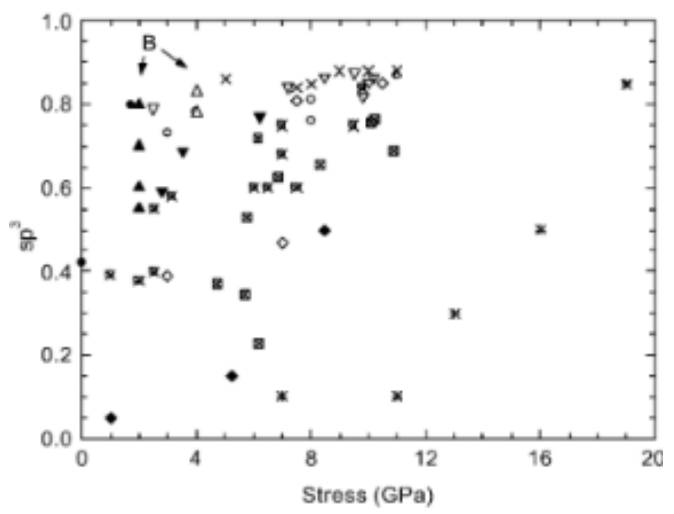

Figure 12 - Collection of stress and sp3 data from as-deposited H-free DLC samples found in literature. Source: (FERRARI et al., 2002).

Thickness is another important point that can influence the overall compressive stresses. Some studies have shown that the maximum compressive stress is achieved in the first tenths of nanometers of the film and then stabilize (CHHOWALLA, 2001; SHEEJA et al., 2002), as seen in Figure 13.
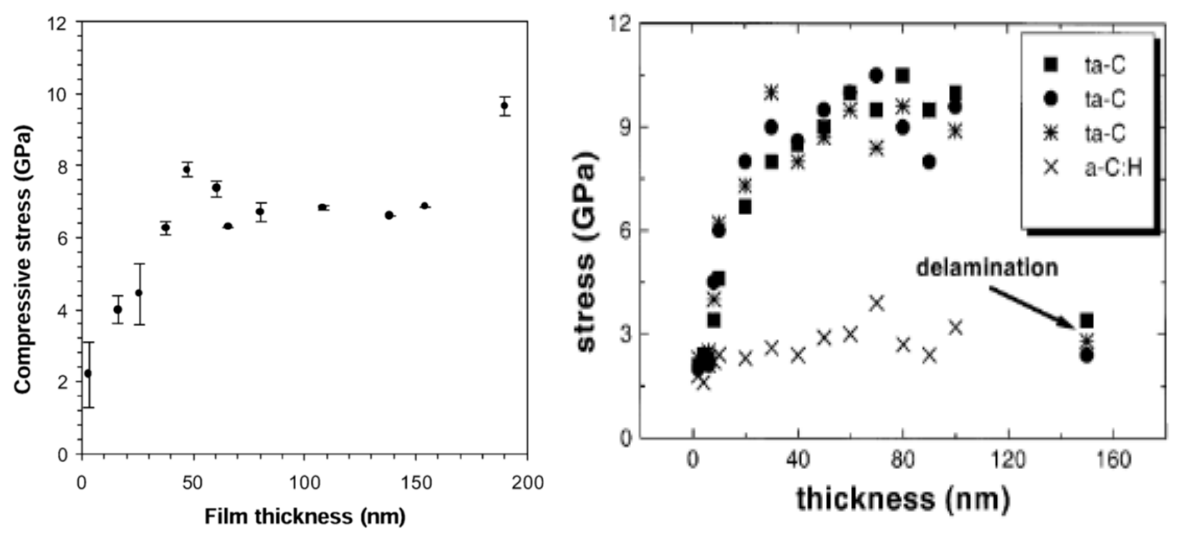

Figure 13 - Thickness influence on compressive stress.

Source: (a) (SHEEJA et al., 2002); (b) (CHHOWALLA, 2001).

The literature reported stresses from 4 to $10 \mathrm{GPa}$ for super hard (>60 GPa) amorphous layer deposited by cathode arc evaporation (CHHOWALLA, 2001; VEERASAMY et al., 1993, FALLON et al., 1993). More recent studies explored other strategies to reduce stress, with the most promising one being high pulsed biasing. A residual stress of $0.9 \mathrm{GPa}$ was achieved for a $1 \mu \mathrm{m}$-thick coating with moderate hardness (36 GPa) by Zhang et al (2005). Tay, Sheeja and 
Yu (2003) also reported an expressive reduction in compressive stress by combining high pulsed biasing and annealing. The reduction in stress due to the pulsed biasing was attributed to the relaxation of the layer during positive pulse, when there is no deposition. In this way, some local transformations from $\mathrm{sp}^{3}$-rich regions to $\mathrm{sp}^{2}$ can occur, with minimum loss of mechanical properties (DELPLANCKE-OGLETREE; MONTEIRO, 2003).

\subsubsection{Thickness}

Thicknesses over $20 \mu \mathrm{m}$ are more common in the literature for hydrogenated DLC films (AN et al., 2019; DALIBÓN et al., 2019). For a-C, only Grimm and Weihnacht (2010) reported thickness up to $70 \mu \mathrm{m}$, produced by pulsed arc, and Araujo et al. (2017) described layers up to $60 \mu \mathrm{m}$ with the use of dc arc evaporation. The reduced occurrence of thicker H-free layers in the literature is mainly due to adhesion problems of super-hard or hard coatings, which usually limit the film thickness to, approximately, $2 \mu \mathrm{m}$ (CHOLERIDIS et al., 2018).

\subsection{Adhesion}

Adhesion can be defined as the molecular attraction that holds the surfaces of two dissimilar substances together (BASTOW; BOWDEN, 1932). In the case of coatings, adhesion is defined as the work necessary to separate the coating-substrate interface (PULKER; PERRY; BERGER, 1981; RICKERBY, 1988). Adhesion is one of the most important features in this field, because most of the failures that occur for hard coatings are related to layer detachment and subsequent component failure. A simple model proposed by Rickerby, Jones and Bellamy (1988) relates the adhesion of two materials to the work performed to separate two surfaces per unit of area, according to Equation (2).

$$
W_{A B}=\gamma_{A}+\gamma_{B}-\gamma_{A B}
$$

In Equation 2, $\gamma_{\mathrm{A}}$ e $\gamma_{\mathrm{B}}$ are the specific surface energies of materials $\mathrm{A}$ and $\mathrm{B}$, while $\gamma_{\mathrm{AB}}$ is the specific interface free energy. Some restrictions for the model are the non-consideration of plastic deformations that the material may suffer and the non-consideration of a possible mechanical locking between the surfaces and/or interdiffusion between them. Even so, the model already demonstrates the importance of reducing interface energy to have higher adhesion. 


\subsubsection{Adhesion of coatings deposited by PVD}

In PVD technology, adhesion arises mainly from chemical interactions between the atoms of the coating and the substrate. The adhesion for coatings is determined by factors such as the mechanical properties of each material, the deposition parameters and deposition strategy, along with the structures formed at the interface.

Poor adhesion may come from contamination of the substrate, formation of brittle interface structure, high level of interface failures, formation of layer nodules (MATTOX, 2010) and/or high coating stress (GANGOPADHYAY, 1998). This last point is relevant for the present work, since H-free DLC coatings tend to have high internal stress. This effect can be intensified by an increase in the thickness of the coating.

Generally, in PVD technology, some procedures and methods are used to improve adhesion. Some of these methods are listed below.

- Minimize any contamination present in the substrate (MATTOX, 2010).

- Ion bombardment of the substrate for removal of impurities (VIHERSALO et al., 1993);

- Increase coating nucleation density to minimize the number of interface defects (MATTOX, 2010);

- Increase substrate roughness to increase mechanical surface locking (BUNSHAH, 2001);

- Maximize the chemical affinity of the substrate with the coating, to increase the forces of atomic interaction (KOSKINEN et al., 1994);

- Use an intermediate layer to provide a transition of mechanical properties (CHEN; HONG, 2005);

- Include deposition steps that cause diffusion of the material deposited with the substrate (BROITMAN; HULTMAN, 2012);

- Use materials with similar mechanical properties and/or provide gradient effect on coating growth (XIANG et al., 2006). 


\subsubsection{Methods to assess coating adhesion}

There are several ways of assessing the adhesion of coatings. The choice of the most appropriate form depends on the type of stresses to which the coating is exposed to. Figure 14 shows four types of adhesion measurements. In three of them, the test is based on layer traction and they differ by the device used to perform traction. In the first, traction loads are applied by an adhesive tape; in the second, by a stud glued to the piece; and in the third, by a wire glued to the piece surface. The fourth is based on shear, where an adhesive ball is glued to the surface and a shear force is applied by a blade (BUNSHAH, 2001).

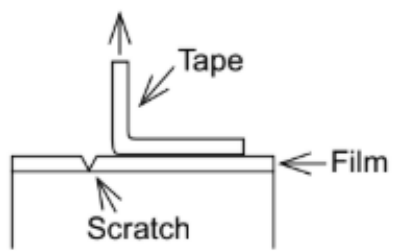

Tape test

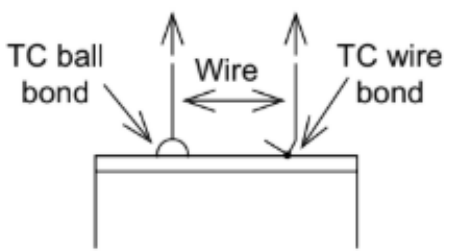

Wire-pull test

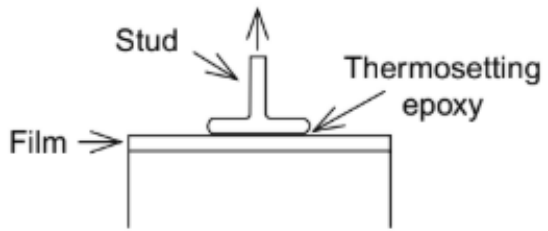

Stud-pull test

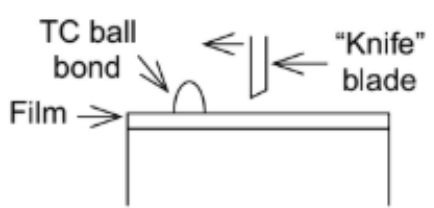

Shear test

Figure 14 - Methods for evaluation adhesion.

Source: (MATTOX, 2010).

Moreover, there are two other evaluation methods that are most used today. The first of these is the indentation test, which is based on visual analysis of coating surface after an indentation is conducted by a Rockwell $\mathrm{C}$ indenter, using a standardized load (VIDAKIS; ANTONIADIS; BILALIS, 2003). A schematic view is shown in Figure 15. 

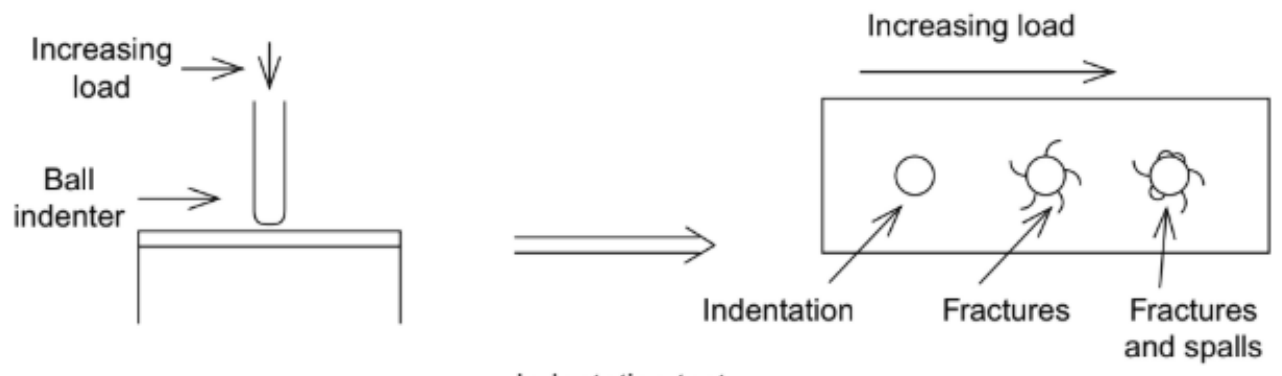

Figure 15 - Schematic view of Indentation test.

Source: (MATTOX, 2010).

The other method is the scratch test, which is widely used for assessing the adhesion strength of coating-substrate systems (BULL; BERASETEGUI, 2006; BURNETT; RICKERBY, 1987). The test consists of using a Rockwell C diamond indenter to apply an increasing or constant load across the coating surface, while the sample is displaced at a constant velocity. A scheme is shown in Figure 16. With progressive load, it is possible to evaluate the load at which the first cracks and adhesion failures appear. The test produces mechanical damage in the coating/substrate through the combination of elastic/plastic indentation, frictional forces and residual stresses in the system (ASTM INTERNATIONAL, 2015). The normal force that produces a specific and reproducible failure type and level is defined as the critical scratch load $\left(\mathrm{L}_{c}\right)$. In general, the critical load is determined by acoustic emission, friction force measurements, or optical microscopy. Many failure mechanisms and coating damage types are described in the literature (ASTM INTERNATIONAL, 2015; BULL, 1991, 1997). The critical load becomes a way of comparing the adhesion of multiple samples. Due to the ease in conducting the test and the usefulness in the definition of critical loads, the scratch test was chosen as the method for adhesion evaluation in the present work.

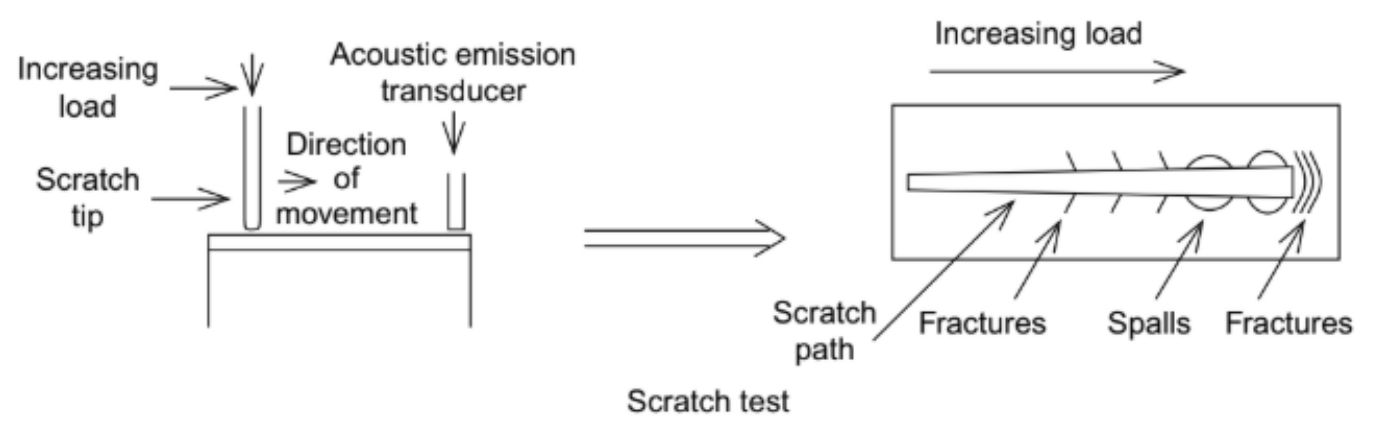

Figure 16 - Schematic view of Scratch test.

Source: (MATTOX, 2010). 
Some factors must be considered in the analysis of the scratch results. It includes scratching speed, tip condition, loading rate, and coating-substrate characteristics such as thickness of the coating, hardness and roughness (STEINMANN, TARDY and HINTERMANN, 1987).

\subsection{Methods for improving DLC adhesion on steel substrates}

This topic is intended to describe and analyze the available strategies for adhesion improvement of DLC coatings, both hydrogenated and hydrogen-free. The study was not limited by thickness nor hardness. The only restriction imposed here was the substrate. The reason for a broader review is the possibility to extend some concepts found for coatings thinner and softer than those in the present work.

In the literature review, substrate sputtering and use of metallic intermediate layer are sufficient to ensure the adhesion for coatings up to $2 \mu \mathrm{m}$. For thicker coatings, these concepts are combined with other strategies such as duplex treatment and/or gradient layers and carbon bombardment.

\subsubsection{Substrate sputtering}

The use of substrate sputtering by ion bombardment is a strategy largely used for PVD. The primary objective of the sputter cleaning is to remove contamination layers and surface oxides (BUNSHAH, 2001). The same strategy is also used for deposition of DLC coatings. Morshed et al. (2003) reported impact in adhesion of thin DLC coatings $(\sim 0,35 \mu \mathrm{m})$ after sputter cleaning with argon applied to a stainless steel substrate. An optimum sputter time of $15 \mathrm{~min}$ was found to maximize adhesion. The variation of adhesion was related to film structure, since different temperatures of the substrate were observed during sputtering. Wasy et al. (2014) also reported a substantial increase in critical loads obtained by scratch test, for samples sputtered with Ar with bias of $-600 \mathrm{~V}$.

Chen and Hong (2005) conducted sputtering with $\mathrm{Cr}$ on a stainless steel substrate with different bias. These authors reported substantial adhesion improvements when using higher bias voltages, at least $-700 \mathrm{~V}$. The adhesion enhancement was attributed to the formation of a mixed zone between $\mathrm{Cr}$ and the steel substrate. The size of the mixed layer was about $20 \mathrm{~nm}$, identified by compositional analysis made by Auger spectroscopy. A similar mixed layer was also observed by Broitman and Hultman (2012), in the application of a sputtering with 
chromium, using a HIPIMS source. Figure 17 presents the obtained structure, indicating a 5 $\mathrm{nm}$-thick layer between the $\mathrm{Cr}$ and the steel. In this case, an adhesion enhancement was also seen by indentation adhesion test.

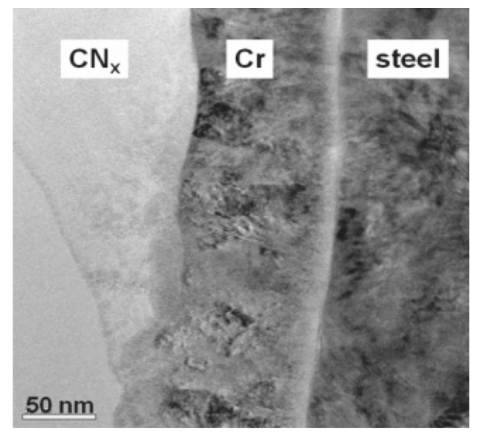

Figure 17 - Cross-sectional TEM image showing the mixed layer between $\mathrm{Cr}$ and Steel substrate.

Source: (BROITMAN; HULTMAN, 2012).

\subsubsection{Metal intermediate layer}

For hard coatings, the use of a metal intermediate layer is a usual practice. The intermediate layer can work as a buffer layer for highly stressed coatings like DLC, in the way that they can accommodate relative displacements between the substrate and the coating. Hence, the intermediate layers usually have properties, such as hardness and Young's modulus, with values between those of the substrate and the coating (MATTOX, 2010). Another important role of the intermediate layers is to control other stresses at the interface, mainly thermal stresses that appear due to the difference between the deposition and ambient temperature (WEI; YANG; TAI, 2010). The reduction of compressive stress was reported by Cao et al. (2018), who observed a reduction from $12.4 \mathrm{GPa}$, for no intermediate layer, to 2.4 $\mathrm{GPa}$, when an intermediate layer of $1.1 \mu \mathrm{m}$ was employed.

The most used intermediate layers for DLC coatings contain Cr (CHEN; HONG, 2005), Ti (CAO et al., 2018), Si (CEMIN; BOEIRA; FIGUEROA, 2016) and W (ISONO et al., 2018). Chromium is the most used for steel substrates. The literature indicates the use of chromium interlayer for DLC coatings over steel substrates for the following reasons: a) the thermal expansion coefficient of chromium is close to iron ( $\mathrm{Cr}: 11.8 \times 10^{-6}$ and Fe: $12.5 \times 10^{-6}$ ), which minimizes thermal stresses (CHEN; HONG, 2005); b) the constituents of steel used in most applications have chromium as one of its main constituents, which can increase the bonding between the substrate and the intermediate layer (CHEN; HONG, 2005); c) chromium can react with carbon, resulting in the formation of carbides that can increase adhesion between the 
carbon coating and the intermediate layer (FUJIHANA; OKABE; IWAKI, 1997; GLOZMAN; HOFFMAN, 1997).

The thickness of the intermediate layer is important for adhesion. Shahsavari et al. (2016) reported that $20 \mathrm{~nm}$ of chromium intermediate layer can provide adhesion for a DLC layer of $200 \mathrm{~nm}$. For thicker coatings, about $2 \mu \mathrm{m}$, an intermediate layer thickness of $0.3 \mu \mathrm{m}$ was needed to maintain a sufficient adhesion level (PANCIELEJKO et al., 2012). Hence, a trend of thicker intermediate layer for thicker coatings is seen in the literature. However, Chen and Hong (2005) reported that further increase in chromium thickness can jeopardize the adhesion, due to an increase in compressive stress. That study (CHEN; HONG, 2005) described chromium intermediate layers with $0.1 \mu \mathrm{m}, 0.3 \mu \mathrm{m}$ and $0.5 \mu \mathrm{m}$. The adhesion was evaluated by indentation test, with results as shown in Figure 18. Poor adhesion was observed for intermediate thicknesses of $0.1 \mu \mathrm{m}$ and $0.5 \mu \mathrm{m}$, while good adhesion was obtained for $0.3 \mu \mathrm{m}$.
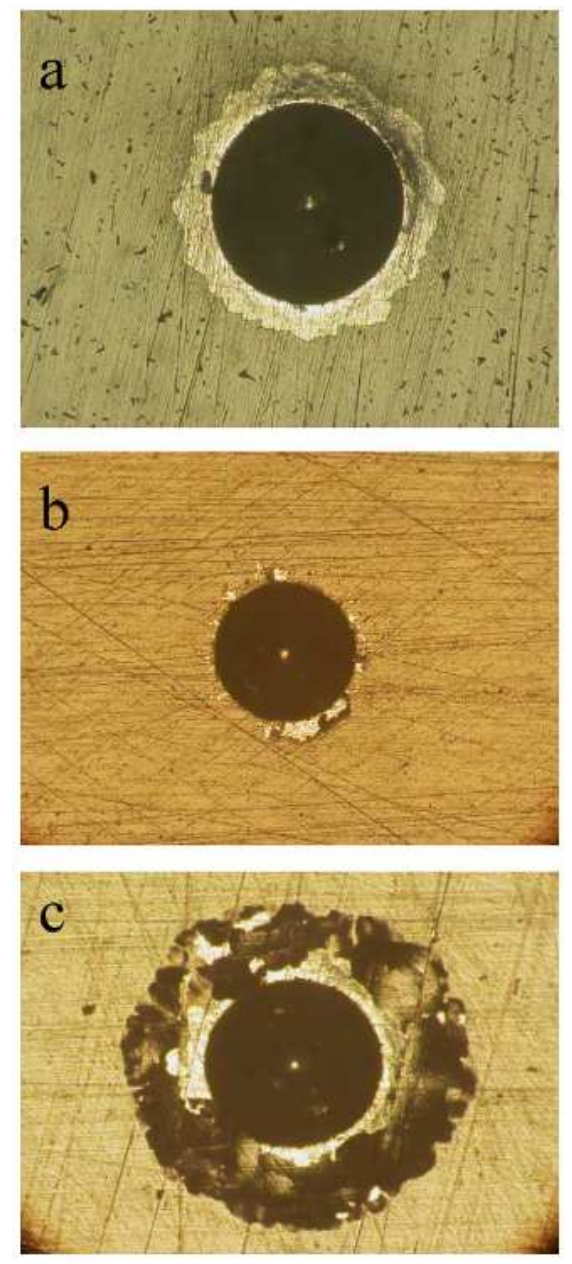

Figure 18 - Influence of chromium intermediate thickness on adhesion of DLC coating. (a) $0.1 \mu \mathrm{m}$, (b) $0.3 \mu \mathrm{m}$ and (c) $0.5 \mu \mathrm{m}$.

Source: (CHEN; HONG, 2005). 


\subsubsection{Duplex treatment}

The use of very hard coatings over relatively soft substrates such as steel can lead to the “eggshell” effect (KESSLER; HOFFMANN; MAYR, 2000). This effect occurs due to excessive deformation of the substrate under mechanical loads, in conjunction with the incapacity of the coating to deform in the same level. The excessive strain causes coating failure, typically in the form of coating fracture, detachment or buckling (LIU et al., 2018a). The strategy used to overcome the "eggshell" effect is to increase the mechanical properties of the substrate, to minimize the deformation under load. Waseen et al. (2015) supported that conclusion with their results, which showed better adhesion for harder steel substrates. When the substrate cannot be changed, by other reasons, surface treatments, such as nitriding, carbonitriding or carburizing, can be used to increase the mechanical properties close to the surface (CAPOTE; TRAVA-AIROLDI; BONETTI, 2014).

Some authors have worked on the adhesion improvement of thick a-C:H layers using plasma nitriding process. Dalibón et al. (2017) reported an increase in the critical load measured by scratch test, from $29 \mathrm{~N}$ to $36 \mathrm{~N}$, when a substrate nitriding process was used. Figure 19 shows this improvement in scratch test results. Delfín et al. (2018) have also seen an increase in the critical load of about $10 \mathrm{~N}$ when a nitriding treatment was carried out.
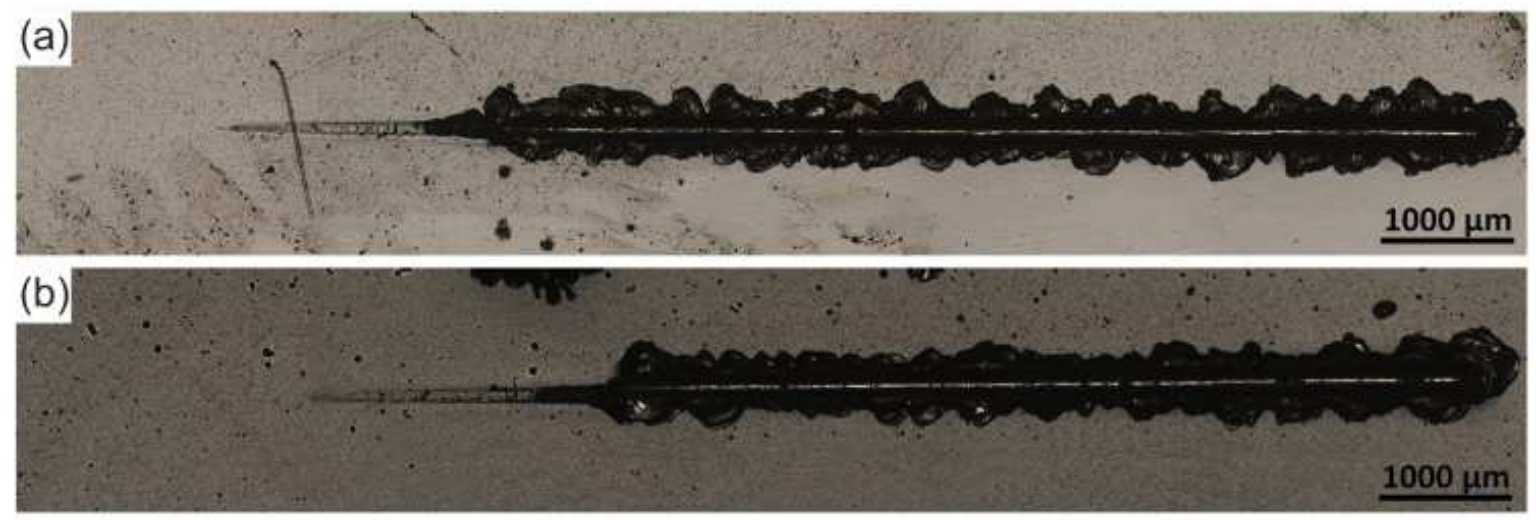

Figure 19 - Scratch test track in (a) coated sample, (b) duplex sample.

Source: (DALIBÓN et al., 2017).

According to the study (DALIBÓN et al., 2017), the duplex system prevents crack propagation and reduces the stress between coating and substrate. The reduction of stresses with application of surface treatments was verified by Capote, Trava-Airoldi and Bonetti (2014). In their work, a treatment composed by nitriding, carbonitriding and carburizing showed the lowest stress. In addition, the highest critical load was obtained for this treatment, in comparison 
with nitriding only and a combined treatment with nitriding and carbonitriding. Both results were explained by the gradient of mechanical properties obtained close to the surface of the substrate.

\subsubsection{Gradient coatings}

Another strategy to decrease the difference between the properties of the hard film and the substrate is to deposit a gradient coating system. The gradient relates not only to the mechanical properties of the intermediate films, but also to the chemical composition. Voevodin et al. (1997) produced a coating system where a functionally gradient coating was placed between the steel substrate and the DLC. The gradient coating was based on Ti and TiC. Firstly, a soft titanium bonding layer was applied to the steel substrate. A gradient TiC was applied over the bonding layer, with an increasing carbon content and decreasing titanium content. Figure 20 presents a schematic of the gradient coating system. In their study (VOEVODIN et al., 1997), a substantial increase in adhesion, measured by scratch test, was also seen.

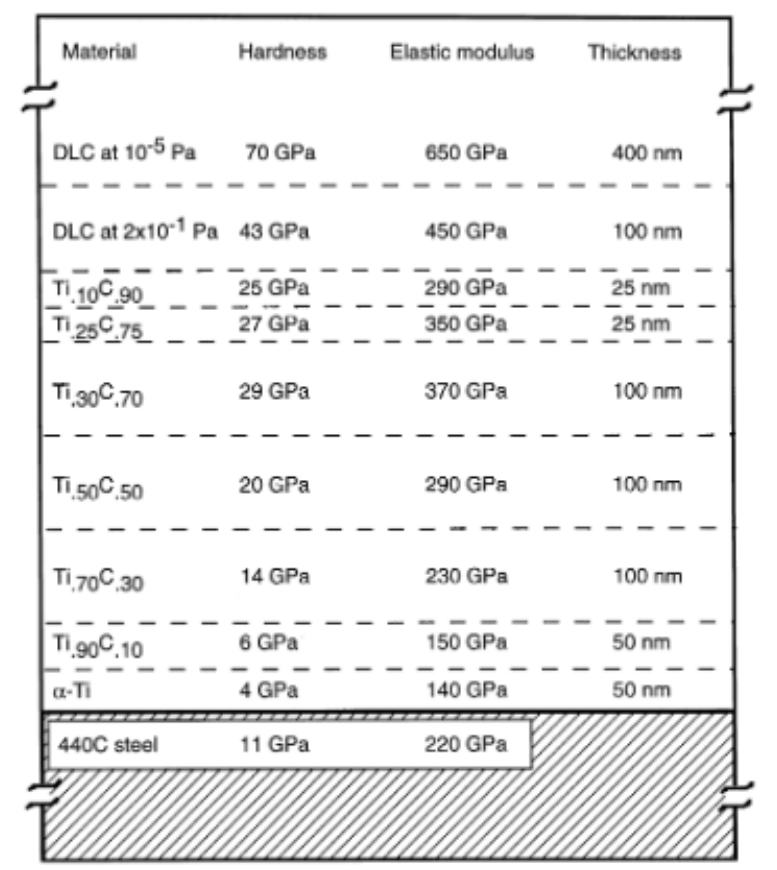

Figure 20 - Schematic of the functionally gradient Ti/TiC/DLC coating design.

Source: (VOEVODIN et al., 1997).

Gilewicz et al. (2013) employed a $\mathrm{CrCN} / / \mathrm{CrN}$ multilayer before depositing a ta-C layer. The multilayer $\mathrm{CrCN} / / \mathrm{CrN}$ presented very high adhesion to the substrate and served to increase the adhesion of the entire system. Liu et al. (2018b) worked with a gradient system based on $\mathrm{Cr}$ and $\mathrm{CrC}$. The bonding layer of $\mathrm{Cr}$ was first deposited over the substrate, followed by a gradient 
layer of $\mathrm{CrC}$, with increasing carbon content. Superior adhesion was observed for the system with $\mathrm{CrC}$ during scratch test, in comparison with concepts with no gradient layer (Cr/DLC) and less gradual transition ( $\mathrm{Cr} / \mathrm{CrC} / \mathrm{DLC})$, as seen in Figure 21. This superior adhesion permitted the deposition of a $50 \mu \mathrm{m}$-thick hydrogenated DLC.

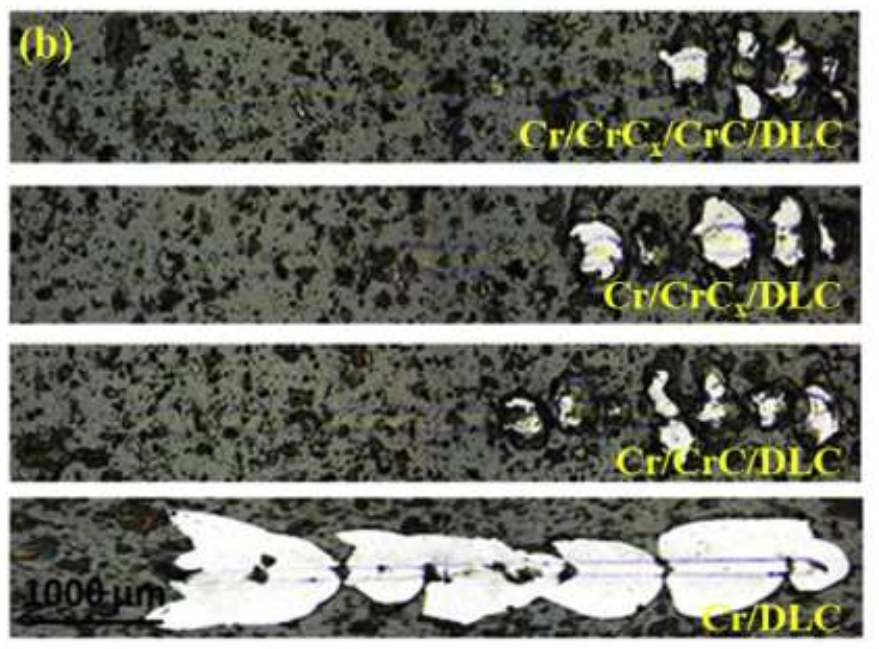

Figure 21 - Scratch test tracks for the gradient coatings based in $\mathrm{Cr}, \mathrm{CrC}$ and DLC.

Source: (LIU et al., 2018b).

\subsubsection{Carbon bombardment}

For cathodic arc deposition, a strategy much used is the inclusion of a carbon bombardment step before the DLC film deposition. Some authors reported improvements on adhesion for thin $(20-300 \mathrm{~nm}) \mathrm{H}$-free DLC layers using this strategy (ANDERS et al., 1994; GERSTNER et al., 1995; HIRVONEN et al., 1993; KOSKINEN et al., 1994; PHARR et al., 1996; PIVIN et al., 1993). Anders et al. (1994) produced a crack-free coating after applying 2,4 $\mathrm{kV}$ bias voltage in the bombardment step. The adhesion improvement was explained by the formation of an extended mixed layer, up to $30 \mathrm{~nm}$, between the carbon and the substrate. The formation of a mixed layer was also found by Gerstner et al. (1995), when a pulsed bias ranging between $10 \mathrm{kV}$ and $20 \mathrm{kV}$ was applied. In addition to that, the mixing layer was characterized by an amorphous structure. Furthermore, Pharr et al. (1996) reported not only the presence a 10 nm-thick mixed layer, but also a lower density carbon layer formed over the mixed layer, which was codeposited during the bombardment stage with $2 \mathrm{kV}$ of bias. Figure 22 presents the described structure. In turn, Koskinen et al. (1993), in their study with 19 different substrates, suggested that the adhesion improvement is closely correlated with the formation of carbides at the interface. Substrates containing elements with high affinity with carbon presented higher adhesion. 


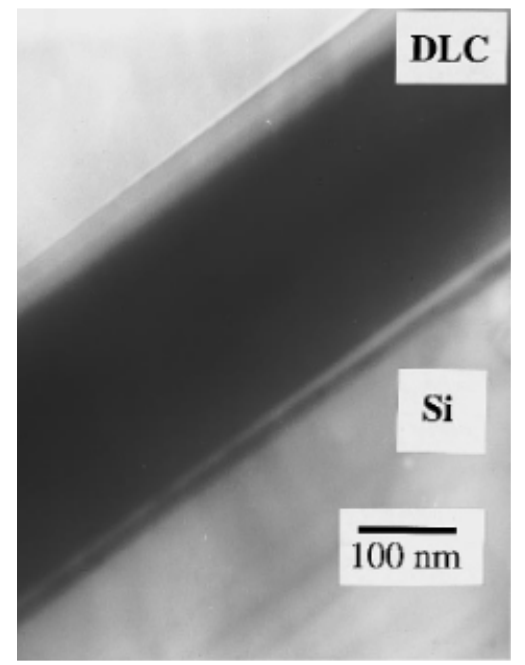

Figure 22 - Bright field TEM image showing the formation of mixed layer and a lower density carbon layer.

Source: (PHARR et al., 1996).

Another study (SHEEJA et al., 2001) complemented the understanding of the impact of the mixed layer in the adhesion. That study reported a critical load increase for increasing bias voltages (from 2,5 kV to 7,0 kV), as presented in Figure 23. This improvement was attributed to the increase in the mixed layer thickness.

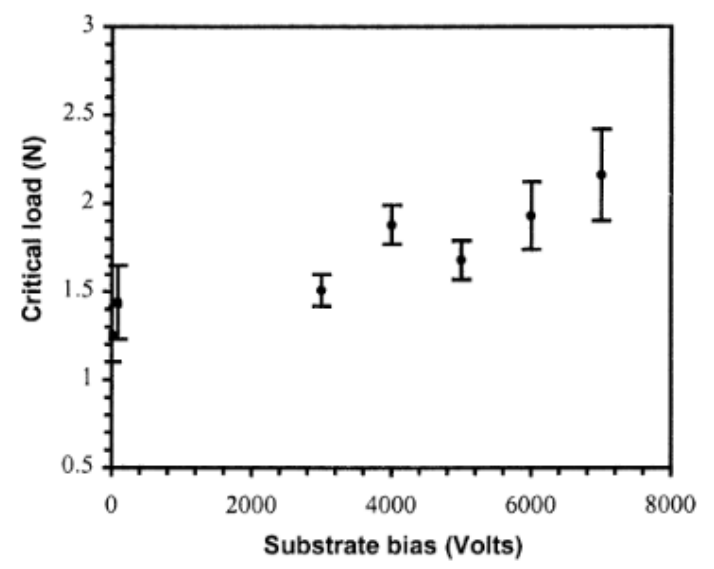

Figure 23 - Critical load as a function of substrate bias voltage during bombardment stage.

Source: (SHEEJA et al., 2001).

Further investigations stated improvements in adhesion for thicker coatings, from 2 to 8 $\mu \mathrm{m}$, using the carbon bombardment step, combined with metal interlayers (ANTTILA et al., 1997; CHHOWALLA, 2001; ZAVALEYEV et al., 2013; ZAVALEYEV; WALKOWICZ, 2015). The improvements were also accounted for the formation of a mixed layer (ANTTILA et al., 1997; CHHOWALLA, 2001) and carbide formation at the interface (ZAVALEYEV et al., 2013; ZAVALEYEV; WALKOWICZ, 2015). Zavaleyev et al. (2013) have reported that a 
bias voltage of $500 \mathrm{~V}$ during the bombardment stage is also effective in the adhesion of the DLC with the chromium intermediate layer. This result is in line with the observation from Ratayski et al. (2011), where the formation of a mixed layer between carbon and chromium was seen for ion energies of $200 \mathrm{eV}$ (bias: $\sim 200 \mathrm{~V}$ ) and $500 \mathrm{eV}$ (bias: $\sim 500 \mathrm{~V}$ ). Zavaleyev et al. (2013) have also seen an impact of the temperature during bombardment and deposition on the adhesion. The adhesion of DLC increased with the decrease in temperature. The adhesion improvement was connected to the formation of the carbide $\mathrm{Cr}_{7} \mathrm{C}_{3}$, due to low substrate temperature $\left(67\right.$ and $81{ }^{\circ} \mathrm{C}$ ). For higher temperatures, the carbide formed was mainly $\mathrm{C}_{23} \mathrm{C}_{6}$, measured by XRD.

Another explanation reported in the literature for the increase in adhesion due to the carbon bombardment is related to the removal of an oxide layer formed inside the chamber (OKA; YATSUZUKA, 2019; YATSUZUKA et al., 2008). Cooling steps are needed before the deposition of DLC, during which, even in vacuum, an oxide layer can form. Yatsuzuka et al. (2009) reported that, besides the carbon implantation during bombardment, it also promotes breakage of the oxide layer. This removal of oxide layer was considered to be essential for the improvement in adhesion, observed in scratch tests. Oka et al. (2019) complemented the understanding when reported that oxidation of the substrate was suppressed by a continuous bombardment. 


\section{MATERIALS AND METHODS}

\subsection{Investigation strategy}

The experimental procedure of this investigation is divided into two main parts. First, a preliminary analysis will be conducted in samples with different carbon bombardment durations and one with no carbon bombardment. These samples will be used as the first assessment to correlate the adhesion performance to the coating interface structure. In this stage, a deep study will be conducted at the DLC interface, to identify the structures formed at the interface with the substrate and to verify possible formation of brittle phases. Additionally, scratch tests will be used to assess the adhesion performance. The results from this analysis, together with the literature review, will be used for the definition of important factors and parameters of the carbon bombardment step, to be explored in the second part of the work.

The second part refers to the evaluation of additional parameters during the carbon bombardment step and its impact in adhesion. It consists of the elaboration and execution of an experimental plan with the variation of the parameters selected in the first stage. From those studies it will be possible to identify the most important factor and propose the best alternative of carbon bombardment parameters, to further improve the adhesion of thick a-C coatings.

\subsection{Coating deposition}

Depositions were conducted in an industrial cathodic arc physical vapor deposition equipment, where five pure graphite cathodes (>99.99\%at.) and four chromium targets are disposed. Figure 24 shows a schematic drawing of the cross section of the equipment, displaying the cathode positions. The carbon cathodes have $20 \mathrm{~mm}$ in diameter and $300 \mathrm{~mm}$ in length, and an individual feeding system pushes the cathode towards the arc spot as it is being consumed. The chromium targets are disks with $150 \mathrm{~mm}$ in diameter. The distance between the targets and the substrate was $150 \mathrm{~mm}$. The chamber has three walls with cathodes, each one capable of working independently and having its own power supply. All cathodes work with direct current $(\mathrm{dc})$ arc. The heater position and table movement (2-fold rotation) are also indicated in Figure 24. The table rotation speed was 5 RPM (main gear). 


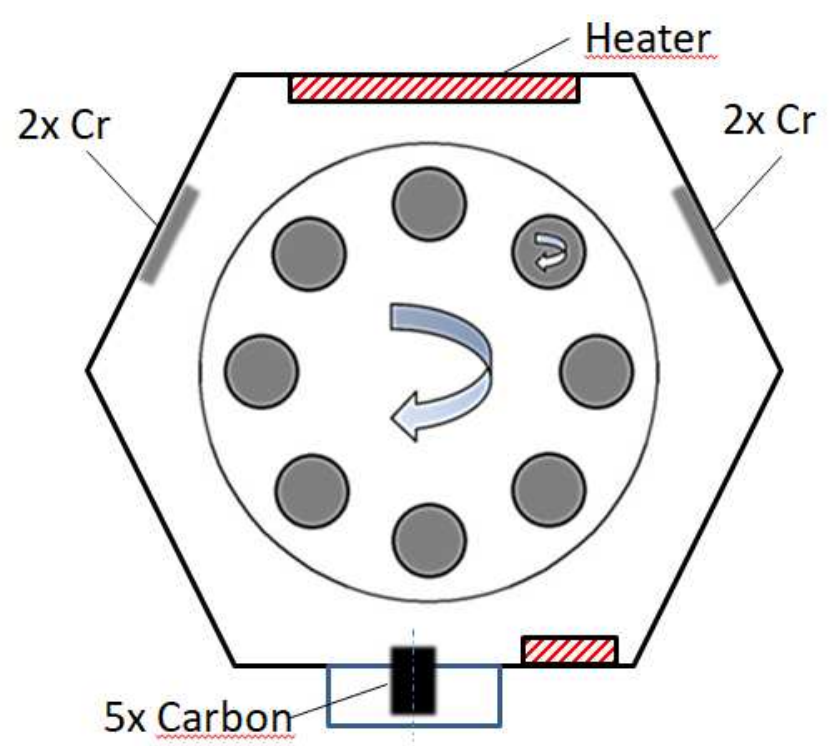

Figure 24 - Cross section scheme of the deposition machine.

The coatings were deposited onto gas nitrided martensitic stainless steel (AISI 440B) samples. The use of steel is motivated by the goal to apply the thick a-C coating in automotive applications where a steel part is already used. The gas nitriding process was included prior to the deposition to avoid the "eggshell effect", where coating failure occurs due to excessive substrate deformation under mechanical loads (KESSLER; HOFFMAN; MAYR, 2000). Prior studies have shown the benefits of using the nitriding layer to increase mechanical properties close to the surface (DALIBÓN et al, 2017; CAPOTE; TRAVA-AIROLDI; BONETTI, 2014), mitigating substrate deformation. Before the coating deposition process, the substrates were cleaned in ultrasonic deionized water baths. The deposition process started with the chamber pumping to a base pressure of $10^{-5} \mathrm{mbar}$ and the heaters were turned on to increase the substrate temperature to $350{ }^{\circ} \mathrm{C}$, to help chamber degassing (BUNSHAH, 2001). The substrates were then sputter cleaned with chromium ions with a bias voltage of $1000 \mathrm{~V}$ in 6 steps of 1 minute each. The following stage was the deposition of, approximately, $1 \mu \mathrm{m}$ of metallic chromium bonding layer. Such thick intermediate layer work as a buffer layer for the $20 \mu \mathrm{m}$ thick DLC, since it can accommodate relative displacements between the substrate and the coating (WEI, YANG and TAI, 2010). After the bonding layer deposition, the substrates were cooled down to $100^{\circ} \mathrm{C}$. Afterwards, a carbon bombardment step was included, where carbon ions were accelerated by high bias voltage. The bias of $1000 \mathrm{~V}$ was chosen because other authors reported that adhesion increase when using voltages higher than $500 \mathrm{~V}$ (RATAYSKI et al, 2011; ZAVALEYEV; WALKOWICZ, 2015). This stage was performed in cycles, in a way that each of five cathodes was turned on individually to minimize the increase in temperature during the 
stage. One complete cycle means that all five cathodes were turned on one time. The total duration of this step is given the number of cycles. Finally, the a-C layer was deposited with a cathode current of $80 \mathrm{~A}$, bias voltage of $40 \mathrm{~V}$ and temperature controlled between $160{ }^{\circ} \mathrm{C}$ and $220{ }^{\circ} \mathrm{C}$. The temperature was measured by thermocouples located near the substrate and when the temperature reaches the maximum value, the cathodes were turned off. The duration of the deposition was chosen to provide a minimum thickness of $20 \mu \mathrm{m}$. After the deposition and prior to the Scratch tests, the samples were ground and polished using diamond sandpapers with grain sizes from $45 \mu \mathrm{m}$ to $9 \mu \mathrm{m}$.

For the preliminary analysis, different durations were selected for the carbon bombardment step (experiments A and B). The parameters used for this stage are presented in Table 1. An experiment without this step was also conducted, for reference purposes (experiment $\mathrm{C}$ ). One remark is that the temperature during the carbon bombardment step was not controlled for the experiments $\mathrm{A}$ and $\mathrm{B}$, although the temperature profiles for both experiments are equal.

Table 1 - Parameters used in the carbon bombardment for preliminary analysis and for the second part (parameters study).

\begin{tabular}{|c|c|c|c|c|c|}
\hline & Experiment & $\begin{array}{c}\text { Bias voltage } \\
(\mathrm{V})\end{array}$ & $\begin{array}{c}\text { Duration } \\
\text { (s) }\end{array}$ & $\begin{array}{c}\text { Cathode } \\
\text { Current (A) }\end{array}$ & $\begin{array}{c}\text { Temperature } \\
\left({ }^{\circ} \mathrm{C}\right)\end{array}$ \\
\hline \multirow{3}{*}{$\begin{array}{c}\text { Preliminary } \\
\text { analysis }\end{array}$} & $\mathbf{A}$ & 1000 & 180 & 60 & NA \\
\hline & B & 1000 & 330 & 60 & NA \\
\hline & $\mathbf{C}$ & \multicolumn{4}{|c|}{ carbon bombardment not conducted } \\
\hline \multirow{4}{*}{$\begin{array}{c}\text { Effect of } \\
\text { Bias } \\
\text { Voltage and } \\
\text { Duration }\end{array}$} & $\mathbf{D}$ & 500 & 180 & 60 & $80-100$ \\
\hline & $\mathbf{E}$ & 500 & 330 & 60 & $80-100$ \\
\hline & $\mathbf{F}$ & 1000 & 180 & 60 & $80-100$ \\
\hline & $\mathbf{G}$ & 1000 & 330 & 60 & $80-100$ \\
\hline \multirow{3}{*}{$\begin{array}{l}\text { Effect of } \\
\text { Cathode } \\
\text { Current }\end{array}$} & $\mathbf{H}$ & 500 & 180 & 40 & $80-100$ \\
\hline & I & 500 & 180 & 60 & $80-100$ \\
\hline & $\mathbf{J}$ & 500 & 180 & 80 & $80-100$ \\
\hline \multirow{2}{*}{$\begin{array}{c}\text { Effect of } \\
\text { Temperature }\end{array}$} & $\mathbf{K}$ & 1000 & 180 & 60 & $80-100$ \\
\hline & $\mathbf{L}$ & 1000 & 180 & 60 & $60-80$ \\
\hline
\end{tabular}

For the second part of the work, the findings of the first part were considered to design new experiments to change the interfacial structure and achieve the highest adhesion. Three different sets of experiments were planned. For all set of experiments, the functional a-C layer was deposited with the same parameters as already described. The parameters to be explored in the first set are the bias voltage and duration of the carbon bombardment step. This set is also 
presented in the Table 1, with constant cathode current. The experiments were named from "D" to "G".

The second set of parameters explored the influence of cathode current during the bombardment stage. The experiments were named from $\mathrm{H}$ to $\mathrm{J}$. In this set, the bias was kept at $500 \mathrm{~V}$ and the duration in $180 \mathrm{~s}$. The cathode current was set to 40, 60 and $80 \mathrm{~A}$.

Finally, the third set of parameters had the objective of evaluating the influence of the substrate temperature on the interfacial structure and adhesion level. The temperature was measured by three thermocouples located in different positions inside the chamber. The temperature in experiment $\mathrm{K}$ was kept between 80 to $100^{\circ} \mathrm{C}$ and from 60 to $80{ }^{\circ} \mathrm{C}$ in experiment L. The temperature in the bombardment stage can be adjusted by the cooling time just after the chromium intermediate layer deposition.

\subsection{Characterization techniques}

\subsubsection{Instrumented indentation}

The instrumented indentation consists of continuous recording of the load, $F$, and the penetration depth, $h$, during an indentation made by an indenter of a hard material and a known shape. The data collected permits the determination of hardness and some material properties, such as Young's modulus (INTERNATIONAL ORGANIZATION FOR STANDARDZATION, 2015). Figure 25 shows an example of a load-displacement curve obtained during the test. Unlike the conventional indentation test, the instrumented indentation does not require the measurement of the indent after the test, which permits the use of very small loads (thus, very small prints). This feature makes the instrumented indentation the main technique to assess thin coating properties.

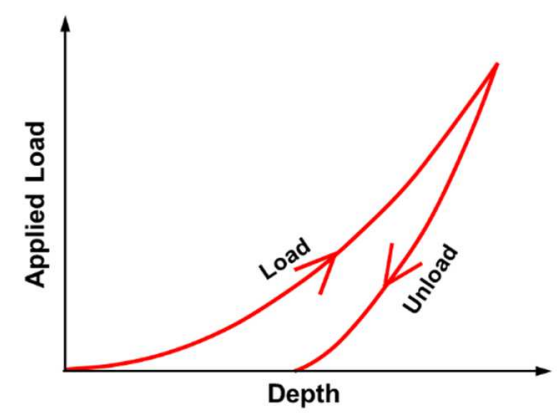

Figure 25 - Instrumented indentation of load/unload curve. 
The calculation of the properties is carried out based on the load-displacement curve, with the methodology proposed by Oliver and Pharr (1992). The indentation hardness, HIT, is calculated using Equation (3).

$$
H I T=\frac{F_{\max }}{A_{p}}
$$

$F_{\text {max }}$ is the maximum applied load and $A_{p}$ is the projected area of contact between the indenter and the test piece. $A_{p}$ is normally given by the indenter area at the contact depth, $h_{c}$. The contact depth, in turn, depends on the stiffness of the contact, $S$, given by a tangent of the unloading curve that passes over the maximum depth.

To calculate the Young's modulus, EIT, it is necessary to calculate the reduced modulus, $\mathrm{E}_{\text {IT, }}^{*}$ first. The reduced modulus is given by Equation (4) (INTERNATIONAL ORGANIZATION FOR STANDARDZATION, 2015).

$$
E_{I T}^{*}=\frac{\sqrt{\pi}}{2} \frac{S}{\sqrt{A_{p}}}
$$

Then, the Young's modulus will be given by Equation (5).

$$
E_{I T}=\frac{1-\left(v_{s}\right)^{2}}{\frac{1}{E_{I T}^{*}}-\frac{1-\left(v_{i}\right)^{2}}{E_{i}}}
$$

In Equation (5), $v_{s}$ and $v_{i}$ are the Poisson's ratio of the test piece and the indenter, respectively, and $E_{i}$ is the Young's modulus of the indenter. A summary of the calculation procedure for hardness and Young's modulus using instrumented indentation is shown in Figure 26. 


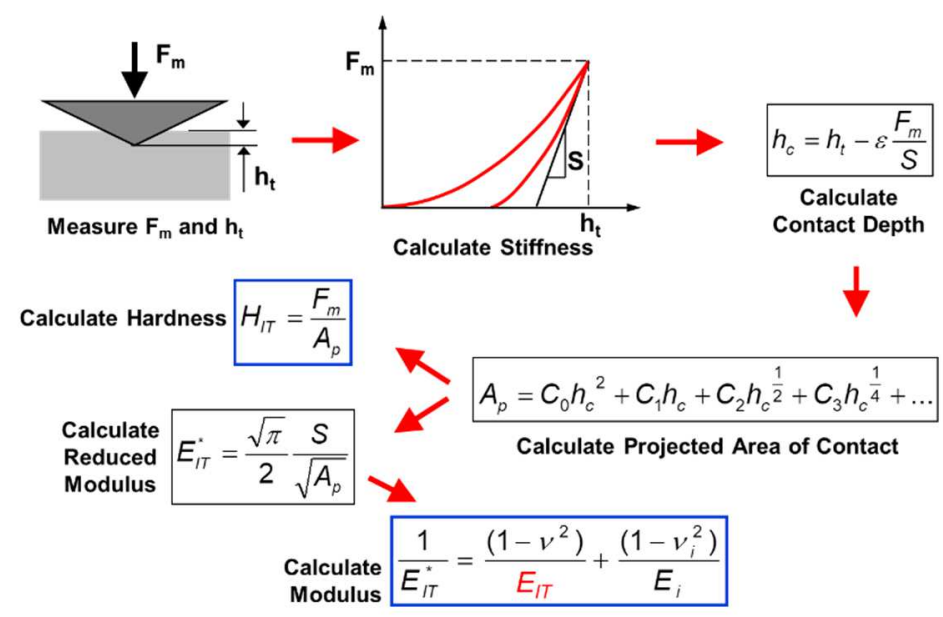

Figure 26 - Summary of the calculation procedure for the hardness and Young's modulus using the instrumented indentation

Source: adapted from CSM instruments.

The indenters are usually made of diamond $\left(v_{i}: 0.07\right.$ and $\left.E_{i}: 1040 \mathrm{GPa}\right)$. The main shapes used for the indenters are the Berkovich (3-sided pyramid), Vickers (4-sided pyramid) and Conical. For very low loads, the mechanical deformation strongly depends on the real shape of the indenter tip. Therefore, careful calibration of both instrument and indenter shape is required in order to achieve an acceptable reproducibility of the materials parameters determined with different machines (INTERNATIONAL ORGANIZATION FOR STANDARDZATION, 2015).

\subsubsection{Equipment and procedure}

The hardness and Young's modulus of the a-C coatings were measured on the cross section of the coating, with a commercial nano-indenter, Anton Paar NHT ${ }^{3}{ }^{\circledR}$, shown in Figure 27. Measurements were conducted with a Berkovich type indenter and properties were calculated using the Oliver \& Pharr method (OLIVER; PHARR, 1992). The load used for the measurements was $20 \mathrm{mN}$, to ensure that border effects were negligible (INTERNATIONAL ORGANIZATION FOR STANDARDZATION, 2016). The average of 10 valid measurements was taken. For the Young's modulus calculation, it was assumed a Poisson's ratio of 0.25 for the coating (ANDERS et al., 1997). 


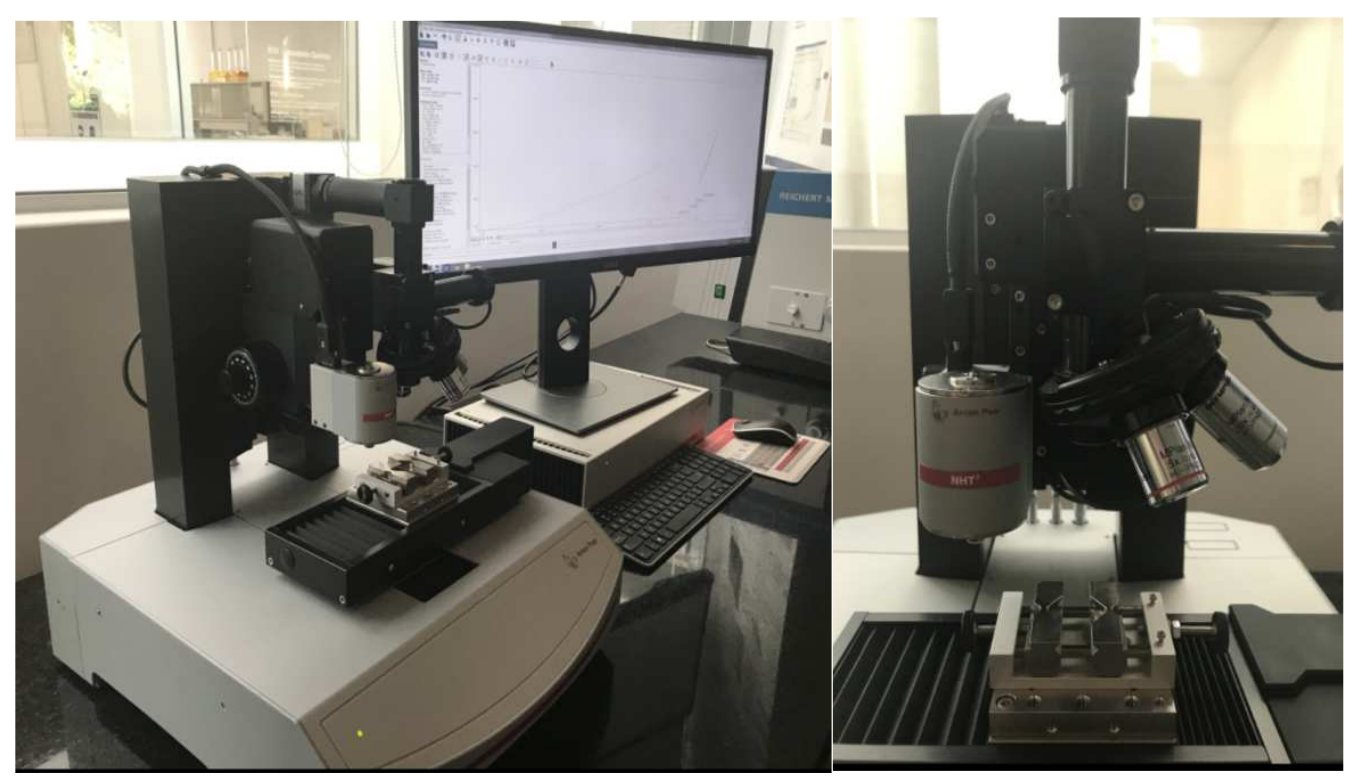

Figure 27 - Commercial nano-indenter, Anton Paar $\mathrm{NHT}^{3{ }^{\circledR}}$.

\subsubsection{Internal stress measurement}

The coating residual stress was assessed by the change of curvature of small steel strips, following the Stoney equation (JANSSEN et al., 2009). The strips were made of SAE 1070 steel with $0.79 \mathrm{~mm}$ in thickness. The Stoney equation to measure the stress $(\sigma)$ is presented in Equation (6).

$$
\sigma=\frac{E_{s S} d_{s s}^{2}}{6\left(1-v_{s s}\right) d_{f}}\left(\frac{1}{R_{f}}-\frac{1}{R_{0}}\right)
$$

where, $E_{S S}, v_{S S}$ and $d_{S S}$ are the Young's modulus, Poisson's ratio and thickness of the steel strips, respectively, and $d_{f}$ is the thickness of the coating. $R_{0}$ and $R_{f}$ are the radii of curvature measured before and after deposition, respectively.

\subsubsection{Transmission Electron Microscopy - TEM}

Unlike optical microscopy, which uses light to produce images, electron microscopy uses electrons. The transmission electron microscopy is based on the transmission of a beam of electrons through a very thin specimen $(<100 \mathrm{~nm})$ to form an image (WILLIAMS; CARTER, 2009). The diagram shown in Figure 28-(a) shows the path of the electron beam to form the image. Electrons are generated in the cannon (Filament + Wehnelt cap + anode plate). Firstly, the electron beam is condensed by the first set of electromagnetic lenses (condensers). In this stage, the beam is focused on the sample. The incident beam will be partly transmitted, partly diffracted and partly absorbed by the interaction with a sample. For the formation of the bright 
field (BF) image, only the transmitted part is considered. The transmitted beam, then, passes through the objective lens, which is responsible for the formation of the first image. The aperture of the objective lens is responsible for blocking the diffracted beam, allowing only the passage of the transmitted beam. If the lens aperture is selected to allow the diffracted beam to pass, the dark field (DF) image will be formed. The image formed after passing through the lens is still small. Therefore, two more sets of lenses (intermediate and projection lens) are used to enlarge the image.

Figure 28-(b) also presents the path of the electron beam for the formation of the diffraction pattern. In this case, one is interested in the beam that diffracted after passing through the specimen. The diffracted beams pass by specific points in the focal plane of the objective. These points are defined according to the type of material analyzed, the crystallinity and the crystal planes present. The aperture is then selected to allow only the diffraction patterns that passed through the area of interest.

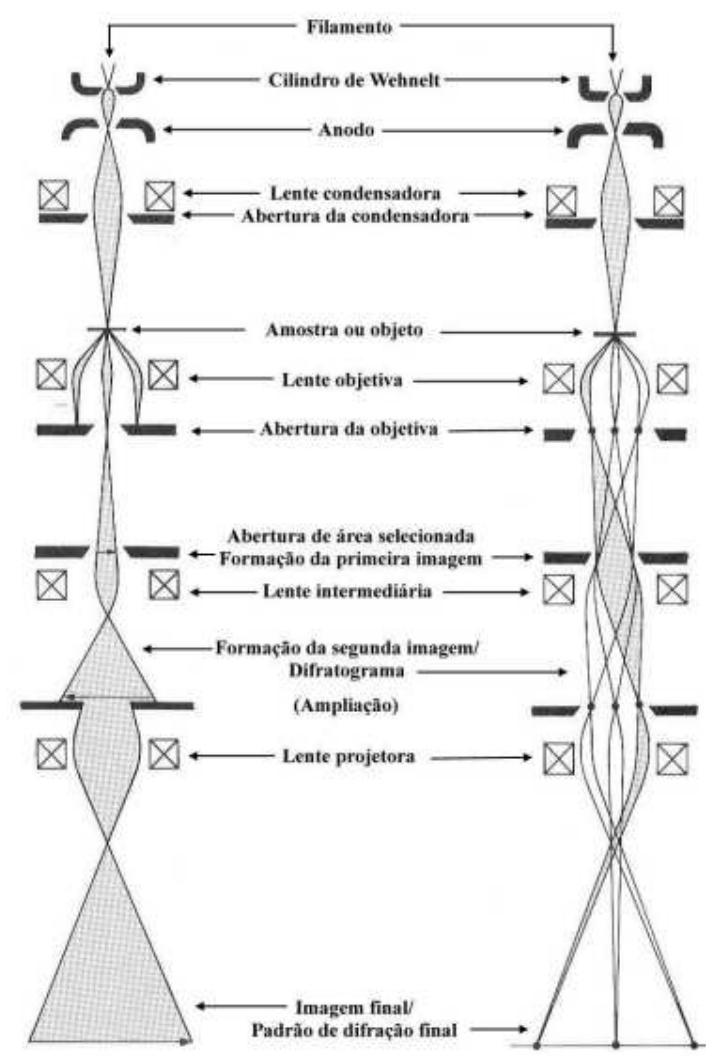

(a)

(b)

Figure 28 - (a) Path of the electron beam to form the image, (b) Path of the electron beam for the formation of the diffraction pattern.

Source: (WILLIAMS; CARTER, 2009) 
Vacuum is essential for electron microscopy, to minimize the interference of gases or molecules with the path of the emitted electrons. It is also important to control the density of electrons that will be used in microanalysis and for the proper functioning of the electron guns.

Most TEM equipment has also the possibility to work in the scanning mode (STEM). In this case, the electron beam is focused in only one point, which is scanned over the sample. The image in the scanning mode is not formed by lenses, but by detectors that read the intensity of signal. The signal is generated at a point on the specimen, detected, amplified, and a corresponding signal displayed at an equivalent point on the computer display. The image builds up over several seconds or even minutes. The advantage of STEM mode is that the resolution is not limited by the lens defects. The STEM has also BF and DF modes. They differ by the location where the signal is detected. The BF detector is found on-axis of the incident beam and collects the signal of the direct beam. For the formation of the DF image, an off-axis annular detector is used. This detector peaks up the signal generated by scattered electrons. In this case, the image will have an enhanced mass-thickness contrast. The scheme for the formation of images in the STEM mode is shown in Figure 29.

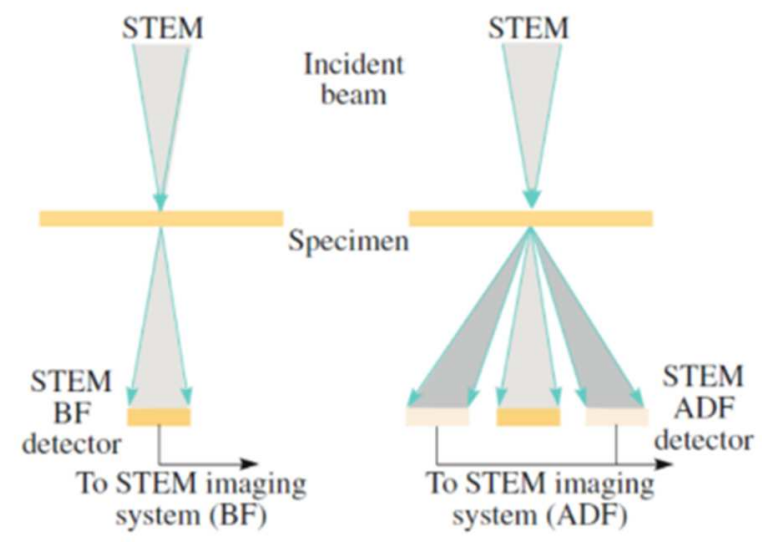

Figure 29 - Scheme for the formation of images in the STEM mode.

Source: (WILLIAMS; CARTER, 2009)

\subsubsection{Equipment}

The structure of the interface between the substrate and the coating was analyzed by Transmission Electron Microscopy (TEM), using a JEOL 2100F microscope operating at an accelerating voltage of $200 \mathrm{kV}$. The microscope was operated in Scanning Transmission Electron Microscopy (STEM) mode. The STEM was adopted for image acquisitions and 
coupled with Electron Energy Loss Spectroscopy (EELS), to generate a compositional analysis at the interface and to obtain the $\mathrm{sp}^{2} / \mathrm{sp}^{3}$ ratio (relative quantification of $\mathrm{sp}^{2}$ ) of the DLC layer.

\subsubsection{Sample preparation}

TEM specimens were prepared using a Focused Ion Beam (FIB) lift-out method in FEI Helios 660 (Dual Beam) equipment. A procedure similar to that reported by (MENGBURANY; ALPAS, 2007) was conducted.

\subsubsection{Electron Energy Loss Spectroscopy - EELS}

Electron energy loss spectroscopy is the analysis of the energy distribution of electrons that passed through the specimen. These electrons may have lost no energy or may have suffered inelastic (usually electron-electron) collisions. The energy loss can be correlated to the chemistry and the electronic structure of the specimen atoms, which in turn reveals details of their bonding/valence state, the nearest-neighbor atomic structure, their dielectric response, the free electron density, the band gap (if there is one), and the specimen thickness (EGERTON, 2009). The EELS can detect and quantify all elements of the periodic table and it is most used for light elements, which are a limitation for the energy dispersive X-ray (EDX) analysis (WILLIAMS; CARTER, 2009).

In order to examine the spectrum of electron energies, a magnetic-prism spectrometer is used. The magnetic prism/energy filter is a highly sensitive device with an energy resolution $<1 \mathrm{eV}$, even with high electron-beam energy. The spectrometer is usually installed after the viewing screen and electron detectors. A schematic view of the spectrometer is presented in Figure 30. The electrons travel down a drift tube, where they are deflected over $90^{\circ}$, due to the magnetic field. Electrons that have loss energy will deflect more than those that did not lose energy. The spectrum is formed in a CCD or photodiode screen, consisting of the distribution of electron intensities as a function of the energy loss (EGERTON, 2009). 


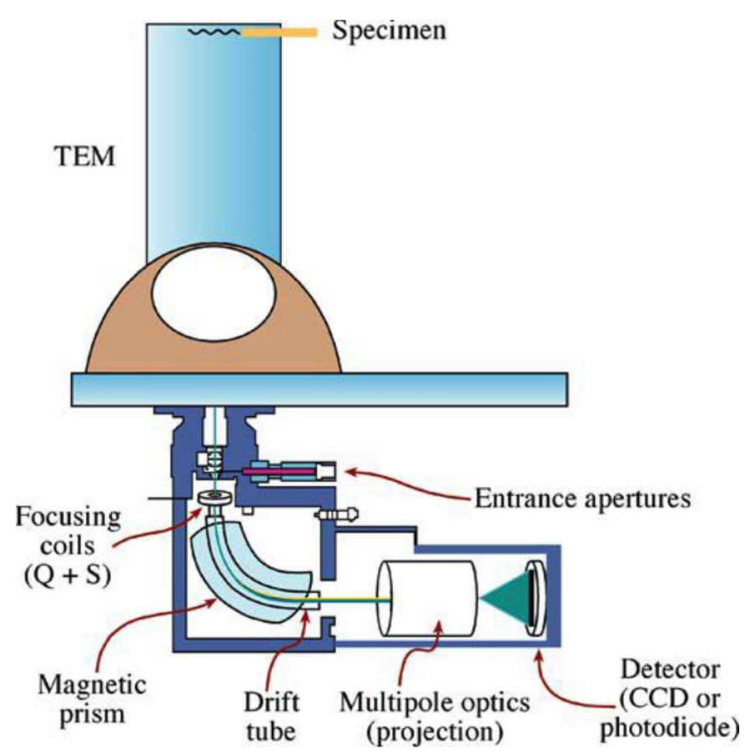

Figure 30 - Schematic view of the EELS.

Source: (WILLIAMS; CARTER, 2009)

\subsubsection{Equipment and procedure}

EELS technique was used to understand standard carbon $\mathrm{k}$ edge features related to $\mathrm{sp}^{2}$ (graphite) and $\mathrm{sp}^{3}$ (diamond) bonding states and to evaluate the $\mathrm{sp}^{2}$ percentage. It is essential to point out that graphite is not $100 \%$ pure $\mathrm{sp}^{2}$ material (graphene is an example of pure $\mathrm{sp}^{2}$ material). However, all the $\mathrm{sp}^{2}$ quantification in this work are related to a graphite sample, which has $95 \%$ of $\mathrm{sp}^{2}$. In order to reduce measurement errors related to $\mathrm{sp}^{2}$ quantification, rigorous and time-consuming methods were adopted based on the literature (PAPWORTH et al., 2000). This method includes the acquisition of EELS spectra of a standard sample in the same working condition of the samples that are analyzed. Further, the ratio between $\mathrm{sp}^{2}$ and $\mathrm{sp}^{3}$ is calculated taking the ratio between the area underneath $\sigma$ peak and $\pi$ peak of the sample and compared to the standard graphite sample (BERGER; MCKENZIE; MARTIN, 1988; GALVAN et al., 2005).

\subsubsection{Scratch test}

The scratch test was already described in the section 3.3.2.

\subsubsection{Equipment and procedure}

The adhesion strength was evaluated by Scratch test, in an equipment available commercially, Anton Paar REVETEST® RST3, presented in Figure 31. The test followed a progressive load procedure, with increase in load from $0 \mathrm{~N}$ to $100 \mathrm{~N}$, at a loading rate of 100 
$\mathrm{N} / \mathrm{min}$. The progressive load was chosen due to better specimen utilization, since one single scratch covers a full load range. The indenter had a Rockwell $\mathrm{C}$ geometry with radius of the stylus of $0.2 \mathrm{~mm}$ and the scratch length was $10 \mathrm{~mm}$. The critical load and failure type were defined by optical microscopy analysis and results representative of three scratches were reported. Before performing the test, the samples were ground and polished using diamond sandpapers with grain sizes from $45 \mu \mathrm{m}$ to $9 \mu \mathrm{m}$. This procedure is performed to achieve a roughness Rz below $1.5 \mu \mathrm{m}$ to avoid any negative effect to the test and to the stylus.

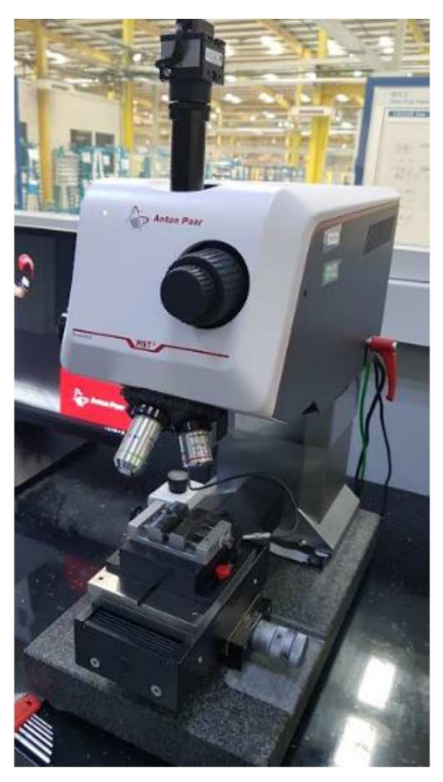

Figure 31 - Anton Paar Revetest RST3. 


\section{RESULTS AND DISCUSSION}

\subsection{Preliminary analysis}

\subsubsection{Coating properties}

Table 2 presents an overview of coating properties obtained during the preliminary analysis. For all three experiments, a chromium interlayer with thickness of $1.1 \mu \mathrm{m}$ was obtained. The similarity in thickness was expected since the same parameters were used during this step. Regarding the functional a-C layer, thicknesses of $21.5 \mu \mathrm{m}, 23.9 \mu \mathrm{m}$ and $21.7 \mu \mathrm{m}$ were found for experiments A, B and C, respectively. The difference of approximately $2 \mu \mathrm{m}$, between experiments $\mathrm{A}$ and $\mathrm{B}$, can be explained by variations of the deposition rate along the position in an industrial-sized chamber. Such small difference does not impact the adhesion behavior measured by Scratch test (FORSICH et al., 2014). A representative cross section of the a-C coating obtained by SEM is presented in Figure 32. The coating structure and properties are expected to be affected by the presence of macroparticles, which are inherent of the cathodic arc deposition process. However, this effect will not be discussed in this work, since it is expected to be similar for all samples.

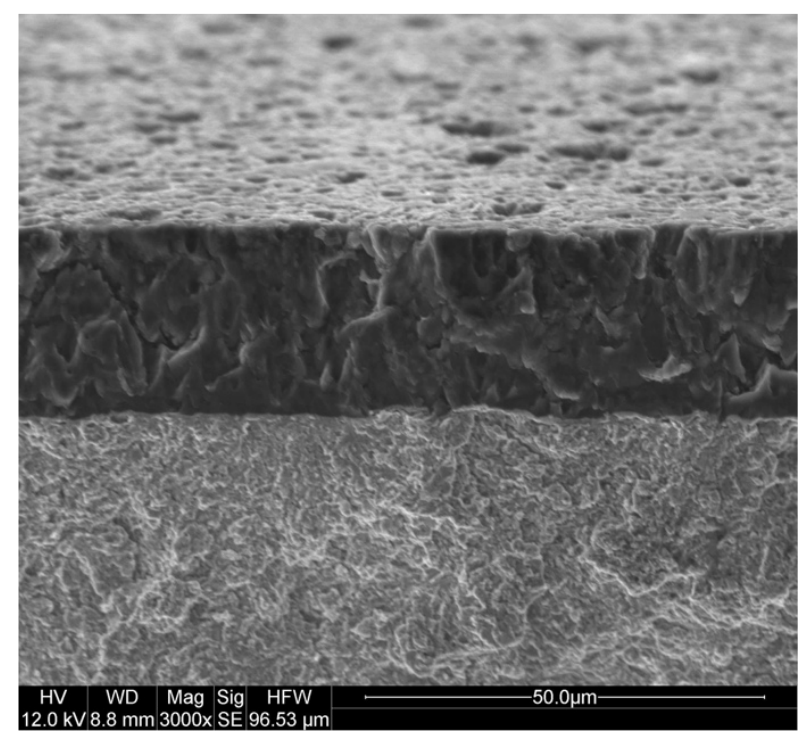

Figure 32 - Representative cross section of DLC coating obtained by SEM. Section taken from coating produced by Experiment A.

Thicknesses over $20 \mu \mathrm{m}$ are more common in the literature for hydrogenated DLC films (AN et al., 2019; DALIBÓN et al., 2019). For H-free amorphous carbon films, only Grimm et al (2010) reported thickness up to $70 \mu \mathrm{m}$, produced by pulsed arc, and Araujo et al [39] disclosed layers up to $60 \mu \mathrm{m}$ with the use of dc arc evaporation. The reduced occurrence of 
thicker a-C layers in the literature is mainly due to adhesion problems of super-hard or hard coatings, which usually limit the film thickness to, approximately, $2 \mu \mathrm{m}$ (CHOLERIDIS et al., 2018).

The hardness evaluation provided values of $28.6 \mathrm{GPa}, 30.9 \mathrm{GPa}$ and $29.0 \mathrm{GPa}$, for experiments $\mathrm{A}, \mathrm{B}$ and $\mathrm{C}$, respectively. The studied a-C can be classified as hard in the classification proposed by (DWIVEDI; KUMAR; MALIK, 2012), since it exceeds $20 \mathrm{GPa}$. The hardness of the three experiments are equivalent when the standard deviation is considered. Therefore, the impact of the carbon bombardment step on the functional layer hardness was not significant. This fact is in accordance with other studies that reported that the hardness of the amorphous carbon layer is affected mainly by the substrate temperature and the carbon ion energy (LIFSHITZ, 1996; LIFSHITZ et al., 1993), which were kept constant in all three experiments. Additionally, those studies reported that the hardness grows with increasing ion energy up to the maximum of $100 \mathrm{eV}$ and decreases for higher energy values, due to thermal effects (ROBERTSON, 1993). The ion energy for the current work is about $60 \mathrm{eV}$, calculated as the sum of the original ion energy in the plasma, which is $\sim 20 \mathrm{eV}$ in carbon cathodic arc plasmas (ANDERS; YUSHKOV, 2004), and the energy gained by a singly charged ion accelerated by the potential of the applied bias (40V for the three samples) (BILEK et al., 2005). Consequently, it can be inferred that the hardness achieved in this work is smaller than those found in other studies, which achieved up to 70 GPa (CHHOWALLA, 2001; PHARR et al., 1996), due to the lower ion energy chosen for the deposition.

The coating residual stress values for the experiments are also presented in the Table 2, with exception of experiment $\mathrm{C}$, which could not be measured due to severe coating detachment from the steel strip used. The longitudinal residual stresses found for the experiments A and B were $0.75 \mathrm{GPa}$ and $0.71 \mathrm{GPa}$, respectively. A residual stress under $1 \mathrm{GPa}$ is lower than that reported for super hard amorphous layer deposited by cathode arc evaporation, which are from 4 to $10 \mathrm{GPa}$ (CHHOWALLA, 2001; VEERASAMY et al., 1993, FALLON et al., 1993). More recent studies explored other strategies to reduce stress, with the most promising being high pulsed biasing (TAY; SHEEJA; YU, 2003). A residual stress of $0.9 \mathrm{GPa}$ was achieved for a 1 $\mu \mathrm{m}$-thick coating with moderate hardness (36 GPa) by Zhang et al (2005), using the same strategy. The reduction in stress was a consequence of the relaxation of the layer during positive pulse, when there is no deposition (DELPLANCKE-OGLETREE; MONTEIRO, 2003). The results achieved in this work suggest that similar effects have occurred during the coating 
deposition. Despite the use of a dc bias, the 2-fold table rotation induces a pulsed-like deposition since the coating is deposited only when the parts are directly in front of the carbon cathodes (Figure 24). Further experiments are recommended to confirm this hypothesis.

Table 2 - Thickness, hardness, Young's modulus and coating stress for the experiments A, B and C.

\begin{tabular}{cccccc}
\hline Experiment & $\begin{array}{c}\text { chromium } \\
\text { Thickness } \\
{[\mu \mathrm{m}]}\end{array}$ & $\begin{array}{c}\text { a-C Thickness } \\
{[\mu \mathrm{m}]}\end{array}$ & $\begin{array}{c}\text { a-C Hardness } \\
{[\mathrm{GPa}]}\end{array}$ & $\begin{array}{c}\text { Young's } \\
\text { Modulus } \\
{[\mathrm{GPa}]}\end{array}$ & $\begin{array}{c}\text { Coating } \\
\text { Stress } \\
{[\mathrm{GPa}]}\end{array}$ \\
\hline $\mathbf{A}$ & $1,1 \pm 0,1$ & $21,5 \pm 0,9$ & $28.6 \pm 2.1$ & $290 \pm 15$ & 0.75 \\
B & $1,1 \pm 0,1$ & $23,9 \pm 0,3$ & $30.9 \pm 0.9$ & $304 \pm 35$ & 0.71 \\
C & $1,0 \pm 0,1$ & $21,7 \pm 0,6$ & $29.0 \pm 1.0$ & $295 \pm 12$ & $\begin{array}{c}\text { Not able } \\
\text { to } \\
\text { measure }\end{array}$ \\
\hline
\end{tabular}

\subsubsection{Interface analysis}

Figure 33 presents bright-field TEM images of the cross sections of the chromium/DLC interface for experiments $\mathrm{A}$ and $\mathrm{B}$. The coating from experiment $\mathrm{C}$ was not analyzed by TEM since the carbon bombardment was not included. The same structure is observed in both samples. The chromium interlayer can be observed at the bottom of the pictures, as a dark layer. Over the chromium interlayer, a very thin dark grey layer is observed. EELS analysis indicated that this layer is composed of chromium and carbon, and it will then be named hereafter as a mixing layer. In addition, a bright layer lies over the mixing layer. For this layer, only carbon was found in the EELS analysis. Thus, it will from now on be referred to as a carbon transition layer. Finally, the functional a-C is set over the carbon transition layer. The functional layer is also only composed of carbon, despite the multilayer aspect. Since the carbon transition layer and the functional a-C layer are both composed only by carbon, the difference in contrast is due to differences in density and to the mechanism of mass-thickness contrast in a BF-STEM image. High density areas of the specimen (darker) will scatter more electrons off axis than lower density (lighter) areas (WILLIAMS et al., 2009). Therefore, it is possible to infer that the carbon transition layer has lower density than the functional a-C. 

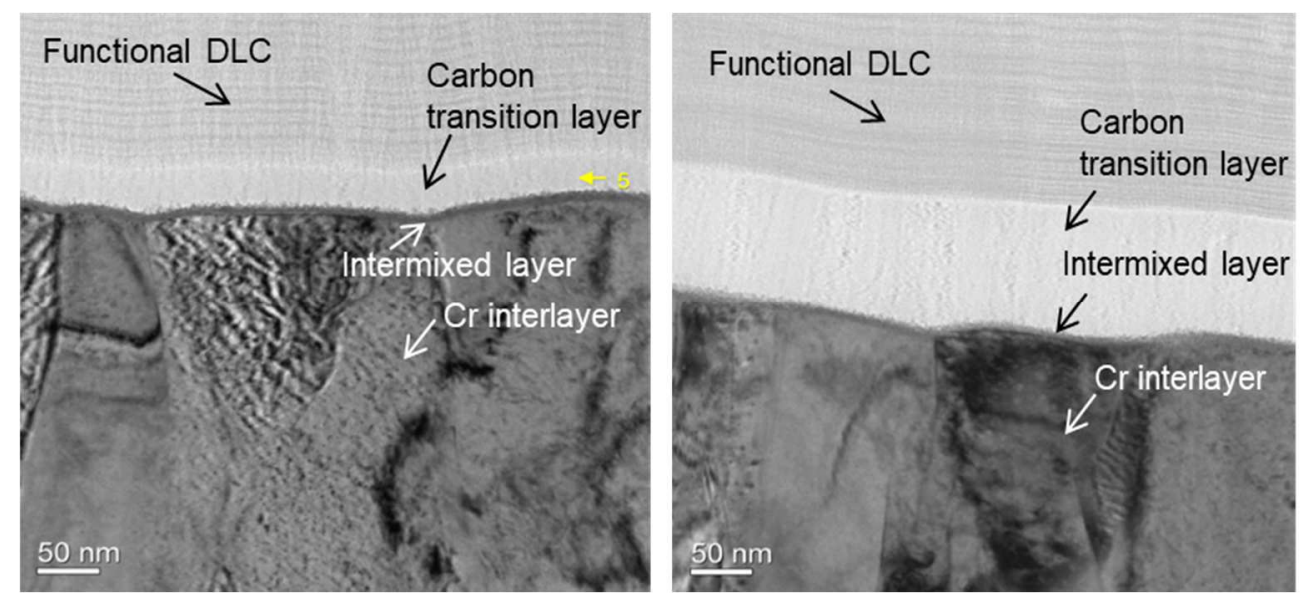

Figure 33 - STEM - Bright-Field images of the chromium/DLC interface for experiments A (a) and B (b).

The multilayer aspect is better seen in Figure 34. This aspect can be derived from different densities that are produced by changes in the a-C growth parameters (SCHULTRICH, 2011). In the present case, the deposition angle is continuously changed along the deposition, due to the two-fold rotation used in the substrate holder, and hence it is the main reason for the formation of the multilayer aspect (DRESCHER et al., 1998). Moreover, the thickness of each sublayer is in the same order of magnitude when compared to the deposition rate and the time that the parts are in front of the carbon targets. In fact, for the functional a-C layer produced, there is a $\mathrm{sp}^{3} / \mathrm{sp}^{2}$ variation along the layer, as shown by a sp ${ }^{2}$ profile measured by EELS (Figure 35). The $\mathrm{sp}^{2}$ varies from $64 \%$ to $70 \%$. This effect can serve as an evidence for the relaxation process that occurs during coating growth. When there is no deposition (sample far from cathode), the layer is relaxed due to the formation of more $\mathrm{sp}^{2}$ bonds. As described before, these periods without deposition may be responsible for residual stress reduction.

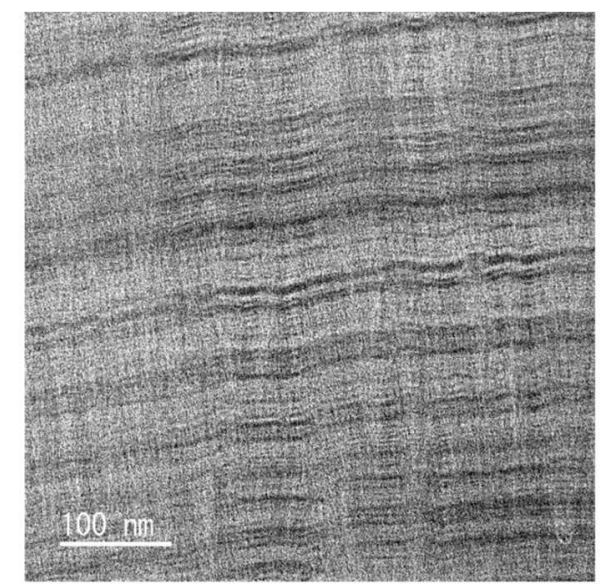

Figure 34 - Detailed picture of functional a-C layer, where the multilayer aspect can be seen. 

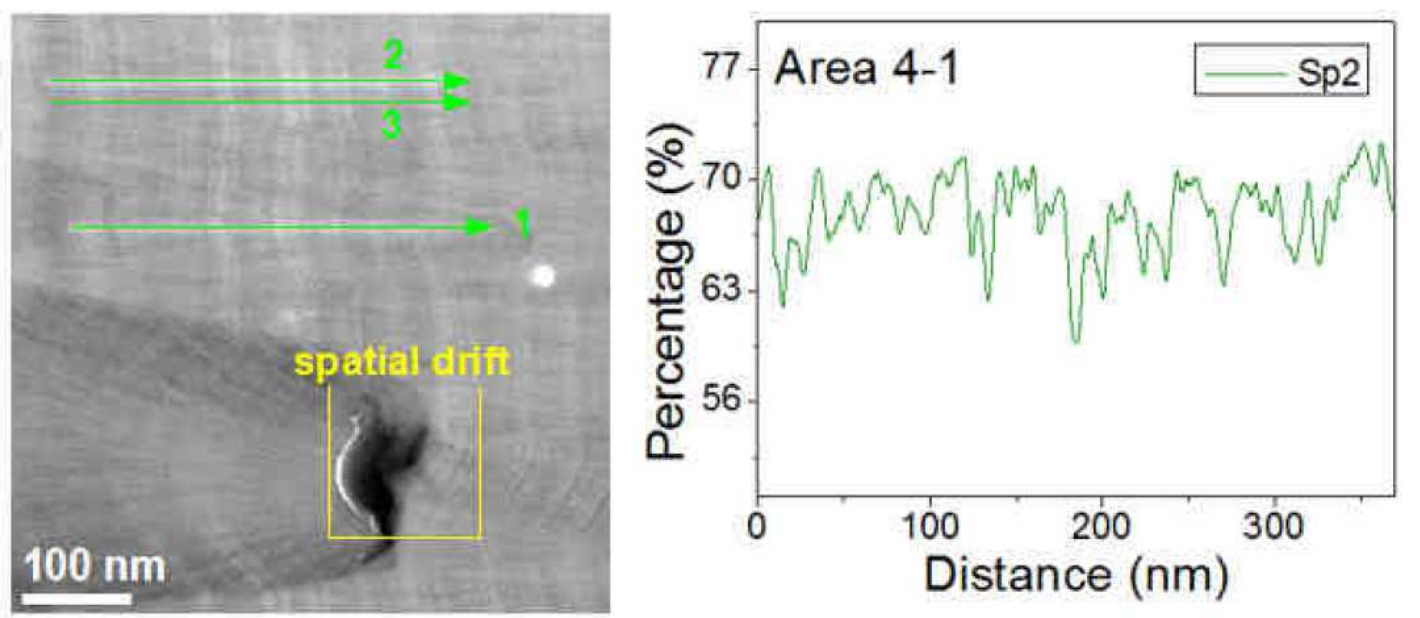

Figure 35 - sp2 profile of functional a-C layer measured by EELS.

Further investigations were conducted by image processing and calculation of the $\mathrm{sp}^{3}$ content measured by EELS. The quantifications of sp-bonds were made based in the height ratio and the energy difference between the decomposed $\sigma$ and $\pi$ carbon K-edge in the EELS spectra collected from samples A and B (GALVAN et al., 2005). Table 3 summarizes the results of thickness and $\mathrm{sp}^{3}$ content of functional DLC, carbon transition layer and mixed layer for experiments A and B. Again, it is possible to confirm that the functional a-C properties are similar in both experiments, since the measured $\mathrm{sp}^{3}$ content was $32 \%$ to $34 \%$ in experiment $\mathrm{A}$ and $30 \%$ to $36 \%$ in the experiment $\mathrm{B}$. The range of 2 points and 6 points for experiments $\mathrm{A}$ and $\mathrm{B}$ is explained by the presence of the multilayer aspect, as already described above, which not only was caused by difference in density, but also resulted in differences in $\mathrm{sp}^{3}$ content. Such trend was reported by another author (VEERASAMY et al., 1993). EELS analysis of the carbon transition layer resulted in a sp3 hybridization much lower than that observed in the functional a-C. The values were $24 \%$ in experiment $\mathrm{A}$ and $17 \%$ in the experiment B.

Figure 36 presents a dark-field image of the region analyzed in sample A along with the EELS spectra of functional a-C layer (point 1) and carbon transition layer (point 2) used to calculate the $\mathrm{sp}^{3}$ content. It can be noted that the spectrum collected from the carbon transition layer has a $\pi$ peak more intense than that observed for the a-C layer spectrum. This observation matches with the calculated $\mathrm{sp}^{3}$, since the $\pi$ peak is a characteristic of graphite (BERGER; MCKENZIE; MARTIN, 1988; ZHANG et al, 2016). 


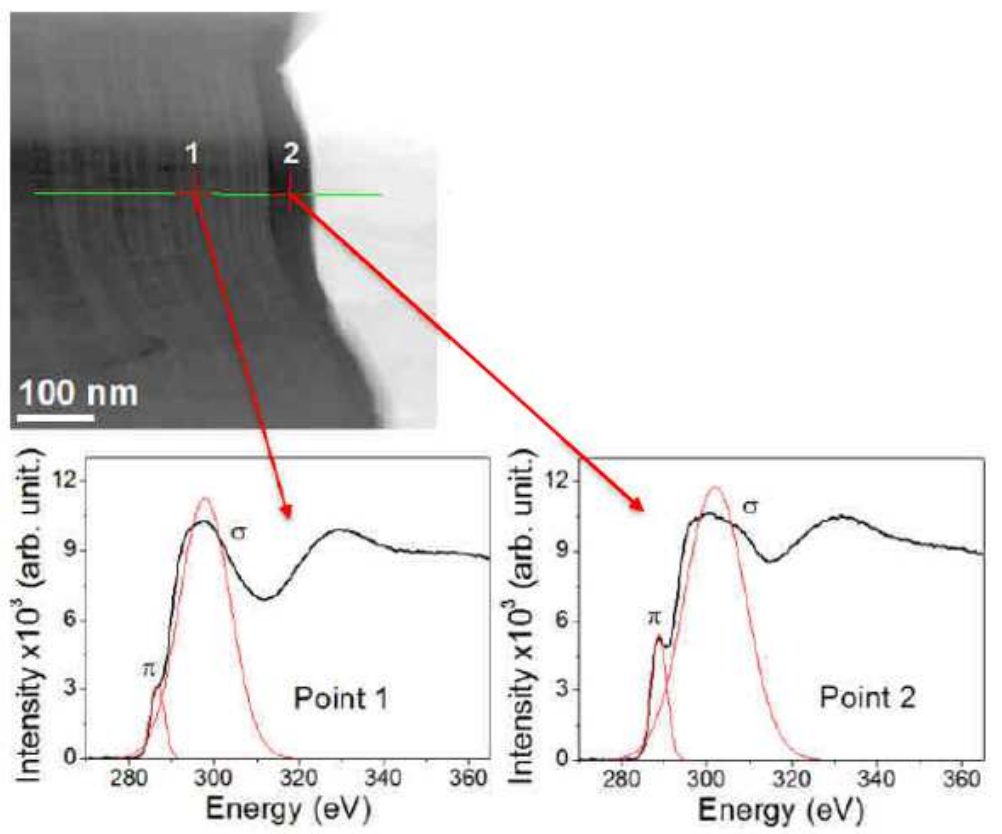

Figure 36 - Dark-field image of a representative region analyzed in sample A. Two EELS spectra extracted from different points of the spectral line marked with 1 (functional a-C layer) and 2 (carbon transition layer) and Gaussian fits of the $\sigma$ and $\pi$ peaks marked with red color.

Regarding the thickness of the carbon transition layer, a significant difference can be seen between experiment $\mathrm{A}$ and experiment $\mathrm{B}$. The former had a thickness of $33 \mathrm{~nm}$, in average, while a thickness of $98 \mathrm{~nm}$ was found in the latter. Furthermore, the image analysis showed that the thickness of the mixed layer was about the same for both experiments, around 3 to $6 \mathrm{~nm}$.

Table 3 - Thicknesses and sp3 content of functional a-C, carbon transition layer and mixed layer for the experiments $\mathrm{A}$ and $\mathrm{B}$.

\begin{tabular}{cccc}
\hline Layer & Feature & Experiment A & Experiment B \\
\hline Functional a-C & sp3 content $(\%)$ & $32-34$ & $30-36$ \\
Carbon & sp3 content $(\%)$ & 24 & 17 \\
Transition layer & Thickness (nm) & 33 & 98 \\
Mixed layer & Thickness (nm) & $5 \pm 1$ & $4 \pm 1$ \\
\hline
\end{tabular}

The formation of the mixed layer and carbon transition layer can be directly correlated to the carbon bombardment step that was included in experiments A and B. Evidence for that statement are: i) the presence of carbon in the mixed layer, caused by penetration of highly energetic carbon ions in the chromium interlayer; and ii) the low $\mathrm{sp}^{3}$ content observed in the 
carbon transition layer is compatible with an a-C layer grown with high energy carbon ions. Similar mixing layers were found by other authors. For instance, Chhowalla et al. (2001) reported a mixed layer of 5 to $10 \mathrm{~nm}$ between carbon and a titanium-based substrate, due to a $1000 \mathrm{eV}$ carbon ion bombardment step. Ratayski et al. (2011) also observed a mixed layer of carbon over chromium with 3 to $4 \mathrm{~nm}$, when an ion energy of $500 \mathrm{eV}$ was employed. It is also detailed in the study from Sheeja et al. (2001) that the mixed layer increases in thickness when higher ion energies are used, in accordance to the subplantation model (LIFSHITZ; LEMPERT; GROSSMAN, 1994), which describes that the penetration depth increases with increasing ion energy. In summary, the mixed layer observed in the present study is in line with the literature, since a $6 \mathrm{~nm}$ layer was detected for an ion energy of, approximately, $1000 \mathrm{eV}$.

Regarding the carbon transition layer, it is clear that the duration of the bombardment step had an impact on its thickness. For the experiment A, where a duration of $180 \mathrm{~s}$ was selected, the thickness was $33 \mathrm{~nm}$, while for the experiment B a duration of 330 s produced a layer of 98 $\mathrm{nm}$. That difference suggests that during the carbon bombardment step an initial intermixing stage occurs followed, after saturation, by coating growth at $1000 \mathrm{~V}$ that formed the carbon transition layer. The saturation refers to the point where the energetic carbon ions that reach the sample stop to penetrate the subsurface to form the mixing layer and start forming a carbon layer onto the mixed layer. The saturation of the mixing layer can explain this difference in growth rate of the layer formed at $1000 \mathrm{~V}$, for instance, a saturation time of 100 seconds could equalize the growth rate of the carbon transition layer in experiments A and B. In this case, the actual duration to be considered in the formation of the carbon transition layer would be $80 \mathrm{~s}$ for experiment A and $230 \mathrm{~s}$ for experiment $\mathrm{B}$ (obtained by subtraction of total duration by the saturation time). Therefore, both samples would present a growth rate of $2.4 \mathrm{~nm} / \mathrm{s}$ for the transition layer. This suggested saturation is also in line with the findings of Ratayski et al. (2011) and Sheeja et al (2001), who have reported that the mixed layer only increases with a change in ion energy. The saturation can also explain why the thickness of the mixed layer was the same for experiments A and B.

Another important aspect is the low $\mathrm{sp}^{3}$ content measured in the carbon transition layer, in comparison with that observed in the functional a-C. This fact can be explained by the increase in surface temperature due to the high energetic carbon ions that reach the substrate (LIFSHITZ et al., 1993; SCHULTRICH, 2011). The values of $17 \%$ to $24 \%$ of $\mathrm{sp}^{3}$ content, obtained for $\sim 1000 \mathrm{eV}$, agree well with the data by Chhowalla (2001) and Fallon et al. (1993), 
who reported values of sp3 lower than $30 \%$ for energies above $500 \mathrm{eV}$. Phaar et al. (1996) also observed the growth of a thin carbon layer with lower density over a mixed layer when a twostep process was applied. Both layers resulted from the first step of the process, where a bias voltage of $2000 \mathrm{~V}$ was employed. Those authors (PHARR et al., 1996) established that the lower density layer was codeposited during carbon implantation. Similar observations were reported by Sheeja et al (2000), who studied a soft carbon interface layer deposited by ion energies from $1000 \mathrm{eV}$ to $3500 \mathrm{eV}$. On the other hand, Chhowalla (2001) also made use of a two-step process, but only a mixed layer was observed. Hence, the formation of a carbon transition layer is not always observed when a carbon bombardment step is used. This is an important observation that can reinforce the hypothesis that the carbon transition layer is formed only after the saturation of the mixing layer.

The present study indicates that the duration of the bombardment step is an important parameter to define the interfacial structure between the substrate and the functional a-C layer. It was observed that an extended duration of the carbon bombardment step is able to produce a carbon transition layer with low density over the mixing layer, and that longer durations can also increase the thickness of the formed low-density layer.

\subsubsection{Adhesion test}

Adhesion tests were conducted on three samples from each experiment. Figure 37 presents representative images of the samples surface after scratch test for experiments $\mathrm{A}, \mathrm{B}$ and C. Failure and quantification of critical load were based on observation of the images made by optical microscopy. The critical load used is the $\mathrm{L}_{\mathrm{c} 2}$, which corresponds to the onset of coating detachment (ASTM INTERNATIONAL, 2015). Different failures can be observed on the three experiments. The sample from experiment A presented only a small exposure of the substrate, near the end of the scratch, and within the track region. In experiment B, a more intense failure is observed at the end of the scratch and the failed area exceeds the lateral limits of the zone with indenter direct action. Finally, in experiment $C$, the failure is characterized by small lateral delaminations along the entire scratch track. Failures observed in samples B and C presented brittle features, similar to the descriptions by Sharma et al. (2012). EDS analyses identified chromium on the failed surface in those samples. Therefore, the adhesion failure occurs between the chromium intermediate layer and the a-C layer. Similar observations were reported by An et al. (2019), for hydrogenated DLC. 


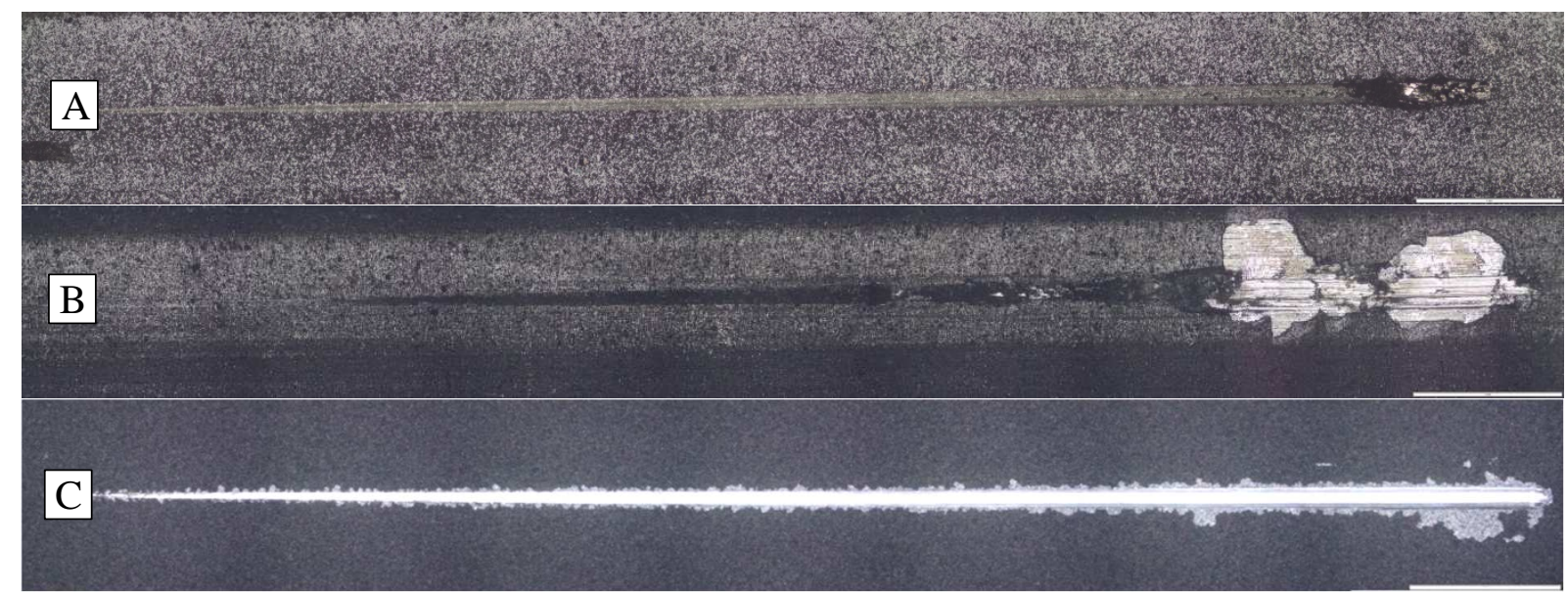

Figure 37 - Representative pictures of sample surface after Scratch test for experiments A (top) B (middle) and $\mathrm{C}$ (bottom).

Figure 38 presents the results of critical load for each experiment. Experiment A was associated with the highest $\mathrm{L}_{\mathrm{c} 2}$, of $87 \mathrm{~N}$, while experiments $\mathrm{B}$ and $\mathrm{C}$ presented $\mathrm{L}_{\mathrm{c} 2}$ of $75 \mathrm{~N}$ and $7 \mathrm{~N}$, respectively. It is difficult to directly compare these critical loads with values presented in other works, since many features can influence the results (STEINMANN; TARDY; HINTERMANN, 1987), for instance, the substrate, coating thickness and scratch parameters. Nevertheless, a similar $\mathrm{L}_{\mathrm{c} 2}$, of $73 \mathrm{~N}$, was achieved by Liu et al. (2018) for a hydrogenated coating with thickness of $50 \mu \mathrm{m}$, deposited by anode layer ion source. For that case, the adhesion improvement was explained by a highly energetic chromium and carbon ion treatment that produced a graded interfacial structure. Such high critical loads obtained for the experiments A and B can also be explained by the high thickness, due to a self-sustaining effect, as stated by Forsich et al. (2014). The stress distribution is more homogeneous along coating thickness, reducing the stress level at the interface, and delaying the failure.

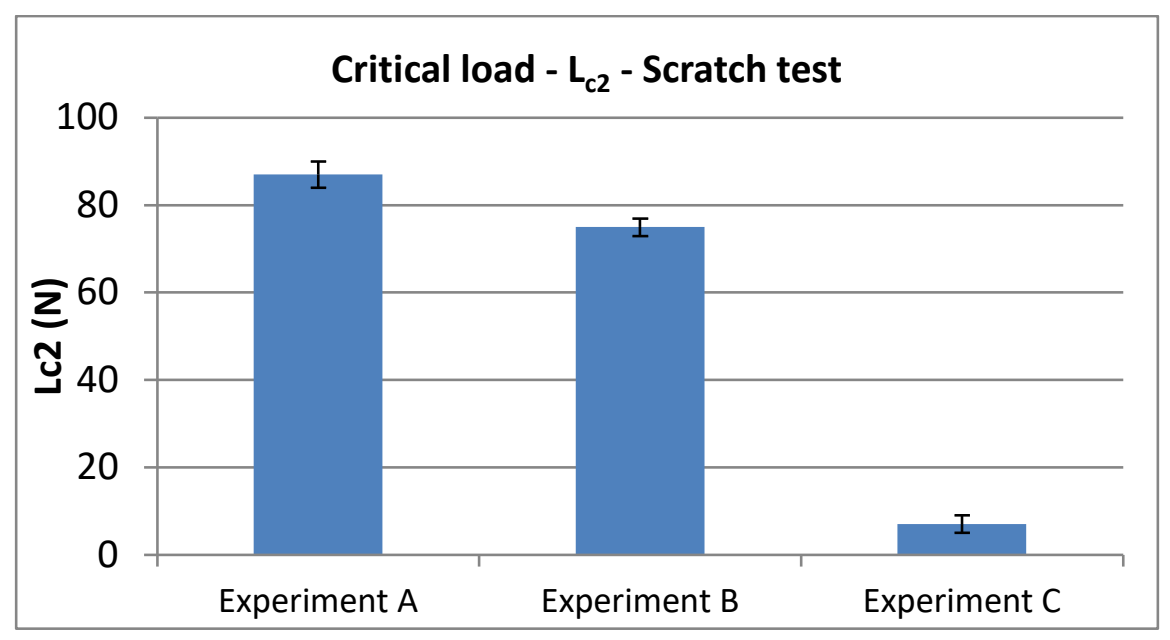

Figure 38 - Critical load $\left(\mathrm{L}_{\mathrm{c} 2}\right)$ for experiments A, B, and C. 
By the comparison of the results of experiments A and B with experiment $\mathrm{C}$, one can see that not only the thickness is responsible for the high critical loads. It can be inferred that the adhesion of the a-C layer has significantly increased when carbon bombardment was used before functional a-C deposition. The significant increase in adhesion can be correlated with the presence of the mixed layer and the carbon transition layer. Other authors that have also worked with cathodic arc deposition observed enhanced adhesion for samples with the formation of a mixed layer (CHHOWALLA, 2001; PHARR et al., 1996) and formation of carbides at the interface (PIVIN et al., 1993; ZAVALEYEV et al., 2013). Koskinen et al. (1994), when studying adhesion over 19 types of substrates, have reported that the adhesion is better for materials with strong affinity to carbon, due to the formation of adherent carbides.

Another important observation is the increase in adhesion from experiment A to experiment B. This increase can be correlated to the thinner carbon transition layer formed in experiment A, due to a shorter bombardment stage. Thicker carbon transition layers can induce early failure, which can possibly be attributed to its lower shear resistance. Since it is a $\mathrm{sp}^{2}$-rich layer, it possesses sheareable basal planes (ROBERTSON, 1991). This effect can be minimized by the decrease of the carbon transition layer thickness. On the other hand, the suppression of the carbon transition layer may be unsuitable for adhesion, since a thin $\mathrm{sp}^{2}$-rich layer can help to reduce the interface stress (IIJIMA et al., 2018). Ha et al. (2006) reported benefits in adhesion when an additional control layer of low stress was added under $\mathrm{H}$-free a-C.

\subsection{Parameters study}

As seen in the Preliminary analysis (5.1), the carbon bombardment duration played an important role in the adhesion. In this chapter, the combination of the duration and bias voltage will be analyzed in a first set of experiments and the cathode current and temperature will be analyzed in other two sets of experiments, as described in the Table 1. The focus of this part is in the adhesion tests since the intention is to improve the adhesion level. Later, some experiments were chosen to be analyzed by TEM to evaluate the interface structure. 


\subsubsection{Effect of bias voltage and duration}

\subsubsection{Coating properties}

The functional a-C layer was evaluated to check if the properties were within a similar range of those of the preliminary tests, since the deposition parameters used were the same. Table 4 summarizes the results for a-C thickness and hardness. Thicknesses of $24.5 \mu \mathrm{m}, 24.9$ $\mu \mathrm{m}, 22.6 \mu \mathrm{m}$ and $23.1 \mu \mathrm{m}$ were found for experiments $\mathrm{D}, \mathrm{E}, \mathrm{F}$ and $\mathrm{G}$, respectively. If the standard deviation is considered, the difference is statistically insignificant. The difference can be explained by variations of the deposition rate along the position in an industrial-sized chamber, as already discussed. Significant differences were not observed in terms of hardness when the standard deviation is considered. The values remained between 28.3 and $29.9 \mathrm{GPa}$.

The minor difference in hardness and thickness for the functional a-C layer implies that the a-C layer will not impact the adhesion results. Therefore, the differences observed in the critical loads could be accounted for only for the interfacial structure produced by the carbon bombardment stage, which is the focus of this study.

Table 4 - Thickness and hardness for the experiments D to G.

\begin{tabular}{ccc|cc}
\hline Experiment & $\begin{array}{c}\text { BIAS voltage } \\
(\mathrm{V})\end{array}$ & $\begin{array}{c}\text { Duration } \\
(\mathrm{s})\end{array}$ & $\begin{array}{c}\text { a-C Thickness } \\
(\mu \mathrm{m})\end{array}$ & $\begin{array}{c}\text { a-C Hardness } \\
(\mathrm{GPa})\end{array}$ \\
\hline $\mathbf{D}$ & 500 & 180 & $24.5 \pm 1.9$ & $29.4 \pm 1.5$ \\
$\mathbf{E}$ & 500 & 330 & $24.9 \pm 1.4$ & $29.9 \pm 1.9$ \\
$\mathbf{F}$ & 1000 & 180 & $22.6 \pm 0.9$ & $28.5 \pm 1.6$ \\
$\mathbf{G}$ & 1000 & 330 & $23.1 \pm 1.1$ & $28.3 \pm 1.7$ \\
\hline
\end{tabular}

\subsubsection{Adhesion tests}

The adhesion tests were evaluated in a similar way as already described in the section 5.1.3. The representative pictures of sample surface after the scratch test for the experiments D to $G$ are presented in Figure 39. The failure mode for all experiments is similar, which is characterized by spallation and an intense coating detachment that exceeds the lateral limits of the zone with the stylus direct action. A similar type of failure was also observed by Zawischa et al. (2021), who concluded that, for this kind of failure in ta-C coatings, the maximum von Mises stress in both coating and substrate material is located near the interface. As seen for experiments $\mathrm{B}$ and $\mathrm{C}$, the adhesion failure occurs between the chromium intermediate layer and the a-C layer, as observed during an EDS analysis of the failed surface (not shown in this work). 
This suggest that the failure presents a relationship with the structure between the chromium layer and the a-C layer.

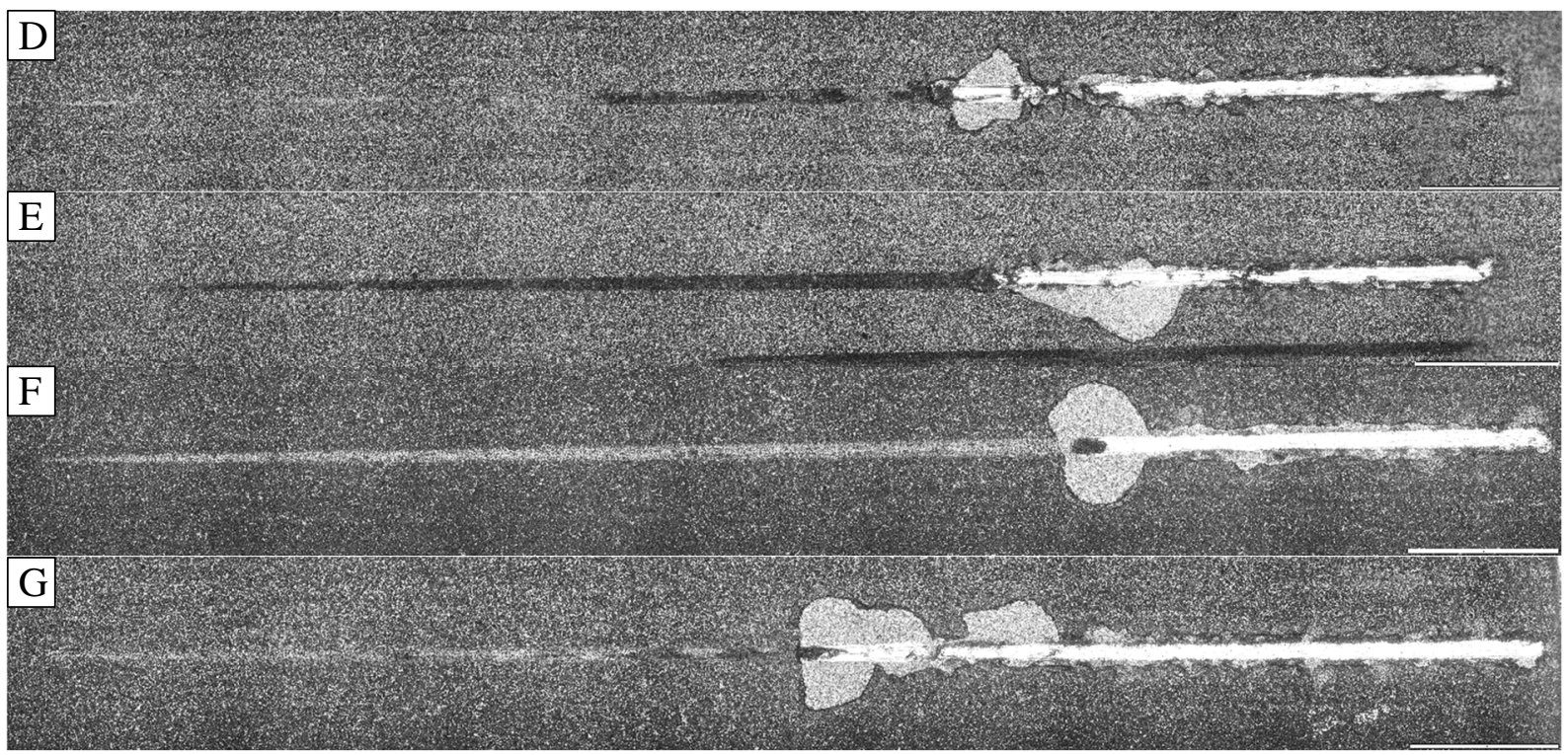

Figure 39 - Representative pictures of sample surface after Scratch test for experiments D to G.

Despite the similarity of the failure mode for all samples, the failure happened at different loads. Therefore, it is important to evaluate the critical load to compare the adhesion level. The average and standard deviation for the $\mathrm{L}_{\mathrm{c} 2}$ of each experiment is shown in Figure 40. The highest $\mathrm{L}_{\mathrm{c} 2}$ was achieved by the experiment $\mathrm{F}(72 \mathrm{~N})$, followed by the experiments $\mathrm{D}(66 \mathrm{~N}), \mathrm{E}(62 \mathrm{~N})$ and $\mathrm{G}(47 \mathrm{~N})$.

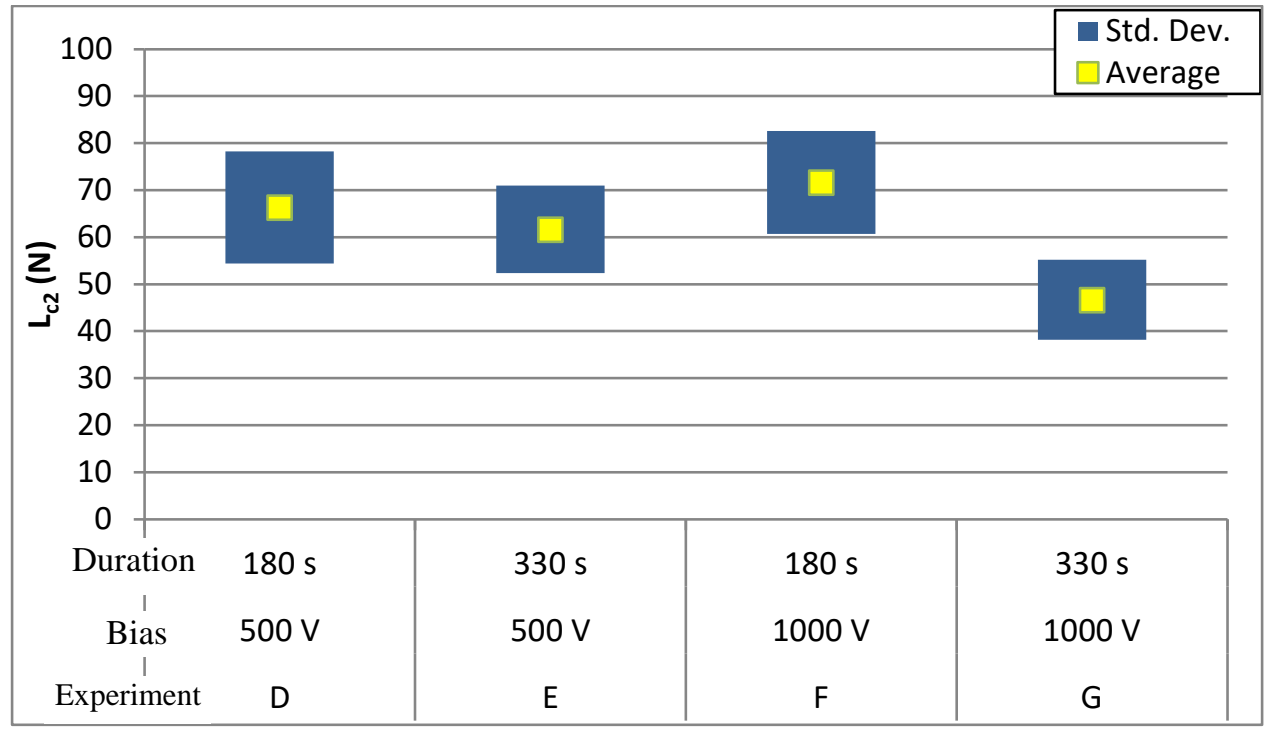

Figure 40 - Critical load $\left(\mathrm{L}_{\mathrm{c} 2}\right)$ for experiments D, E, F and G.

The first effect to be analyzed is the duration. Results showed a reduction in $\mathrm{L}_{\mathrm{c} 2}$ for the experiments with higher duration, experiments $\mathrm{E}$ and $\mathrm{G}$, when compared with its pairs with the 
same bias voltage, experiments D and F, respectively. The same effect was already seen in the preliminary analysis, where the reduction in adhesion was explained by an increase in the carbon transition layer thickness. Thicker carbon transition layers can induce early failure, which can possibly be attributed to its lower shear resistance. On the other hand, the impact was not the same for the two level of bias voltages. For the experiments with $500 \mathrm{~V}$, the decrease in $\mathrm{L}_{\mathrm{c} 2}$ was only $4 \mathrm{~N}$, whilst the decrease in the experiments with $1000 \mathrm{~V}$ was $25 \mathrm{~N}$. This remarkable difference in the effect of the duration can suggest that there is another important factor playing a role in the behavior of the carbon transition layer. The other factor is possibly the $\mathrm{sp}^{3}$ content of the carbon transition layer. A coating grown at a bias voltage of $500 \mathrm{~V}$ is expected to have a higher $\mathrm{sp}^{3}$ content than a coating grown at $1000 \mathrm{~V}$ (FALLON et al., 1993; MCKENZIE et al., 1991; VEERASAMY et al., 1993; XU et al., 1996). Therefore, it is expected that the experiments $\mathrm{D}$ and $\mathrm{E}$ have a carbon transition layer with higher $\mathrm{sp}^{3}$ content that the experiments $\mathrm{F}$ and $\mathrm{G}$. In this way, it can be suggeted that a carbon transition layer with higher $\mathrm{sp}^{3}$ is less susceptible to the thickness variation, since the $\mathrm{sp}^{3}$ bonds provide higher shear strenght.

Regarding the single effect of the bias voltage, the results from the experiments $\mathrm{D}$ and $\mathrm{F}$ (180 s) and E and G (330 s) will be compared. For the lower duration level (D and F), a small increase in the $\mathrm{L}_{\mathrm{c} 2}$ was seen, from $66 \mathrm{~N}$ in the experiment $\mathrm{D}$ to $72 \mathrm{~N}$ in the experiment $\mathrm{F}$. As discussed in the last paragraph, it is expected that the experiment D have a carbon transition layer with a higher $\mathrm{sp}^{3}$ content due to the lower bias voltage. Hence, a better adhesion would be expected, but this was not observed. However, the preliminary analysis showed that not only the carbon transition layer rules the adhesion behavior but also the mixing layer. Focusing on the impact of the bias voltage in the mixing layer, it was already reported that the increase in bias voltage increases the thickness of the mixing layer (RATAYSKI et al., 2011). In the light of that, it is reasonable to suggest that the adhesion increase observed in the experiment $\mathrm{F}$ can be explained by a broader mixing layer produced by the $1000 \mathrm{~V}$ bias. Our analysis was not able to differentiate the mixing layer thickness but the adhesion improvement by a thicker mixing layer was reported in another work (SHEEJA et al., 2001).

Focusing in the higher duration level (E and $\mathrm{G})$, a completely difference results is seen. A reduction of $15 \mathrm{~N}$ in $\mathrm{L}_{\mathrm{c} 2}$ was observed from the experiment $\mathrm{E}$ (500 V) to experiment $\mathrm{G}$ (1000 V). In this case, the positive effect of the higher bias voltage in the mixing layer was not effective in the adhesion behavior. From the preliminary analysis findings regarding the impact 
of duration, it can be deduced that the increase of the carbon transition layer thickness with a lower $\mathrm{sp}^{3}$ content leads to early adhesion failure, overcoming the mixing layer impacts.

\subsubsection{Effect of cathode current}

\subsubsection{Coating Properties}

The a-C thickness and hardness for the experiments related to the carbon cathode current $(\mathrm{H}, \mathrm{I}$ and $\mathrm{J})$ are presented in Table 5. The thicknesses stayed within the range between 23.2 and $24.4 \mu \mathrm{m}$ and the hardness in the range between 28.5 and $30.0 \mathrm{GPa}$. The a-C coatings for all samples can be considered similar, since the hardness and thickness have no significant difference. The minor difference is explained by the reasons already discussed.

Table 5 - Thickness and hardness for the experiments H, I and J.

\begin{tabular}{cccc|cc}
\hline Experiment & $\begin{array}{c}\text { Cathode } \\
\text { Current } \\
(\mathrm{A})\end{array}$ & $\begin{array}{c}\text { BIAS voltage } \\
(\mathrm{V})\end{array}$ & $\begin{array}{c}\text { Duration } \\
(\mathrm{s})\end{array}$ & $\begin{array}{c}\text { a-C Thickness } \\
(\mu \mathrm{m})\end{array}$ & $\begin{array}{c}\text { a-C } \\
\text { Hardness } \\
(\mathrm{GPa})\end{array}$ \\
\hline $\mathbf{H}$ & 40 & 500 & 180 & $23.8 \pm 1.9$ & $28.5 \pm 1.7$ \\
$\mathbf{I}$ & 60 & 500 & 180 & $24.5 \pm 1.9$ & $29.4 \pm 1.5$ \\
$\mathbf{J}$ & 80 & 500 & 180 & $23.2 \pm 1.5$ & $30.0 \pm 1.2$ \\
\hline
\end{tabular}

\subsubsection{Adhesion test}

The adhesion tests were evaluated in a similar way as already described in section 5.1.3. The representative pictures of sample surface after the scratch test for the experiments $\mathrm{H}$ to $\mathrm{J}$ are presented in Figure 41 A strong spallation and detachment of the coating is seen in the experiment $\mathrm{H}$, whilst only one small spallation was seen in the experiments I and J. For all cases, the spallation occurred between the chromium interlayer and the a-C layer, what suggests that the failure is correlated to the interfacial structure between them. 


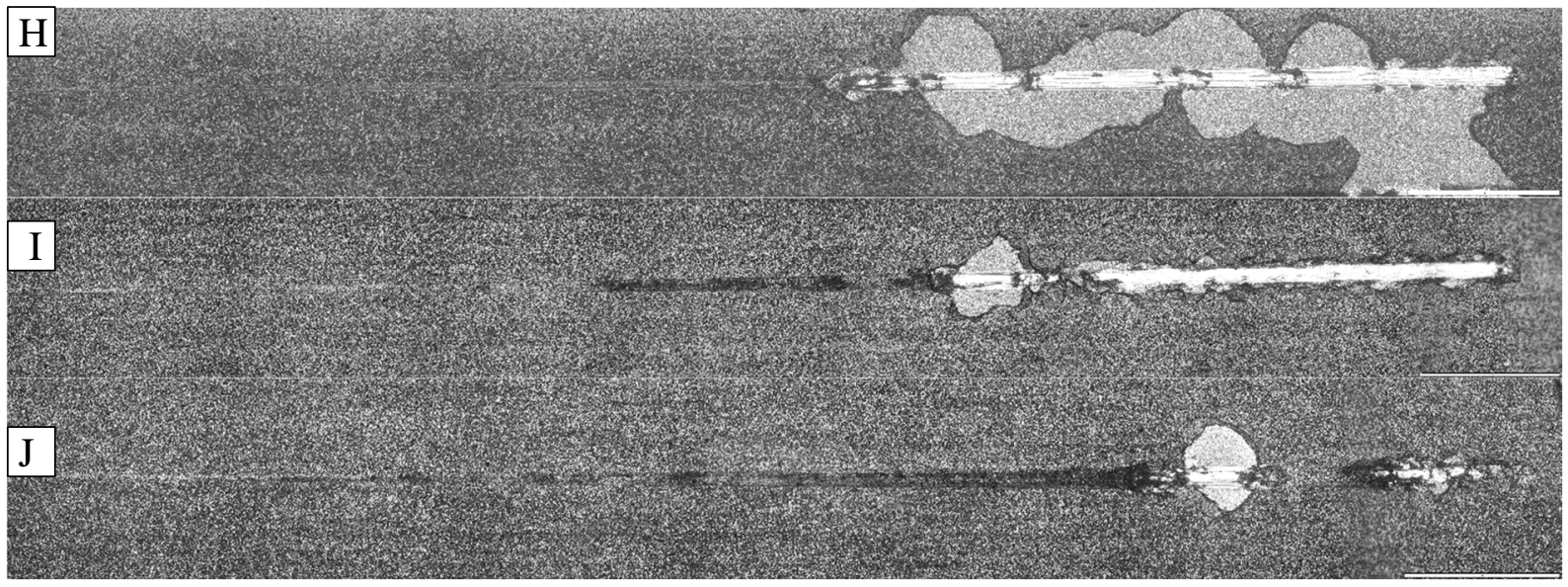

Figure 41 - Representative pictures of sample surface after Scratch test for experiments H, I and J.

Not only the failure mode was evaluated but also the critical load $\left(\mathrm{L}_{\mathrm{c} 2}\right)$, as presented in Figure 42. The remarkable failure observed in experiment $\mathrm{H}$ is accompanied by a low $\mathrm{L}_{\mathrm{c} 2}$, of $57 \mathrm{~N}$. Experiment I achieved a $\mathrm{L}_{\mathrm{c} 2}$ of $66 \mathrm{~N}$ and the value of $76 \mathrm{~N}$ was achieved with experiment $J$. The results of $L_{c 2}$ presented a linear increase with the cathode current. This result suggests that a higher cathode current leads to an improved interface structure. Considering the findings from the preliminary interface analysis, it can be expected that an optimized interface structure would have a well-developed mixing layer and a thin carbon transition layer. As discussed before, the formation of the mixing layer can be correlated directly to the energy of a single carbon ion and the quantity of carbon ions. A higher total energy input at the surface leads to a higher mixing layer thickness (RATAYSKI et al., 2011). In fact, a higher cathode current produces a higher quantity of carbon ions (ANDERS, 2002). Therefore, a higher cathode current can impact positively the formation of the mixing layer, improving coating adhesion as seen with experiment J. On the other hand, a low cathode current can jeopardize the formation of the mixing layer, since a lower quantity of ions is produced. The poor formation of the mixing layer explains the lower $\mathrm{L}_{\mathrm{c} 2}$ result for the experiment $\mathrm{H}$. 


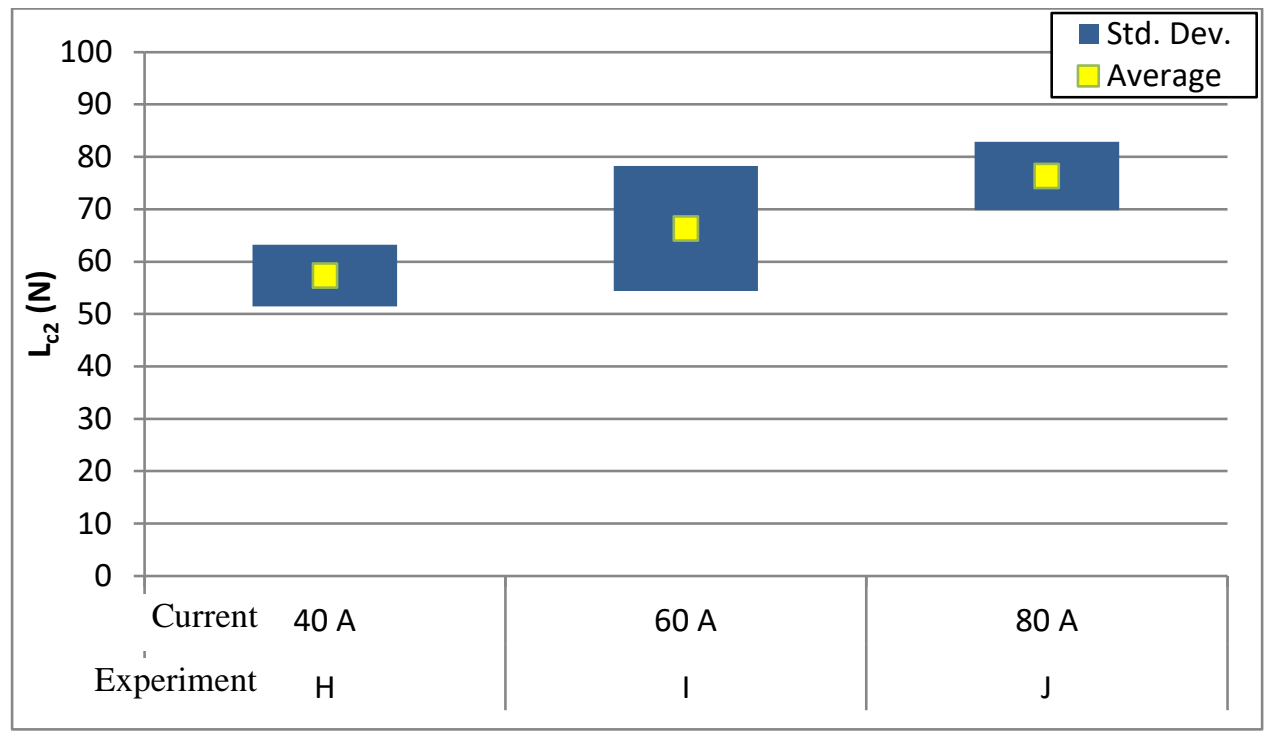

Figure 42 - Critical load $\left(\mathrm{L}_{\mathrm{c} 2}\right)$ for experiments $\mathrm{H}$, I and J.

\subsubsection{Effect of temperature}

\subsubsection{Coating Properties}

For this last set of experiments, the a-C coating properties were also evaluated to confirm that the only factor impacting the adhesion is the interface structure. The thickness and hardness for experiments $\mathrm{K}$ and $\mathrm{L}$ are presented in Table 6 . The thicknesses achieved were $22.6 \mu \mathrm{m}$ and $23.9 \mu \mathrm{m}$ for experiments $\mathrm{K}$ and $\mathrm{L}$, respectively. The difference can be considered as negligible since the standard deviation is from 0.9 to $1.8 \mu \mathrm{m}$. The explanation for this difference was already described before and no impact in the adhesion results is expected. Regarding hardness, experiment $\mathrm{K}$ and $\mathrm{L}$ achieved values of 28.5 and $30.5 \mathrm{GPa}$, respectively. Also, for this feature, the difference is not significant due to the standard deviation of 1.6 and $2.2 \mathrm{GPa}$.

Table 6 - Thickness and hardness for the experiments $\mathrm{K}$ and $\mathrm{L}$.

\begin{tabular}{cccc|cc}
\hline Experiment & $\begin{array}{c}\text { Temperature } \\
\left({ }^{\circ} \mathrm{C}\right)\end{array}$ & $\begin{array}{c}\text { BIAS voltage } \\
(\mathrm{V})\end{array}$ & $\begin{array}{c}\text { Duration } \\
(\mathrm{s})\end{array}$ & $\begin{array}{c}\text { a-C Thickness } \\
(\mu \mathrm{m})\end{array}$ & $\begin{array}{c}\text { a-C } \\
\text { Hardness } \\
(\mathrm{GPa})\end{array}$ \\
\hline $\mathbf{K}$ & $80-100$ & 1000 & 180 & $22.6 \pm 0.9$ & $28.5 \pm 1.6$ \\
$\mathbf{L}$ & $60-80$ & 1000 & 180 & $23.9 \pm 1.8$ & $30.5 \pm 2.2$ \\
\hline
\end{tabular}




\subsubsection{Adhesion test}

The representative pictures of sample surface after the scratch test for experiments $\mathrm{K}$ and $\mathrm{L}$ are presented in Figure 43. The experiment K presented a failure characterized by spallation and an intense coating detachment that exceeds the lateral limits of the zone with the stylus direct action. The experiment $\mathrm{L}$, in turn, presented only small coating detaching within the stylus track and no larger detachment up to $100 \mathrm{~N}$ load.
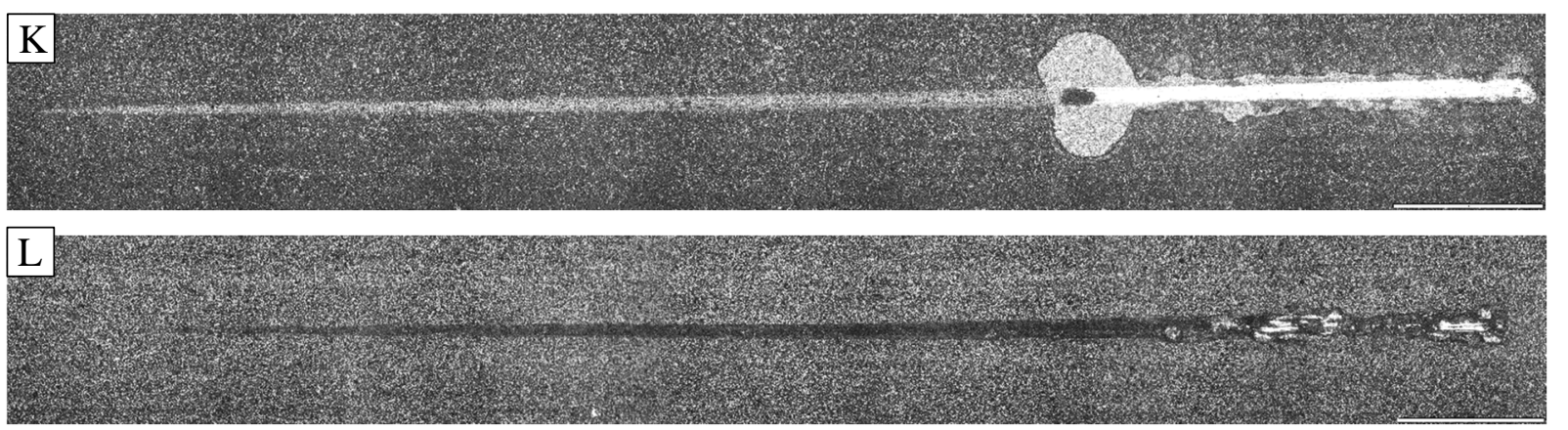

Figure 43 - Representative pictures of sample surface after Scratch test for experiments K and L.

The difference in failure mode is also accompanied by a change in adhesion level, quantified by the $\mathrm{L}_{\mathrm{c} 2}$ and presented in Figure 44. Experiment $\mathrm{K}$ registered a $\mathrm{L}_{\mathrm{c} 2}$ of $72 \mathrm{~N}$, whilst experiment $\mathrm{L}$ achieved a value of $82 \mathrm{~N}$. The increase of $10 \mathrm{~N}$ can be accounted for the decrease in temperature level during the carbon bombardment step. The improvement in the $\mathrm{L}_{\mathrm{c} 2}$ and the small failure observed for the experiment L suggests that the interface structure became less prone to detachment. The interface improvement is related to the mixing layer and/or the carbon transition layer. According to the literature, the temperature difference can impact the carbide composition in the mixing layer. As reported by Zavaleyev et al. (2013), a lower substrate temperature $\left(67^{\circ} \mathrm{C}\right.$ to $\left.81{ }^{\circ} \mathrm{C}\right)$ during the carbon bombardment phase lead to the formation of the chromium carbide $\mathrm{Cr}_{7} \mathrm{C}_{3}$, while in higher temperatures the chromium carbide was composed of $\mathrm{Cr}_{23} \mathrm{C}_{6}$, measured by XRD. The sample produced with lower substrate temperature also presented an increase in adhesion seen in the scratch test. In addition, the carbon transition layer that is grown during the bombardment step can be highly impacted by this temperature difference, since the temperature impacts directly the $\mathrm{sp}^{3}$ content, as stated by Lifshitz (1993 and 1994) and Chhowalla et al. (1997). It is expected that the lower the temperature, the higher the $\mathrm{sp}^{3}$ content. Therefore, the results obtained in this set of experiments suggests that the increase in adhesion is related to change in the carbides formed in the mixing layer and the increase in the $\mathrm{sp}^{3}$ content of the carbon transition layer formed just above the mixing layer. 
The adhesion failure is possibly delayed by the carbon transition layer with more shear strength given by the $\mathrm{sp}^{3}$ bonds. The experiment $\mathrm{L}$ was selected to be evaluated by TEM.

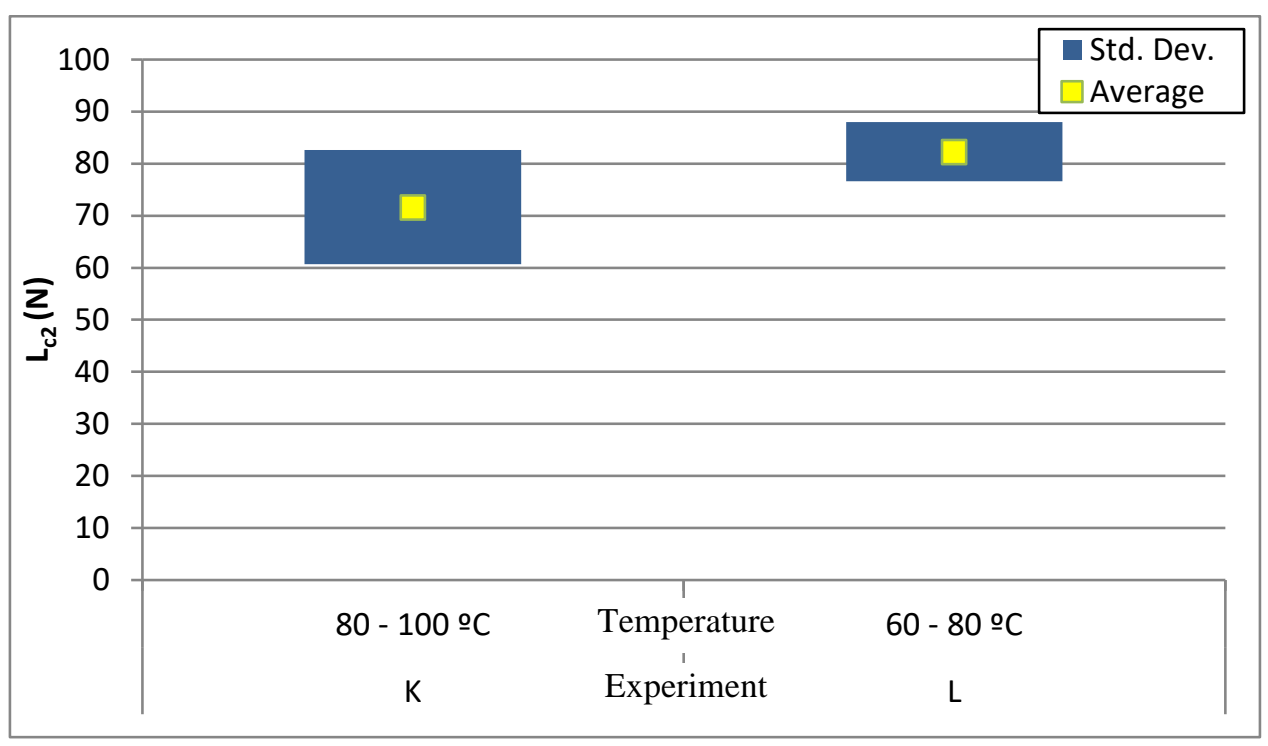

Figure 44 - Critical load $\left(\mathrm{L}_{\mathrm{c} 2}\right)$ for experiments $\mathrm{K}$ and $\mathrm{L}$.

\subsubsection{Interface analysis of selected experiments}

The experiments $\mathrm{J}$ and $\mathrm{L}$ were selected to be analyzed by STEM, to check the interface structure formed in each of them. Experiment $\mathrm{J}$ was selected due to the combination of a lower level of bias voltage $(500 \mathrm{~V})$ and higher level of cathode current $(80 \mathrm{~A})$. The $\mathrm{L}_{\mathrm{c} 2}$ achieved was $76 \mathrm{~N}$, the highest value in the set of experiments that evaluated the impact of cathode current. Experiment L, in turn, was selected due to its lower temperature used. The $\mathrm{L}_{\mathrm{c} 2}$ achieved was 82 $\mathrm{N}$, the highest value of all experiments analyzed in the second phase of this work. The parameters used for the carbon bombardment phase for experiments $\mathbf{J}$ and $\mathrm{L}$ are completely described in the Table 7.

Table 7 - Parameters used in the carbon bombardment phase for the experiments J and L. Both experiments were selected to be analyzed by TEM.

\begin{tabular}{cccccc}
\hline Experiment & $\begin{array}{c}\text { Bias voltage } \\
(\mathrm{V})\end{array}$ & $\begin{array}{c}\text { Duration } \\
(\mathrm{s})\end{array}$ & $\begin{array}{c}\text { Cathode } \\
\text { Current }(\mathrm{A})\end{array}$ & $\begin{array}{c}\text { Temperature } \\
\left({ }^{\circ} \mathrm{C}\right)\end{array}$ & $\begin{array}{c}\mathrm{L}_{\mathrm{c} 2} \\
(\mathrm{~N})\end{array}$ \\
\hline $\mathbf{J}$ & 500 & 180 & 80 & $80-100$ & 76 \\
$\mathbf{L}$ & 1000 & 180 & 60 & $60-80$ & 82 \\
\hline
\end{tabular}

Bright-field images of the interface structure for both experiments are presented in Figure 45. The images at the top have lower magnification, while the images at the bottom have higher 
magnification. It can be seen a similar structure, as obtained in the preliminary analysis: A chromium interlayer at the bottom, as a dark layer; the mixing layer as a very thin dark grey layer; the carbon transition layer as a bright layer that lies over the mixing layer; and finally, the functional $\mathrm{a}-\mathrm{C}$ is set over the carbon transition layer. The analysis of each layer will be focused on the thickness, morphology and chemical composition, which is given by the contrast in the bright-field image. The full thickness of the chromium interlayer cannot be seen in the STEM images, but have the same thickness of approximately $1 \mu \mathrm{m}$, when analyzed with SEM. No difference in composition is expected since the images show a similar color and contrast. Regarding the mixing layer, no differences are seen when the two experiments are compared. However, the low thickness of this layer results in difficulties for the comparison. The change in the bias voltage should produce differences on the thickness of this layer, which was not revealed in the pictures taken by STEM, due to its limited resolution. The recommendation to check this difference is to evaluate the thickness of the mixing layer by a chemical composition profile taken by EELS or an image taken by a High Resolution TEM (HRTEM) as performed by Ratayski et al. (2011).

The main difference observed when comparing both samples is in the carbon transition layer. The thickness is similar, as expected, since the duration of the carbon bombardment step was the same (180 s). Nevertheless, the morphology and composition have shown major differences. The carbon transition layer obtained with experiment $\mathbf{J}$ is not homogeneous as already seen in the preliminary analysis and in experiment L. Possibly, the combination of a lower bias voltage and higher cathode current are responsible for the occurrence of a nonhomogeneous layer. The second important difference is related to the brightness difference of the carbon transition layer between experiments $\mathbf{J}$ and $\mathrm{L}$. In experiment $\mathrm{L}$, the layer is similar to that observed in the preliminary analysis, where the carbon transition layer was brighter than the functional a-C layer, as an indication of more $\mathrm{sp}^{2}$ bonds. On the other hand, the brightness observed for the carbon transition layer in the experiment $\mathrm{J}$ is lower than that in experiment $\mathrm{L}$ and much closer to the brightness observed for the functional a-C layer. Therefore, it can be assumed that the carbon transition layer in experiment $\mathrm{J}$ is richer in $\mathrm{sp}^{3}$ bonds, confirming the suggestion that a lower bias voltage produced a layer with more $\mathrm{sp}^{3}$ bonds (CHHOWALLA et al., 1997; FALLON et al., 1993; MCKENZIE et al., 1991; VEERASAMY et al., 1993; XU et al., 1996). 
Comparing the adhesion performance of both experiments, it can be said that the reduction in temperature was more effective than the change in the bias voltage and cathode current. However, no clear indication of the reason for this improvement was seen in the interface structure of experiment L. Instead, it was observed a carbon transition layer with higher $\mathrm{sp}^{3}$ in the experiment $\mathrm{J}$ (still lower than the $\mathrm{sp}^{3}$ observed for the functional layer), which would lead to a higher adhesion. Therefore, it can be suggested that another element of the interface structure was modified. As highlighted before, the mixing layer could not be fully characterized since it is very thin. In this way, the most probable improvement for the experiment $\mathrm{L}$ occurred in the mixing layer and may be related to the carbide composition formed due to the lower temperature. The change in the carbide formation due to temperature was reported by Zavaleyev et al. (2013) after evaluating the samples by XRD. The formation of the carbide $\mathrm{Cr}_{7} \mathrm{C}_{3}$ was seen for low substrate temperature $\left(67\right.$ and $\left.81{ }^{\circ} \mathrm{C}\right)$ and, for higher temperatures, the carbide formed was mainly $\mathrm{C}_{23} \mathrm{C}_{6}$.
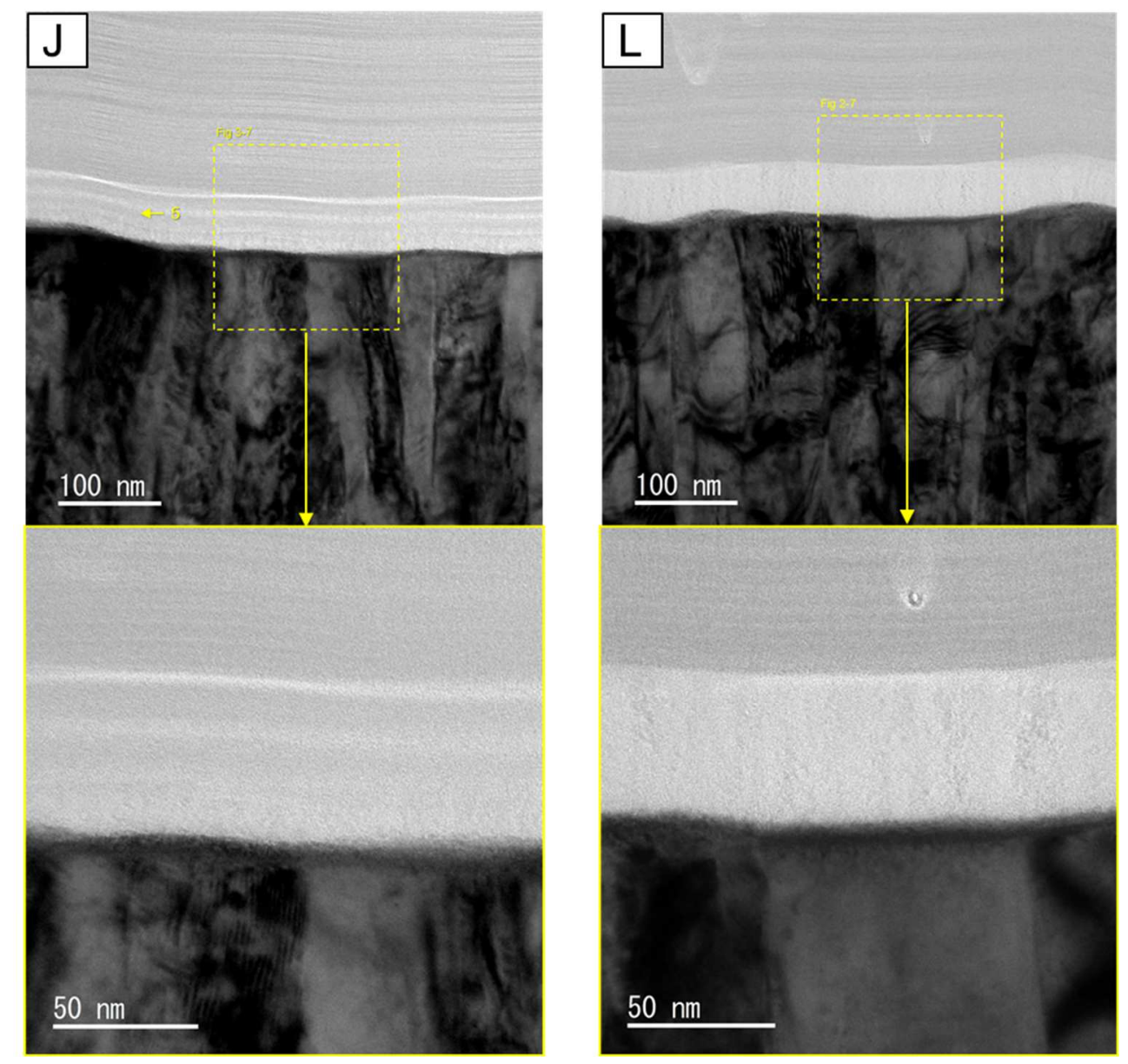

Figure 45 - STEM - Bright-Field images of the chromium/DLC interface for experiments J and L. The images at the top have lower amplification and the images at the bottom have higher amplification. 


\subsubsection{Model of impact of carbon transition layer thickness on adhesion}

Based on the STEM images it was possible to measure the carbon transition layer thickness and correlate with the achieved $\mathrm{Lc}_{2}$. Figure 46 shows the critical load as a function of the carbon transition layer thickness. The points are the measured values for experiments A, B, $\mathrm{C}, \mathrm{J}$ and $\mathrm{L}$. The solid line indicates the trend based on the available data, whilst the dashed line indicates uncertainty due to lack of data for thicknesses below $25 \mathrm{~nm}$. In the absence of carbon transition layer (thickness: $0 \mathrm{~nm}$ ) the adhesion level is very low due to a sharp transition between the soft chromium intermediate layer and the very hard DLC. When a thin carbon transition layer is applied, a sharp increase in the $\mathrm{Lc}_{2}$ is achieved. The increase in $\mathrm{Lc}_{2}$ can be explained by the carbon transition layer acting as a buffer layer that decreases the strain and the interfacial stress. Although, for thicker carbon transition layer, the adhesion has a small decrease. This effect can be attributed to an early failure of the thicker carbon transition layer, induced by its lower shear resistance.

In the model described and shown in Figure 46, an estimate of the decrease in $\mathrm{Lc}_{2}$ with the increase in carbon transition layer thickness is represented by a grey area. Based on the experiments and discussions, it is expected that the slope of this decrease is dependent on $\mathrm{sp}^{3}$ content of the carbon transition layer and on the formation of the mixed layer. When the $\mathrm{sp}^{3}$ content is higher or the mixed layer is broader, the decrease in $\mathrm{Lc}_{2}$ will be lower. In the case of a lower $\mathrm{sp}^{3}$ content or a thinner mixed layer, the decrease will be higher.

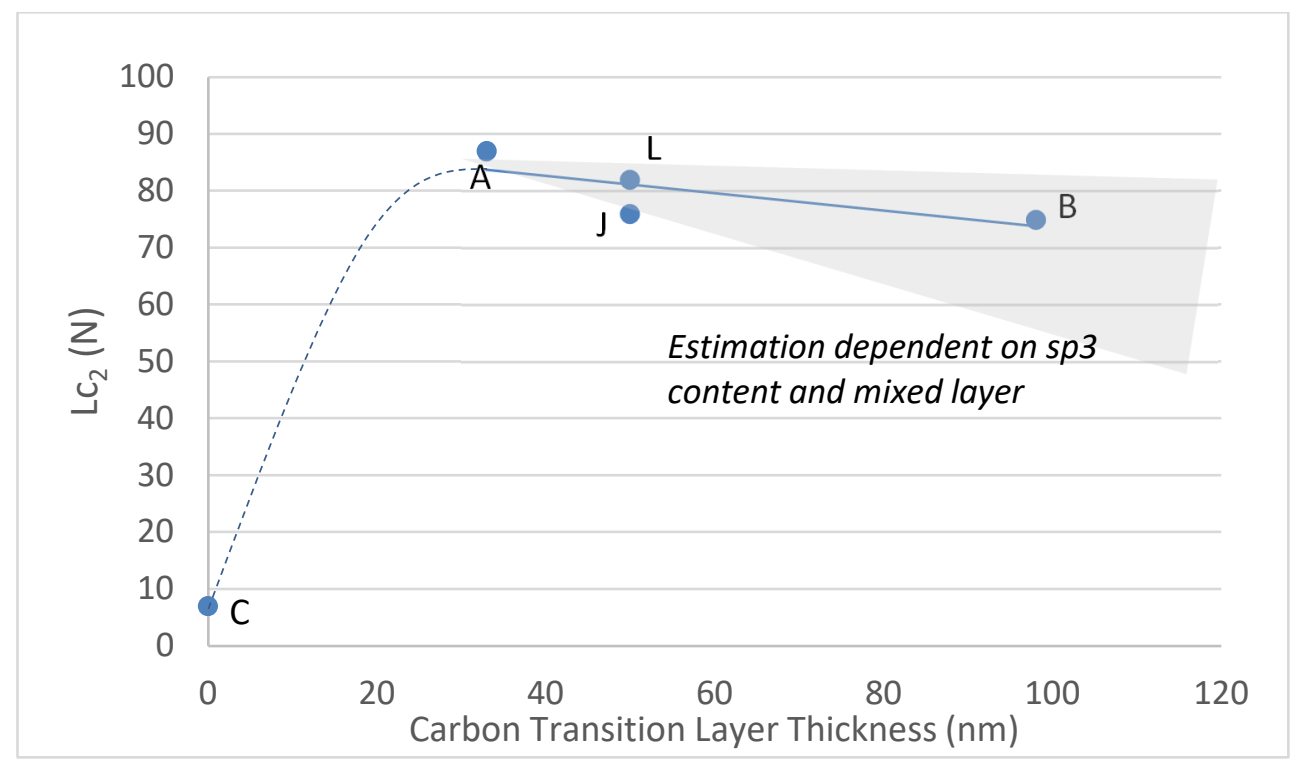

Figure 46 - Critical load $\left(\mathrm{Lc}_{2}\right)$ in function of carbon transition layer thickness. The solid line indicates the trend based on the available data, whilst the dashed line indicates uncertainty due to lack of data for thicknesses below $25 \mathrm{~nm}$. 


\section{CONCLUSIONS}

Thick amorphous carbon coatings were produced by cathodic arc evaporation, including a stage of carbon bombardment after the deposition of the chromium interlayer and before the deposition of its functional coating. Thicknesses of 22 to $24 \mu \mathrm{m}$ and hardness of 29 to $31 \mathrm{GPa}$ were achieved. No impact of the carbon bombardment step in the mechanical properties (hardness and Young's modulus) nor in the thickness was observed. The lower hardness of the coating, in comparison with the literature for $\mathrm{a}-\mathrm{C}$, can be explained by the relatively low ion energy used for the deposition. Also, it was found a residual stress near $0.7 \mathrm{GPa}$, which is considered low for a-C coatings. It is suggested that the 2 -fold table rotation induces a pulsedlike deposition, which produces a coating relaxation during a-C growth.

During the preliminary phase, interface analysis by TEM and compositional analysis by EELS were able to characterize the structure formed due to the carbon bombardment stage. A thin $(3-6 \mathrm{~nm})$ mixed layer of chromium and carbon was observed over the chromium interlayer. Additionally, it was noticed that an extended duration of the carbon bombardment step is able to form a carbon transition layer with low density and low sp3 content over the mixed layer, and that longer durations can also increase the thickness of this low-density layer. Depending on the duration of the step, thicknesses of 33 and $98 \mathrm{~nm}$ were obtained for the carbon transition layer. Therefore, it was shown that the carbon bombardment step, and the corresponding interface structure, has strong impact on the adhesion, as measured by scratch tests. Critical loads higher than $75 \mathrm{~N}$ were achieved during experiments where the carbon bombardment was employed. In comparison, the experiment without this stage resulted in a critical load of only $7 \mathrm{~N}$. Moreover, the adhesion failure observed in all cases occurs between the intermediate layer of chromium and the a-C. Another important finding is the adhesion increase observed when the thickness of the carbon transition layer was reduced by the decrease of the duration of the carbon bombardment step. This effect was attributed to an early failure of the thicker carbon transition layer, induced by its lower shear resistance.

In a second phase, different sets of experiments were designed to enhance the adhesion by varying the parameters of the carbon bombardment stage. It was found that not only the thickness of the carbon transition layer is important for the adhesion but also the $\mathrm{sp}^{3}$ content. For instance, a lower bias voltage possibly increased the $\mathrm{sp}^{3}$ content of the carbon transition layer mitigating the negative impact of a thicker carbon transition layer. Moreover, an increase in the carbon cathode current could increase the adhesion possibly by extending the mixing 
layer. Finally, the best adhesion result was achieved when the temperature of the bombardment was reduced. The most probable cause for this improvement is a compositional modification in the mixing layer, like a change in the carbides formed in that region.

Overall, the adhesion of thick and hard a-C coatings was enhanced as proposed in the beginning of the work. Several experiments and analysis indicated that the carbon bombardment phase is essential to achieve adhesion for this type of coating due to the formation of a structured interface (mixing layer and carbon transition layer). The final proposal regarding carbon bombardment parameters to achieve the highest adhesion is:

- Bias voltage: from $500 \mathrm{~V}$ to $1000 \mathrm{~V}$ to provide enough ion energy to produce a wellformed mixing layer.

- Duration: $180 \mathrm{~s}$ in our machine setup. It must be enough to reach the mixing layer saturation point, where the carbon transition layer starts to be formed, but not too long to avoid the increase in thickness of the carbon transition layer.

- Carbon cathode current: 80 A in our machine setup. Higher values helped the formation of an extended mixing layer.

- Temperature: between $60{ }^{\circ} \mathrm{C}$ to $80{ }^{\circ} \mathrm{C}$, to avoid the formation of $\mathrm{sp}^{2}$ bonds in excess in the carbon transition layer and to help the formation of carbides with stronger bonds within the mixing layer. 


\section{FUTURE WORK}

- Cr x C co-deposition: it was found that the mixed layer $(\mathrm{Cr}$ and $\mathrm{C})$ is an important feature to achieve higher adhesion. A mixed layer was observed in the current work due to the use of the carbon bombardment over the chromium interlayer. One future point to be investigated is if the mixed layer can be further increased by the use of a co-deposition between $\mathrm{C}$ and $\mathrm{Cr}$, where all the targets would be turned on at the same time to produce a intermediate layer between the Cr layer and the functional DLC.

- Use of software TRIM to simulate the subplantation of carbon over chromium: In the work, the bias voltage for the carbon bombardment was chosen based on literature and the mixed layer thickness was not measured for all deposition conditions, including some with TEM analysis, due to TEM resolution limitation. It is possible, for future work, to use the TRIM software to anticipate the mixed layer thickness based on the bias voltage.

- Use of HRTEM for interface investigations: As already discussed, the mixed layer thickness was not fully measured due to TEM resolution limitation. In future work, it is recommended to perform the interface analysis with the use of a HRTEM, which have higher resolution and would be useful to measure the actual mixed layer thickness.

- Deep investigations on low residual stresses obtained: The residual stresses below $1 \mathrm{GPa}$ for thick and hard DLC was found to be low. In the literature, this effect is achieved by pulse biasing. In this work, the most probable cause for low stress is the table movement (2-fold rotation). In order to confirm this hypothesis it is suggested to produce a sample without the table movement (sample positioned directly in front of the carbon target) to evaluate if the stress is high. Another important point to be considered in this investigation is how important is the role of macroparticles on the stress reduction.

- Stress measurement robustness: It is recommended to increase the sample size for measurement of the stress, mostly to calculate the confidence interval of the obtained average. Also, it is possible to conduct a comparison with the stress data obtained with another method, such as Raman spectroscopy. 


\section{REFERENCES}

AN, Xiaokai et al. High-ion-energy and low-temperature deposition of diamond-like carbon (DLC) coatings with pulsed kV bias. Surface and Coatings Technology, v. 365, p. 152-157, 2019. DOI: 10.1016/j.surfcoat.2018.08.099.

ANDERS, Andre. Cathodic Arc Plasma Deposition. Vacuum Technology \& Coating, v. 3 , n. 7 , p. $27-35,2002$.

ANDERS, André. Approaches to rid cathodic arc plasmas of macro- and nanoparticles: A review. Surface and Coatings Technology, v. 120-121, p. 319-330, 1999. DOI: 10.1016/S0257-8972(99)00460-0.

ANDERS, André; YUSHKOV, George Yu. Ion flux from vacuum arc cathode spots in the absence and presence of a magnetic field. Journal of Applied Physics, v. 91, n. 8, p. 48244832, 2002. DOI: 10.1063/1.1459619. Disponível em: http://aip.scitation.org/doi/10.1063/1.1459619.

ANDERS, André; YUSHKOV, George Yu. The kinetic energy of carbon ions in vacuum arc plasmas: A comparison of measuring techniques. J. Appl. Phys, v. 96, p. 970-974, 2004. DOI: $10.1063 / 1.1762712$.

ANDERS, S.; ANDERS, A.; BROWN, I. G.; WEI, B.; KOMVOPOULOS, K.; AGER, J. W.; YU, K. M. Effect of vacuum arc deposition parameters on the properties of amorphous carbon thin films. Surface and Coatings Technology, v. 68-69, p. 388-393, 1994. DOI: 10.1016/0257-8972(94)90191-0.

ANDERS, Simone; ANDERS, André; YU, Kin Man; YAO, Xiang Y.; BROWN, Ian G. On the Macroparticle Flux from Vacuum Arc Cathode Spots. IEEE Transactions on Plasma Science, v. 21, n. 5, p. 440-446, 1993. DOI: 10.1109/27.249623.

ANDERS, Simone; CALlAHAN, Daniel L.; PHARR, George M.; TSUI, Ting Y.; BHATIA, C. Singh. Multilayers of amorphous carbon prepared by cathodic arc deposition. Surface and Coatings Technology, v. 94-95, p. 189-194, 1997. DOI: 10.1016/S02578972(97)00346-0.

ANTTILA, Asko; LAPPALAINEN, Reijo; TIAINEN, Veli-Matti; HAKOVIRTA, Marko. Superior attachment of high-quality hydrogen-free amorphous diamond films to solid 
materials. Advanced Materials, v. 9, n. 15, p. 1161-1164, 1997. DOI: 10.1002/adma.19970091507.

ARAUJO, Juliano Avelar; COSTA, Nuno; MORDENTE, Paulo José; SARABANDA, José Valentim. WO2018189255A1 - Piston ring for internal combustion engines, 2017.

ASTM INTERNATIONAL. C1624-05: Standard Test Methods for Adhesion Strength and Mechanical Failure Modes of Ceramic Coatings by Quantitative Single Point Scratch Testing, West Conshohocken, PA. 2015. DOI: 10.1520/C1624-05R15.

BASTOW, S., BOWDEN, F. Contact of Smooth Surfaces. Nature, 129, pp. 438, 1932. DOI: $10.1038 / 129438 \mathrm{a} 0$.

BERGER, S. D.; MCKENZIE, D. R.; MARTIN, P. J. Eels analysis of vacuum arcdeposited diamond-like films. Philosophical Magazine Letters, v. 57, n. 6, p. 285-290, 1988. DOI: $10.1080 / 09500838808214715$.

BILEK, M. M. M.; VERDON, M.; RYVES, L.; OATES, T. W. H.; HA, C. T.; MCKENZIE, D. R. A model for stress generation and stress relief mechanisms applied to asdeposited filtered cathodic vacuum arc amorphous carbon films. Thin Solid Films, v. 482, n. 1-2, p. 69-73, 2005. DOI: 10.1016/j.tsf.2004.11.159.

BROITMAN, E.; HULTMAN, L. Adhesion improvement of carbon-based coatings through a high ionization deposition technique. Journal of Physics: Conference Series, v. 370, n. 1, 2012. DOI: 10.1088/1742-6596/370/1/012009.

BRUNO, Rafael Antonio; RABELLO, Rafael Bettini; SILVA, Davi Antonio; ARAUJO, Juliano Avelar. DLC COATED RING PACK FOR HEAVY DUTY DIESEL ENGINES. In: BLUCHER ENGINEERING PROCEEDINGS 2017, São Paulo. Editora Blucher, 2017. p. 462-476. DOI: 10.5151/engpro-simea2017-35.

BULL, S. J. Failure modes in scratch adhesion testing. Surface and Coatings Technology, v. 50, n. 1, p. 25-32, 1991. DOI: 10.1016/0257-8972(91)90188-3.

BULL, S. J. Failure mode maps in the thin film scratch adhesion test. Tribology International, v. 30, n. 7, p. 491-498, 1997. DOI: 10.1016/S0301-679X(97)00012-1.

BULL, S. J.; BERASETEGUI, E. G. An overview of the potential of quantitative coating adhesion measurement by scratch testing. Tribology International, v. 39, n. 2, p. 99-114, 
2006. DOI: 10.1016/j.triboint.2005.04.013.

BUNSHAH, Rointan F. Handbook of Hard Coatings: Deposition Technologies, Properties and Applications. William Andrew Publishing, 2001. DOI: 10.1007/s13361-0140995-8.

BURNETT, P. J.; RICKERBY, D. S. The relationship between hardness and scratch adhession. Thin Solid Films, v. 154, n. 1-2, p. 403-416, 1987. DOI: 10.1016/00406090(87)90382-8.

CAO, Hongshuai; QI, Fugang; OUYANG, Xiaoping; ZHAO, Nie; ZHOU, Yun; LI, Beibei; LUO, Wenzhong; LIAO, Bin; LUO, Jun. Effect of Ti transition layer thickness on the structure, mechanical and adhesion properties of Ti-DLC coatings on aluminum alloys. Materials, v. 11, n. 9, 2018. DOI: 10.3390/ma11091742.

CAPOTE, Gil; TRAVA-AIROLDI, Vladimir J.; BONETTI, Luis F. Plasma treatments for metallic surface modification to obtain highly adherent diamond-like carbon coatings. IEEE Transactions on Plasma Science, v. 42, n. 6, p. 1742-1746, 2014. DOI: 10.1109/TPS.2014.2320854.

CEMIN, F.; BOEIRA, C. D.; FIGUEROA, C. A. On the understanding of the siliconcontaining adhesion interlayer in DLC deposited on steel. Tribology International, v. 94, p. 464-469, 2016. DOI: 10.1016/j.triboint.2015.09.044.

CHEN, Chun Chin; HONG, Franklin Chau Nan. Interfacial studies for improving the adhesion of diamond-like carbon films on steel. Applied Surface Science, v. 243, n. 1-4, p. 296-303, 2005. DOI: 10.1016/j.apsusc.2004.09.085.

CHHOWALLA, M. Thick, well-adhered, highly stressed tetrahedral amorphous carbon. Diamond and Related Materials, v. 10, n. 3-7, p. 1011-1016, 2001. DOI: 10.1016/S09259635(00)00530-6.

CHHOWALlA, M.; ROBERTSON, J.; CHEN, C. W.; SILVA, S. R. P.; DAVIS, C. A.; AMARATUNGA, G. A. J.; MILNE, W. I. Influence of ion energy and substrate temperature on the optical and electronic properties of tetrahedral amorphous carbon (ta-C) films. Journal of Applied Physics, v. 81, n. 1, p. 139-145, 1997.

CHOLERIDIS, Antonios et al. Experimental study of wear-induced delamination for 
DLC coated automotive components. Surface and Coatings Technology, v. 352, p. 549-560, 2018. DOI: 10.1016/j.surfcoat.2018.08.048.

DALIBÓN, E. L.; ESCALADA, L.; SIMISON, S.; FORSICH, C.; HEIM, D.; BRÜHL, S. P. Mechanical and corrosion behavior of thick and soft DLC coatings. Surface and Coatings Technology, v. 312, p. 101-109, 2017. DOI: 10.1016/j.surfcoat.2016.10.006.

DALIBÓN, Eugenia L.; CZERWIEC, Thierry; TRAVA-AIROLDI, Vladimir J.; GHAFOOR, Naureen; ROGSTRÖM, Lina; ODÉN, Magnus; BRÜHL, Sonia P. Characterization of DLC coatings over nitrided stainless steel with and without nitriding pretreatment using annealing cycles. Journal of Materials Research and Technology, v. 8, n. 2, p. 1653-1662, 2019. DOI: 10.1016/j.jmrt.2018.12.002.

DELFÍN, Francisco Andrés; BRÜHL, Sonia Patricia; FORSICH, Christian; HEIM, Daniel. Carbon based DLC films: Influence of the processing parameters on the structure and properties. Revista Materia, v. 23, n. 2, 2018. DOI: 10.1590/s1517-707620180002.0395.

DELPLANCKE-OGLETREE, M.; MONTEIRO, O.R. Monteiro, In situ measurement of stresses in diamond-like carbon films, Diam. Relat. Mater. v. 12, p. 2119-2127, 2003. https://doi.org/10.1016/S0925-9635(03)00240-1.

DRESCHER, D.; KOSKINEN, J.; SCHEIBE, H. J.; MENSCH, A. A model for particle growth in arc deposited armophous carbon films. Diamond and Related Materials, v. 7, p. 1375-1380, 1998.

DWIVEDI, Neeraj; KUMAR, Sushil; MALIK, Hitendra K. Superhard behaviour, low residual stress, and unique structure in diamond-like carbon films by simple bilayer approach. Journal of Applied Physics, v. 112, n. 2, 2012. DOI: 10.1063/1.4739287.

EGERTON, R. F. Electron energy-loss spectroscopy in the TEM. Reports on Progress in Physics, v. 72, n. 1, 2009. DOI: 10.1088/0034-4885/72/1/016502.

ERDEMIR, Ali; FONTAINE, Julien; DONNET, Christophe. An overview of superlubricity in diamond-like carbon films. In: Tribology of Diamond-Like Carbon Films: Fundamentals and Applications. Springer US, 2008. p. 237-262. DOI: 10.1007/978-0-38749891-1_8.

ERDEMIR, Ali; MARTIN, Jean Michel. Superior wear resistance of diamond and DLC 
coatings. Current Opinion in Solid State and Materials Science, v. 22, n. 6, p. 243-254, 2018. DOI: 10.1016/j.cossms.2018.11.003.

FALABELLA, Steven; KARPOV, Dmitri A. Continuous cathodic Arc sources. In: Handbook of Vacuum Arc Science and Technology. Elsevier, 1996. p. 397-423. DOI: 10.1016/b978-081551375-9.50014-x.

FALLON, P. J.; VEERASAMY, V. S.; DAVIS, C. A.; ROBERTSON, J.; AMARATUNGA, G. A. J.; MILNE, W. I.; KOSKINEN, J. Properties of filtered-ion-beamdeposited diamondlike carbon as a function of ion energy. Physical Review B, v. 48, n. 7, p. 4777-4782, 1993. DOI: 10.1103/PhysRevB.48.4777.

FERRARI, A. C. et al. Density, sp3 fraction, and cross-sectional structure of amorphous carbon films determined by x-ray reflectivity and electron energy-loss spectroscopy. Physical Review B - Condensed Matter and Materials Physics, v. 62, n. 16, p. 11089-11103, 2000. DOI: 10.1103/PhysRevB.62.11089.

FERRARI, A. C.; ROBERTSON, J.; BEGHI, M. G.; BOTTANI, C. E.; FERULANO, R.; PASTORELLI, R. Elastic constants of tetrahedral amorphous carbon films by surface Brillouin scattering. Applied Physics Letters, 1999. DOI: 10.1063/1.124863.

FERRARI, A. C.; RODIL, S. E.; ROBERTSON, J.; MILNE, W. I. Is stress necessary to stabilise sp bonding in diamond-like carbon? Diamond and Related Materials, v. 11, p. 994999, 2002.

FERRARI, A.; ROBERTSON, J. Interpretation of Raman spectra of disordered and amorphous carbon. Physical Review B - Condensed Matter and Materials Physics, v. 61, n. 20, p. 14095-14107, 2000. DOI: 10.1103/PhysRevB.61.14095.

FERREIRA, Rita; MARTINS, Jorge; CARVALHO, Óscar; SOBRAL, Luis; CARVALHO, Sandra; SILVA, Filipe. Tribological solutions for engine piston ring surfaces: an overview on the materials and manufacturing. Materials and Manufacturing Processes, 2019. DOI: $10.1080 / 10426914.2019 .1692352$.

FONTAINE, Julien; DONNET, Christophe; ERDEMIR, Ali. Fundamentals of the tribology of DLC coatings. In: Tribology of Diamond-Like Carbon Films: Fundamentals and Applications. Springer US, 2008. p. 139-154. DOI: 10.1007/978-0-387-49891-1_5. 
FORSICH, Christian; DIPOLT, Christian; HEIM, Daniel; MUELLER, Thomas; GEBESHUBER, Andreas; HOLECEK, Reinhard; LUGMAIR, Christoph. Potential of thick aC: H: Si films as substitute for chromium plating. Surface and Coatings Technology, v. 241, p. 86-92, 2014. DOI: 10.1016/j.surfcoat.2013.11.011.

FUJIHANA, Takanobu; OKABE, Yoshio; IWAKI, Masaya. Crystal structure of carbonimplanted titanium, vanadium and chromium. Nuclear Instruments and Methods in Physics Research, Section B: Beam Interactions with Materials and Atoms, v. 127-128, p. 660663, 1997. DOI: 10.1016/S0168-583X(96)01150-0.

GALVAN, D.; PEI, Y. T.; DE HOSSON, J. Th M.; CAVALEIRO, A. Determination of the sp3 C content of a-C films through EELS analysis in the TEM. Surface and Coatings Technology, v. 200, n. 1-4, p. 739-743, 2005. DOI: 10.1016/j.surfcoat.2005.02.071.

GANGOPADHYAY, Arup. Mechanical and tribological properties of amorphous carbon films. Tribology Letters, v. 5, p. 29-39, 1998. DOI: 10.1023/A:1019152515982.

GERSTNER, E. G.; MCKENZIE, D. R.; PUCHERT, M. K.; TIMBRELL, P. Y.; ZOU, J. Adherent carbon film deposition by cathodic arc with implantation. Journal of Vacuum Science \& Technology A: Vacuum, Surfaces, and Films, v. 13, n. 2, p. 406-411, 1995. DOI: $10.1116 / 1.579372$.

GILEWICZ, A.; WARCHOLINSKI, B.; SZYMANSKI, W.; GRIMM, W. CrCN/CrNta$\mathrm{C}$ multilayer coating for applications in wood processing. Tribology International, v. 57, p. 1-7, 2013. DOI: 10.1016/j.triboint.2012.07.006.

GLOZMAN, O.; HOFFMAN, A. Adhesion improvement of diamond films on steel subtrates using chromium nitride interlayers. Diamond and Related Materials, v. 6, n. 5-7, p. 796-801, 1997. DOI: 10.1016/s0925-9635(96)00671-1.

GRIMM, Werner; WEIHNACHT, Volker. Properties of super-hard carbon films deposited by pulsed arc process. Vacuum, v. 85, n. 4, p. 506-509, 2010. DOI: 10.1016/j.vacuum.2010.01.022.

HA, Peter C. T.; MCKENZIE, D. R.; BILEK, M. M. M.; DOYLE, E. D.; MCCULLOCH, D. G.; CHU, P. K. Control of stress and delamination in single and multi-layer carbon thin films prepared by cathodic arc and RF plasma deposition and implantation. Surface and Coatings 
Technology, v. 200, n. 22- 23, p. 6405-6408, 2006. DOI: 10.1016/j.surfcoat.2005.11.011.

HANG, Lingxia; YIN, Y.; XU, Junqi. Optimisation of diamond-like carbon films by unbalanced magnetron sputtering for infrared transmission enhancement. Thin Solid Films, v. 515, n. 1, p. 357-361, 2006. DOI: 10.1016/j.tsf.2005.12.099.

HAUERT, R.; THORWARTH, K.; THORWARTH, G. An overview on diamond-like carbon coatings in medical applications. Surface and Coatings Technology, v. 233, p. 119130, 2013. DOI: 10.1016/j.surfcoat.2013.04.015.

HIRVONEN, J. P.; KOSKINEN, J.; KOPONEN, I.; LIKONEN, J.; KATTELUS, H. Modification of interfacial characteristics between diamondlike carbon films and substrates by using ion bombardment. Nuclear Inst. and Methods in Physics Research, B, v. 80-81, n. PART 2, p. 1472-1476, 1993. DOI: 10.1016/0168-583X(93)90823-O.

IIJIMA, Yushi et al. Preparation of multi-layer film consisting of hydrogen-free DLC and nitrogen-containing DLC for conductive hard coating. In: AIP CONFERENCE PROCEEDINGS 2018, American Institute of Physics Inc., 2018. DOI: 10.1063/1.5021937.

INTERNATIONAL ORGANIZATION FOR STANDARDZATION, ISO 14577-1:2015 - Metallic materials - Instrumented indentation test for hardness and materials parameters - Part 1: Test method. 2015.

INTERNATIONAL ORGANIZATION FOR STANDARDZATION, ISO 14577-4:2016 - Metallic materials - Instrumented indentation test for hardness and materials parameters — Part 4: Test method for metallic and non-metallic coatings. 2016.

ISONO, Ryo et al. Improvement of adhesion of hydrogen-free DLC film by employing an interlayer of tungsten carbide. In: AIP CONFERENCE PROCEEDINGS, 2018, DOI: 10.1063/1.5021932.

JANSSEN, G. C. A. M.; ABDALLA, M. M.; VAN KEULEN, F.; PUJADA, B. R.; VAN VENROOY, B. Celebrating the 100th anniversary of the Stoney equation for film stress: Developments from polycrystalline steel strips to single crystal silicon wafers. Thin Solid Films, v. 517, n. 6, p. 1858-1867, 2009. DOI: 10.1016/j.tsf.2008.07.014.

JÜTTNER, B. Erosion Craters and Arc Cathode Spots in Vacuum. Beiträge aus der Plasmaphysik, v. 19, n. 1, p. 25-48, 1979. DOI: 10.1002/ctpp.19790190104. 
JÜTTNER, Burkhard. Cathode spots of electric arcs. Journal of Physics D: Applied Physics, v. 34, n. 17, p. 103-123, 2001. DOI: 10.1088/0022-3727/34/17/202.

KANO, Makoto. Overview of DLC-Coated Engine Components. In: Coating Technology for Vehicle Applications. Springer International Publishing, 2015. p. 37-62. DOI: 10.1007/978-3-319-14771-0_3.

KANO, Makoto; MARTIN, Jean Michel; YOSHIDA, Kentaro; DE BARROS BOUCHET, Maria Isabel. Super-low friction of ta-C coating in presence of oleic acid. Friction, v. 2 , n. 2 , p. 156-163, 2014. DOI: 10.1007/s40544-014-0047-1.

KESSLER, O.; HOFFMANN, F.; MAYR, P. The Role of CVD Parameters in Producing the "Eggshell" Effect During the Coating of Steel. Chemical Vapor Deposition, v. 6, n. 5, p. 253-259, 2000. DOI: 10.1002/1521-3862(200010)6:5<253::AID-CVDE253>3.0.CO;2-5.

KOSKINEN, J.; LAPPALAINEN, R.; ANTTILA, A.; HIRVONEN, J. P. Interfacial characteristics of arc-discharge-deposited diamond-like films on 19 different substrate materials. Diamond and Related Materials, v. 3, n. 1-2, p. 52-55, 1994. DOI: 10.1016/09259635(94)90030-2.

LIFSHITZ, Y. Hydrogen-free amorphous carbon films: Correlation between growth conditions and properties. Diamond and Related Materials, v. 5, n. 3-5, p. 388-400, 1996. DOI: 10.1016/0925-9635(95)00445-9.

LIFSHITZ, Y.; KASI, S. R.; RABALAIS, J. W. Subplantation model for film growth from hyperthermal species: Application to diamond. Physical Review Letters, v. 62, n. 11, p. 1290-1293, 1989. DOI: 10.1103/PhysRevLett.62.1290.

LIFSHITZ, Y.; LEMPERT, G. D.; GROSSMAN, E. Substantiation of Subplantation Model for Diamondlike Film Growth by Atomic Force Microscopy. Physical Review Letters, v. 72, n. $17,1994$.

LIFSHITZ, Y.; LEMPERT, G. D.; ROTTER, S.; AVIGAL, I.; UZAN-SAGUY, C.; KALISH, R. The influence of substrate temperature during ion beam deposition on the diamond-like or graphitic nature of carbon films. Diamond and Related Materials, v. 2, n. $2-$ 4, p. 285-290, 1993. DOI: 10.1016/0925-9635(93)90069-E.

LIU, D. G.; ZHENG, L.; LIU, J. Q.; LUO, L. M.; WU, Y. C. Residual stress relief of hard 
a-C films though buckling. Ceramics International, v. 44, n. 4, p. 3644-3648, 2018. a. DOI: 10.1016/j.ceramint.2017.11.115.

LIU, Liangliang et al. Excellent adhered thick diamond-like carbon coatings by optimizing hetero-interfaces with sequential highly energetic $\mathrm{Cr}$ and $\mathrm{C}$ ion treatment. Journal of Alloys and Compounds, v. 735, p. 155-162, 2018. b. DOI: 10.1016/j.jallcom.2017.11.057.

MATTOX, Donald M. Handbook of Physical Vapor Deposition (PVD) Processing. [s.1.] : Elsevier Inc., 2010.

MCKENZIE, D. R. et al. Properties of tetrahedral amorphous carbon prepared by vacuum arc deposition. Diamond and Related Materials, v. 1, n. 1, p. 51-59, 1991. DOI: 10.1016/0925-9635(91)90011-X.

MCKENZIE, D. R.; MULLER, D.; PAILTHORPE, B. A. Compressive-Stress-Induced Formation of Thin-Film Tetrahedral Amorphous Carbon. Physical Review Letters, v. 67, n. 6, p. 773-776, 1991.

MEHRAN, Q. M.; FAZAL, M. A.; BUSHROA, A. R.; RUBAIEE, Saeed. A Critical Review on Physical Vapor Deposition Coatings Applied on Different Engine Components. Critical Reviews in Solid State and Materials Sciences, v. 43, n. 2, p. 158-175, 2018. DOI: 10.1080/10408436.2017.1320648.

MENG-BURANY, X.; ALPAS, A. T. FIB and TEM studies of damage mechanisms in DLC coatings sliding against aluminum. Thin Solid Films, v. 516, n. 2-4, p. 325-335, 2007. DOI: 10.1016/j.tsf.2007.06.038.

MESIATS, G. A.; PROSKUROVSKII, D. I. Pulsed electric discharges in vacuum. Novosibirsk Izdatel Nauka, 1984.

MESYATS, Gennadii Andreevich. Explosive electron emission and the portion model of the electric arc. Herald of the Russian Academy of Sciences, v. 84, n. 4, p. 242-251, 2014. DOI: $10.1134 / \mathrm{S} 1019331614040017$.

MONTEIRO, Othon R. Thin Film Synthesis by Energetic Condensation. Annual Review of Materials Research, v. 31, n. 1, p. 111-137, 2001. DOI: 10.1146/annurev.matsci.31.1.111.

MORSHED, M. M.; MCNAMARA, B. P.; CAMERON, D. C.; HASHMI, M. S. J. Effect of surface treatment on the adhesion of DLC film on $316 \mathrm{~L}$ stainless steel. Surface and 
Coatings Technology, v. 163-164, p. 541-545, 2003. DOI:10.1016/S0257-8972(02)00619-9.

OKA, Y.; YATSUZUKA, M. Effects of consecutive processing between cleaning and deposition on adhesion of diamond-like carbon prepared by plasma-based ion implantation and deposition. Nuclear Instruments and Methods in Physics Research, Section B: Beam Interactions with Materials and Atoms, v. 449, p. 58-61, 2019. DOI: 10.1016/j.nimb.2019.04.052.

OLIVER, W. C.; PHARR, G. M. An improved technique for determining hardness and elastic modulus using load and displacement sensing indentation experiments. Journal of Materials Research, v. 7, n. 6, p. 1564-1583, 1992. DOI: 10.1557/JMR.1992.1564.

PANCIELEJKO, M.; CZYŻNIEWSKI, Andrzej; ZAVALEYEV, V. A.; PANDER, Adam Michal; WOJTALIK, Krzysztof. Optimization of the deposition parameters of DLC coatings with the MCVA method. Archives of Materials Science and Engineering, v. 54, n. $2,2012$.

PAPWORTH, A. J.; KIELY, C. J.; BURDEN, A. P.; SILVA, S. R. P.; AMARATUNGA, G. A. J. Electron-energy-loss spectroscopy characterization of the $\mathrm{sp} 2$ bonding fraction within carbon thin films. Physical Review B - Condensed Matter and Materials Physics, v. 62, n. 19, p. 12628-12631, 2000. DOI: 10.1103/PhysRevB.62.12628.

PAULEAU, Yves. Residual stresses in DLC films and adhesion to various substrates. In: Tribology of Diamond-Like Carbon Films: Fundamentals and Applications. Springer US, 2008. p. 102-136. DOI: 10.1007/978-0-387-49891-1_4.

PETROV, I.; LOSBICHLER, P.; BERGSTROM, D.; GREENE, J. E.; MÜNZ, W. D.; HURKMANS, T.; TRINH, T. Ion-assisted growth of Ti1-xAlxN/Ti1-yNbyN multilayers by combined cathodic-arc/magnetron-sputter deposition. Thin Solid Films, v. 302, n. 1-2, p. 179192, 1997. DOI: 10.1016/S0040-6090(96)09524-7.

PHARR, George M. et al. Hardness, elastic modulus, and structure of very hard carbon films produced by cathodic-arc deposition with substrate pulse biasing. Applied Physics Letters, v. 68, n. 6, p. 779-781, 1996.

PIVIN, J. C.; LEE, T. J.; YOU, J. H.; PARK, H.; DAVANLOO, F.; COLLINS, C. B.; CATANIA, P.; SAMPEUR, Y.; BERNAS, H. Use of ion implantation for improving the 
adhesion of diamond-like carbon films deposited by means of other techniques. Nuclear Inst. and Methods in Physics Research, B, v. 80-81, n. PART 2, p. 1499-1501, 1993. DOI: 10.1016/0168-583X(93)90829-U.

PODGORNIK, Bojan. Tribological behavior of dlc films in various lubrication regimes. In: Tribology of Diamond-Like Carbon Films: Fundamentals and Applications. Springer US, 2008. p. 410-453. DOI: 10.1007/978-0-387-49891-1_16.

POLO, M. C.; ANDÚ JAR, J. L.; HART, A.; ROBERTSON, J.; MILNE, W. I. Preparation of tetrahedral amorphous carbon films by filtered cathodic vacuum arc deposition. Diamond and Related Materials, v. 9, p. 663-667, 2000.

PUCHERT, M. K.; TIMBRELL, P. Y.; LAMB, R. N.; MCKENZIE, D. R. Thicknessdependent stress in sputtered carbon films. Journal of Vacuum Science \& Technology A: Vacuum, Surfaces, and Films, v. 12, n. 3, p. 727-732, 1994. DOI: 10.1116/1.578814.

PULKER, H. K, PERRY, A. J, BERGER, R. Adhesion, Surface Technology, v. 14, n. 1, p. 25-39, 1981. DOI: 10.1016/0376-4583(81)90005-4.

RATAYSKI, Ulrike; RAFAJA, David; KLEMM, Volker; MÜHLE, Uwe; LEONHARDT, Michael; SCHEIBE, Hans Joachim. Effect of the carbon ion energy on the microstructure of ta-C/Cr multilayers. Surface and Coatings Technology, v. 206, n. 7, p. 1753-1758, 2011. DOI: 10.1016/j.surfcoat.2011.09.055.

RICKERBY, D. S. A review of the methods for the measurement of coating-substrate adhesion. Surface and Coatings Technology, v. 36, n. 1-2, p. 541-557, 1988. DOI: 10.1016/0257-8972(88)90181-8.

RICKERBY, D. S.; JONES, A. M.; BELLAMY, B. A. Internal stress in tatanium nitride coatings: modeling of complex stress systems. Surface and Coatings Technology, v. 36, p. 661-674, 1988.

ROBERTSON, J. Properties of diamond-like carbon. Surface and Coatings Technology, v. 50, n. 3, p. 185-203, 1992. DOI: 10.1016/0257-8972(92)90001-Q.

ROBERTSON, J. Deposition mechanisms for promoting sp3 bonding in diamond-like carbon. Diamond and Related Materials, v. 2, n. 5-7, p. 984-989, 1993. DOI: 10.1016/09259635(93)90262-Z. 
ROBERTSON, J. Diamond-like amorphous carbon. Materials Science and Engineering: R: Reports, v. 37, n. 4-6, p. 129-281, 2002. DOI: 10.1016/s0927796x(02)00005-0.

ROBERTSON, John. Hard amorphous (diamond-like) carbons. Progress in Solid State Chemistry, v. 21, n. 4, p. 199-333, 1991. DOI: 10.1016/0079-6786(91)90002-H.

ROBERTSON, John. The deposition mechanism of diamond-like a-C and a-C: H. Diamond and Related Materials, v. 3, n. 4-6, p. 361-368, 1994. DOI: 10.1016/09259635(94)90186-4.

RONKAINEN, H.; KOSKINEN, J.; LIKONEN, J.; VARJUS, S.; VIHERSALO, J. Characterization of wear surfaces in dry sliding of steel and alumina on hydrogenated and hydrogen-free carbon films. Diamond and Related Materials, v. 3, n. 11-12, p. 1329-1336, 1994. DOI: 10.1016/0925-9635(94)90147-3.

SCHULTRICH, B. Modeling of ta-C growth: Influence of the technological parameters. Diamond and Related Materials, v. 20, n. 5-6, p. 785-792, 2011. DOI: 10.1016/j.diamond.2011.03.035.

SHAHSAVARI, Fatemeh; EHTESHAMZADEH, Maryam; NAIMI-JAMAL, M. Reza; IRANNEJAD, Ahmad. Nanoindentation and nanoscratch behaviors of DLC films growth on different thickness of Cr nanolayers. Diamond and Related Materials, v. 70, p. 76-82, 2016. DOI: 10.1016/j.diamond.2016.10.003.

SHARMA, Neha; KUMAR, N.; DASH, S.; DAS, C. R.; SUBBA RAO, R. V.; TYAGI, A. K.; RAJ, Baldev. Scratch resistance and tribological properties of DLC coatings under dry and lubrication conditions. Tribology International, v. 56, p. 129-140, 2012. DOI: 10.1016/j.triboint.2012.06.020.

SHEEJA, D.; TAY, B. K.; LAU, S. P.; SHI, X. Tribological properties and adhesive strength of DLC coatings prepared under different substrate bias voltages. Wear, v. 249, n. 56, p. 433-439, 2001. DOI: 10.1016/S0043-1648(01)00541-5.

SHEEJA, D.; TAY, B. K.; LEONG, K. W.; LEE, C. H. Effect of film thickness on the stress and adhesion of diamond-like carbon coatings. Diamond and Related Materials, v. 11, p. 1643-1647, 2002. 
STEINMANN, P. A.; TARDY, Y.; HINTERMANN, H. E. Adhesion testing by the scratch test method: The influence of intrinsic and extrinsic parameters on the critical load. Thin Solid Films, v. 154, n. 1-2, p. 333-349, 1987. DOI: 10.1016/0040-6090(87)90377-4.

TAY, B. K.; SHEEJA, D.; YU, L.J. On stress reduction of tetrahedral amorphous carbon films for moving mechanical assemblies, Diam. Relat. Mater. 12, p. 185-194, 2003. https://doi.org/10.1016/S0925-9635(03)00021-9.

TOMANIK, Eduardo; FUJITA, Hiroshi; SATO, Shinya; PAES, Eliel; GALVAO, Ciro; MORAIS, Paulo. Investigation of PVD Piston Ring Coatings With Different Lubricant Formulations. In: VOLUME 2: EMISSIONS CONTROL SYSTEMS; INSTRUMENTATION, CONTROLS, AND HYBRIDS; NUMERICAL SIMULATION; ENGINE DESIGN AND MECHANICAL DEVELOPMENT 2017, American Society of Mechanical Engineers, 2017. DOI: 10.1115/ICEF2017-3559.

VEERASAMY, V. S.; AMARATUNGA, G. A. J.; MILNE, W. I.; ROBERTSON, J.; FALLON, P. J. Influence of carbon ion energy on properties of highly tetrahedral diamond-like carbon. Journal of Non-Crystalline Solids, v. 164-166, p. 1111-1114, 1993. DOI: 10.1016/0022-3093(93)91193-7.

VETTER, J. 60years of DLC coatings: Historical highlights and technical review of cathodic arc processes to synthesize various DLC types, and their evolution for industrial applications. Surface and Coatings Technology, v. 257, p. 213-240, 2014. DOI: 10.1016/j.surfcoat.2014.08.017.

VIDAKIS, N.; ANTONIADIS, A.; BILALIS, N. The VDI 3198 indentation test evaluation of a reliable qualitative control for layered compounds. Journal of Materials Processing Technology, v. 143-144, p. 481-485, 2003. DOI: 10.1016/S0924-0136(03)003005.

VIHERSALO, Jarmo; VARJUS, Simo; EHRNSTEN, Ulla; ZILLIACUS, Riitta; SAARILAHTI, Jaakko; NENONEN, Pertti; RONKAINEN, Helena. Influence of substrate material, sputter cleaning and intermediate layer on the adhesion of RF-plasma a-C:H coatings. In: 2ND INTERNATIONAL CONFERENCE ON THE APPLICATIONS OF DIAMOND FILMS AND RELATED MATERIALS 1993, 1993.

VOEVODIN, Aa U.; CAPANO, Ma; LAUBE, SJP; DONLEY, MS; ZABINSKI, JS. 
Design of a Ti/TiC/DLC functionally gradient coating based on studies of structural transitions in Ti-C thin films. Thin Solid Films, v. 298, p. 107-115, 1997.

WASEEM, B.; ALAM, S.; IRFAN, M.; SHAHID, M.; FAROOQ, M.; SOOMRO, B. D.; HASHIM, S.; IQBAL, R. Optimization and Characterization of Adhesion Properties of DLC Coatings on Different Substrates. In: MATERIALS TODAY: PROCEEDINGS 2015, Elsevier Ltd, 2015. p. 5308-5312. DOI: 10.1016/j.matpr.2015.11.041.

WASY, Abdul; BALAKRISHNAN, G.; LEE, S. H.; KIM, J. K.; KIM, D. G.; KIM, T. G.; SONG, J. I. Argon plasma treatment on metal substrates and effects on diamond-like carbon (DLC) coating properties. Crystal Research and Technology, v. 49, n. 1, p. 55-62, 2014. DOI: 10.1002/crat.201300171.

WEI, Chehung; YANG, Jui Feng; TAI, Fong Cheng. The stress reduction effect by interlayer deposition or film thickness for diamond like carbon on rough surface. Diamond and Related Materials, v. 19, n. 5-6, p. 518-524, 2010. DOI: 10.1016/j.diamond.2010.01.015.

WEISSMANTEL, C.; BEWILOGUA, K.; DIETRICH, D.; ERLER, H. J.; HINNEBERG, H. J.; KLOSE, S.; NOWICK, W.; REISSE, G. Structure and properties of quasi-amorphous films prepared by ion beam techniques. Thin Solid Films, v. 72, n. 1, p. 19-32, 1980. DOI: 10.1016/0040-6090(80)90554-4.

WILliAMS, David B.; CARTER, C. Barry. Transmission electron microscopy: A textbook for materials science. Springer US, 2009. DOI: 10.1007/978-0-387-76501-3.

WILLIAMS, David B.; CARTER, C. Barry; WILlIAMS, David B.; CARTER, C. Barry. Amplitude Contrast. In: Transmission Electron Microscopy. Springer US, 2009. p. 371-388. DOI: 10.1007/978-0-387-76501-3_22.

XIANG, Yu; CHENG-BIAO, Wang; YANG, Liu; DE-YANG, Yu. A study of hard diamond-like carbon films in mid-frequency dual-magnetron sputtering. Diamond and Related Materials, v. 15, n. 9, p.1223-1227, 2006. DOI: 10.1016/j.diamond.2005.09.040.

XU, Shi; FLYNN, D.; TAY, B. K.; PRAWER, S.; NUGENT, K. W.; SILVA, S. R. P.; LIFSHITZ, Y.; MILNE, W. I. Mechanical properties and Raman spectra of tetrahedral amorphous carbon films with high sp3 fraction deposited using a filtered cathodic arc. Philosophical Magazine B: Physics of Condensed Matter; Statistical Mechanics, 
Electronic, Optical and Magnetic Properties, v. 76, n. 3, p. 351-361, 1997. DOI: $10.1080 / 01418639708241099$.

XU, Shi; TAY, B. K.; TAN, H. S.; ZHONG, Li; TU, Y. Q.; SILVA, S. R. P.; MILNE, W. I. Properties of carbon ion deposited tetrahedral amorphous carbon films as a function of ion energy. Journal of Applied Physics, v. 79, n. 9, p. 7234-7240, 1996. DOI: 10.1063/1.361440.

YATSUZUKA, Mitsuyasu; OKA, Yoshihiro; NISHIJIMA, Masahiko; HIRAGA, Kenji. Microstructure of interface for high-adhesion DLC film on metal substrates by plasma-based ion implantation. Vacuum, v. 83, n. 1, p. 190-197, 2008. DOI: 10.1016/j.vacuum.2008.03.021.

ZAVALEYEV, V.; WALKOWICZ, J. Influence of the substrate bias potential on the properties of ta-C coatings deposited using Venetian blind plasma filter. Thin Solid Films, v. 581, p. 32-38, 2015. DOI: 10.1016/j.tsf.2014.11.074.

ZAVALEYEV, V.; WALKOWICZ, J.; GRECZYNSKI, G.; HULTMAN, L. Effect of substrate temperature on properties of diamond-like films deposited by combined DC impulse vacuum-arc method. Surface and Coatings Technology, v. 236, p. 444-449, 2013. DOI: 10.1016/j.surfcoat.2013.10.023.

ZAWISCHA, M; BIN MOHAMAD SUPIAN, M.; MAKOWSKI, S.; SCHALLER, F.; WEIHNACHT, V. Generalized approach of scratch adhesion testing and failure classification for hard coatings using the concept of relative area of delamination and properly scaled indenters. Surface and Coatings Technology, v. 415, n. January, p. 127118, 2021. DOI: 10.1016/j.surfcoat.2021.127118.

ZHANG, Y.B.; LAU, S.P.; SHEEJA, D.; TAY, B.K. Study of mechanical properties and stress of tetrahedral amorphous carbon films prepared by pulse biasing, Surf. Coatings Technol. v. 195, p. 338-343, 2005. https://doi.org/10.1016/j.surfcoat.2004.09.009.

ZHANG, X., SCHNEIDER, R., MüLLER, E., GERTHSEN, D., Practical aspects of the quantification of sp2-hybridized carbon atoms in diamond-like carbon by electron energy loss spectroscopy, Carbon 102 (2016) 198-207. https://doi.org/10.1016/j.carbon.2016.02.020.

ZOU, Y. S.; WU, Y. F.; YANG, H.; CANG, K.; SONG, G. H.; LI, Z. X.; ZHOU, K. The microstructure, mechanical and friction properties of protective diamond like carbon films on 
magnesium alloy. Applied Surface Science, v. 258, n. 4, p. 1624-1629, 2011. DOI: 10.1016/j.apsusc.2011.10.031. 